BNL-91286-2009-IR

\title{
Evaluation of Gas, Oil and Wood Pellet Fueled Residential Heating System Emissions Characteristics
}

\author{
Roger McDonald
}

December 2009
Energy Sciences and Technology Department/Energy Resources Division Brookhaven National Laboratory
P.O. Box 5000
Upton, NY 11973-5000
www.bnl.gov

\begin{abstract}
Notice: This manuscript has been authored by employees of Brookhaven Science Associates, LLC under Contract No. DE-AC02-98CH10886 with the U.S. Department of Energy. The publisher by accepting the manuscript for publication acknowledges that the United States Government retains a non-exclusive, paid-up, irrevocable, world-wide license to publish or reproduce the published form of this manuscript, or allow others to do so, for United States Government purposes.
\end{abstract}




\section{DISCLAIMER}

This report was prepared as an account of work sponsored by an agency of the United States Government. Neither the United States Government nor any agency thereof, nor any of their employees, nor any of their contractors, subcontractors, or their employees, makes any warranty, express or implied, or assumes any legal liability or responsibility for the accuracy, completeness, or any third party's use or the results of such use of any information, apparatus, product, or process disclosed, or represents that its use would not infringe privately owned rights. Reference herein to any specific commercial product, process, or service by trade name, trademark, manufacturer, or otherwise, does not necessarily constitute or imply its endorsement, recommendation, or favoring by the United States Government or any agency thereof or its contractors or subcontractors. The views and opinions of authors expressed herein do not necessarily state or reflect those of the United States Government or any agency thereof. 
Evaluation of Gas, Oil and Wood Pellet Fueled Residential Heating System Emissions Characteristics

\author{
Brookhaven National Laboratory \\ Energy Sciences and Technology Department \\ Energy Resources Division
}

December 2009

Roger J. McDonald

Under Agreement No. 8909

New York State Energy Research and Development Authority

Managed by

Brookhaven Science Associates, LLC

For the United States Department of Energy under

Contract No. DE-AC02-98CH10866 


\section{Legal Notes}

\section{NYSERDA}

This report was prepared by Brookhaven National Laboratory in the course of performing work contracted for and sponsored by the New York State Energy Research and Development Authority (NYSERDA). The opinions expressed in this report do not necessarily reflect those of NYSERDA or the State of New York, and reference to any specific product, service, or method does not constitute an implied or expressed recommendation or endorsement of it. Further, NYSERDA and the State of New York make no warranties or representations, expressed or implied, as to the fitness for particular purpose or merchantability of any product, apparatus, or service, or the usefulness, completeness or accuracy of any process, methods, or other information contained, described, disclosed, or referred to in this report. NYSERDA, the State of New York, and the contractor make no representations that the use of any product, apparatus, process, method, or other information will not infringe privately owned rights and will assume no liability for any loss, injury, or damage resulting from, or occurring in connection with, the use of information contained, described, disclosed, or referred to in this report.

\section{United States Department of Energy}

This report was prepared as an account of work sponsored by an agency of the United States Government. Neither the United States Government nor any agency thereof, nor any of their employees, nor any of their contractors, subcontractors, or their employees makes any warranty, express or implied, or assumes any legal liability or responsibility for the accuracy, completeness, or usefulness of any information, apparatus, product, or process disclosed, or represents that its use would not infringe privately owned rights. Reference herein to any specific commercial product, process, or service by trade name, trademark, manufacturer, or otherwise, does not necessarily constitute or imply its endorsement, recommendation, or favoring by the United States Government or any agency, contractor or subcontractor thereof. The views and opinions of authors expressed herein do not necessarily state or reflect those of the United States Government or any agency, contractor, or subcontractor thereof.

\section{Acknowledgements}

The author would like to acknowledge the valuable contributions of many people who have either worked on parts of this project or provided valuable critique of the many drafts of this report including C.R. Krishna, PH.D., Thomas A. Butcher, Ph.D., Yusuf Celebi, George Wei, Wei Lin Litzke all from Brookhaven National Laboratory, and John E. Batey of Energy Research Center Inc. and of course the project managers at NYSERDA which included Raymond Albrecht (retired), Nathan Russell and Peter Douglas. 


\section{Table of Contents}

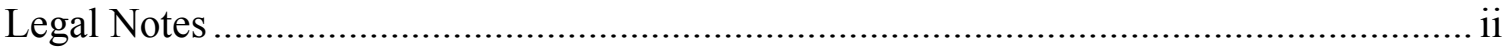

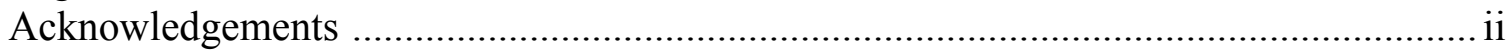

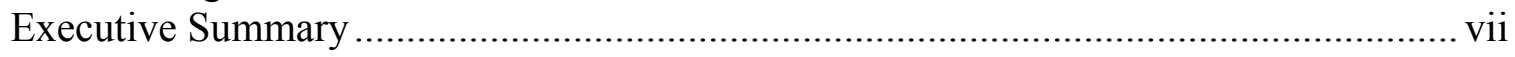

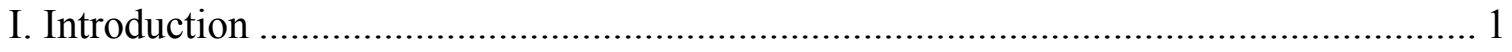

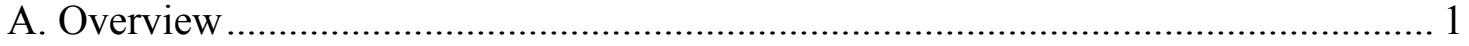

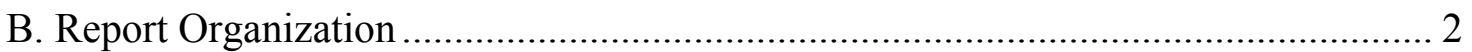

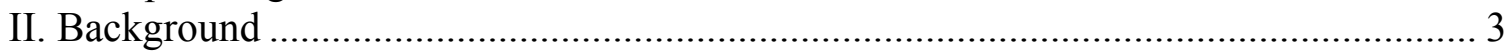

A. Fuel Use Demographics and Current Fuel Specifications ...................................... 3

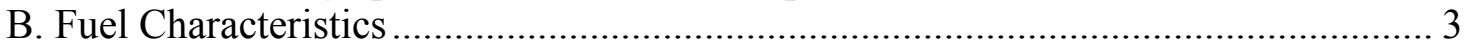

C. Prior Research in Emissions from Residential Heating Systems ............................ 4

D. Fine Particulate Emissions and Related Air Quality Concerns................................ 5

E. Considerations Related to Pending Changes in Diesel Fuel Specifications.............. 7

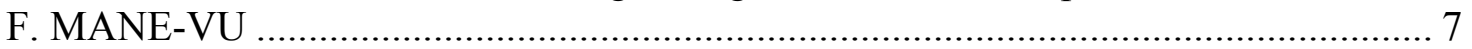

G. Importance of Sulfur Content in Petroleum Heating Fuels..................................... 8

H. Middle Distillate Fuel Cost and Product Supply Concerns .................................... 9

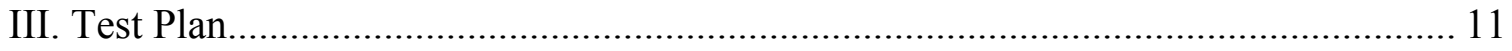

A. List of Equipment Included in the Project ...................................................... 11

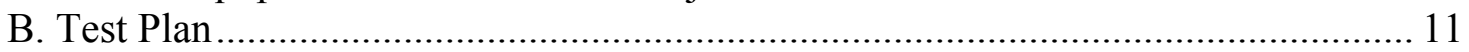

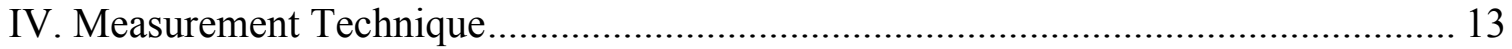

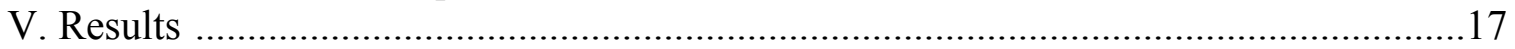

A. Oil-fired cast iron boiler and flame retention head burner, firing various fuels ...... 17

B. Oil-fired warm air furnace, with flame retention head burner and various fuels.... 25

C. Gas-fired cast iron boiler, atmospheric burner and electronic spark ignition .......... 28

D. Gas-fired warm air furnace, in-shot induced draft burner with spark ignition ........ 30

E. Gas-fired condensing aluminum boiler, premixed power burner, spark ignition..... 32

F. Oil-fired condensing steel boiler, flame retention head burner, with various fuels . 33

G. Oil-fired condensing furnace with flame retention head burner, various fuels ....... 38

H. Oil-fired cast iron boiler with combustion gas recirculation burner (blue flame) ... 40

I. Wood pellet stove; drop down over fed, open burner grate, and electric ignition .... 42

J. Pellet stove, over fed burner, enclosed self-clean burn grate, electric ignition........ 44

K. Wood pellet stove, horizontal under feed, open grate, with manual gel ignition .... 46

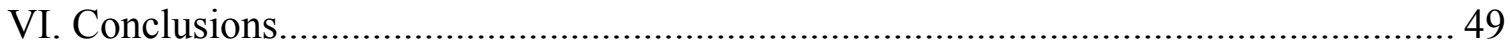

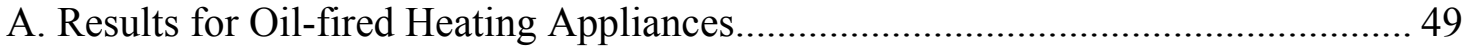

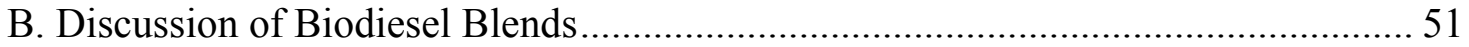

C. Results for Gas-fired Heating Appliances....................................................... 52

D. Results for Wood Pellet Stoves Manufactured in the United States....................... 53

E. Comparison of Results for all Residential Heating Appliances ............................. 54

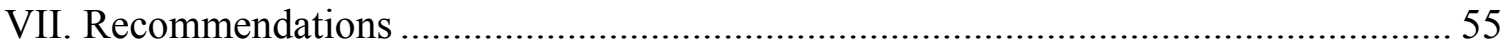

Appendix A: Examples of Fuel Analysis Results.................................................... 57

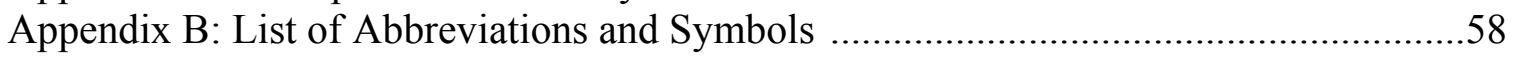




\section{List of Figures}

Figure 1. Schematic of the PM 2.5 Measurement......................................................... 15

Figure 2. Cast iron boiler and PM 2.5 Dilution Tunnel Sampler.................................... 19

Figure 3. BNL and EPA Staff Conducting Simulations PM 2.5 Measurements ............. 21

Figure 4. Cast iron boiler fueled with ULS diesel fuel .......................................... 23

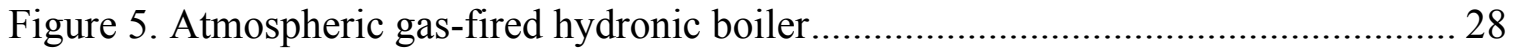

Figure 6. Gas-fired warm air furnace with in-shot induced draft burner........................ 31

Figure 7. Gas-fired condensing boiler .................................................................... 32

Figure 8. Oil-fired condensing steel boiler during PM 2.5 dilution tunnel testing ........... 34

Figure 9. Cast iron boiler fired with biodiesel for comparison purposes........................ 37

Figure 10. Oil-fired condensing warm air furnace, 95\% AFUE rating .......................... 38

Figure 11. Combustion gas recirculation (blue flame) burner.................................... 41

Figure 12. Pellet stove with drop down over fed, open burner grate, electric ignition.... 42

Figure 13. Stove, overfed burner, enclosed self-clean burn pot/grate, electric ignition ... 44

Figure 14. Pellet stove, side feed burner, open burner grate, and manual gel ignition.... 46

Figure 15. Cast iron boiler, PM 2.5 as a function of sulfur content.............................. 50

Figure 16. Cast iron boiler PM $2.5 \mathrm{mg} / \mathrm{MJ}, \mathrm{mg} / \mathrm{kg}, \mathrm{mg} / \mathrm{dscm}$ for three fuels.................. 50

Figure 17. PM 2.5 for conventional and condensing, boilers and furnaces..................... 51

Figure 18. PM 2.5 emission factors for gas furnace, boiler and condensing boiler......... 52

Figure 19. Three stoves evaluated for PM 2.5 and PM $>2.5$ Microns ........................... 53

Figure 20. Comparison of average PM 2.5 emissions for five heating fuel options......... 54 


\section{List of Tables}

Table 1. PM 2.5, oil-fired cast iron boiler, retention head burner, steady-state firing No. 2 .... 19

Table 2. PM 2.5, oil-fired cast iron boiler, retention head burner, cyclic operation, (EPA) ..... 20

Table 3. Flue gases, oil-cast iron boiler, flame retention burner firing No. 2 fuel .................. 20

Table 4. PM 2.5, oil-fired cast iron boiler with flame retention head burner firing LS fuel .....21

Table 5. Flue gases, oil-fired cast iron boiler with flame retention head burner LS fuel ..........22

Table 6. PM 2.5, oil-fired cast iron boiler with flame retention head burner firing ULS.......... 22

Table 7. Flue gases, oil-fired cast iron boiler with flame retention head burner firing ULS .... 23

Table 8. PM 2.5, oil-fired cast iron boiler, flame retention head burner steady state, No. 2 .... 24

Table 9. Flue gases, oil-fired cast iron boiler with flame retention head burner, No. 2 ........... 24

Table 10. PM 2.5, oil-fired cast iron boiler, retention head burner, No. 2, cyclic operation ..... 24

Table 11. PM 2.5, oil-fired warm air furnace, retention head burner, No. 2 fuel .................... 25

Table 12. Flue gases, oil-fired warm air furnace, retention head burner, No. 2 fuel ............... 25

Table 13. PM 2.5, oil-fired warm air furnace, retention head burner, LS fuel ........................26

Table 14. Flue gases, oil-fired warm air furnace, retention head burner, LS fuel .................. 26

Table 15. PM 2.5, oil-fired warm air furnace, retention head burner, ULS fuel ....................27

Table 16. Flue gases, oil-fired warm air furnace, retention head burner, ULS fuel .................27

Table 17. PM 2.5, gas-fired cast iron boiler, atmospheric burner, steady state operation ......... 28

Table 18. Flue gases, gas-fired cast iron boiler, atmospheric burner, steady state operation.....29

Table 19. PM 2.5, gas-fired cast iron boiler, atmospheric burner, cyclic operation ................ 29

Table 20. PM 2.5, gas-fired furnace, induced draft burners, steady state operation.................. 30

Table 21. Flue gases, gas-fired furnace, induced draft burners, steady state operation ............ 30

Table 22. PM 2.5, gas-fired furnace, induced draft burners, cyclic operation ........................ 31

Table 23. PM 2.5, gas-fired condensing aluminum boiler, premixed power burner ................ 32

Table 24. Flue gases, gas-fired condensing aluminum boiler, premixed power burner ........... 33

Table 25. Flue gases, oil-fired condensing steel boiler, flame retention burner, No. 2 fuel ...... 33

Table 26. PM 2.5, oil-fired condensing steel boiler, flame retention burner, No. 2 fuel .......... 34

Table 27. PM 2.5, oil-fired condensing steel boiler, flame retention burner, ULS fuel ........... 35

Table 28. Flue gases, oil-fired condensing steel boiler, flame retention burner, ULS fuel ....... 35

Table 29. PM 2.5, oil-fired condensing steel boiler, flame retention burner, biodiesel ........... 36

Table 30. Flue gases, oil-fired condensing steel boiler, flame retention burner, biodiesel ....... 36

Table 31. PM 2.5, oil-fired cast iron boiler, flame retention head burner, biodiesel fuel .......... 37

Table 32. Flue gases, oil-fired cast iron boiler, flame retention head burner, biodiesel fuel...... 37

Table 33. PM 2.5, oil-fired condensing warm air furnace, retention head burner, No. 2 .......... 38

Table 34. Flue gases, oil-fired condensing warm air furnace, retention head burner, No. 2 ..... 39

Table 35. PM 2.5, oil-fired condensing warm air furnace, retention head burner, LS fuel ....... 39

Table 36. Flue gases, oil-fired condensing warm air furnace, retention head burner, LS ......... 39

Table 37. PM 2.5, oil-fired condensing warm air furnace, retention head burner, ULS .......... 40

Table 38. PM 2.5, oil-fired condensing warm air furnace, retention head burner, ULS .......... 40

Table 39. Flue gases, cast iron boiler with combustion gas recirculation burner, ULS .......... 41

Table 40. PM 2.5, cast iron boiler with combustion gas recirculation burner, ULS ............... 41

Table 41. PM 2.5, wood pellet stove, drop down over fed, open burner grate ...................... 43

Table 42. Flue gases, wood pellet stove, drop down over fed, open burner grate .................... 43

Table 43. PM 2.5, pellet stove, over fed burner, closed self-clean burn grate ........................ 45

Table 44. Flue gases, pellet stove, over fed burner, closed self-clean burn grate .................... 45 
Table 45. PM 2.5, wood pellet stove, horizontal under feed burner, open grate 47

Table 46. Flue gases, wood pellet stove, horizontal under feed burner, open grate 


\section{Executive Summary}

This study has measured the emissions from a wide range of heating equipment burning different fuels including several liquid fuel options, utility supplied natural gas and wood pellet resources. The major effort was placed on generating a database for the mass emission rate of fine particulates (PM 2.5) for the various fuel types studied. The fine particulates or PM 2.5 (less than 2.5 microns in size) were measured using a dilution tunnel technique following the method described in US EPA CTM-039. The PM 2.5 emission results are expressed in several units for the benefit of scientists, engineers and administrators. The measurements of gaseous emissions of $\mathrm{O}_{2}, \mathrm{CO}_{2}, \mathrm{CO}, \mathrm{NO}_{\mathrm{x}}$ and $\mathrm{SO}_{2}$ were made using a combustion analyzer based on electrochemical cells These measurements are presented for each of the residential heating systems tested. This analyzer also provides a steady state efficiency based on stack gas and temperature measurements and these values are included in the report. The gaseous results are within the ranges expected from prior emission studies with the enhancement of expanding these measurements to fuels not available to earlier researchers. Based on measured excess air levels and ultimate analysis of the fuel's chemical composition the gaseous emission results are as expected and fall within the range provided for emission factors contained in the US-EPA AP 42, Emission Factors Volume I, Fifth Edition. Since there were no unexpected findings in these gaseous measurements, the bulk of the report is centered on the emissions of fine particulates, or PM 2.5.

The fine particulate (PM 2.5) results for the liquid fuel fired heating systems indicate a very strong linear relationship between the fine particulate emissions and the sulfur content of the liquid fuels being studied. This is illustrated by the plot contained in the first figure on the next page which clearly illustrates the linear relationship between the measured mass of fine particulate per unit of energy, expressed as milligrams per MegaJoule (mg/MJ) versus the different sulfur contents of four different heating fuels. These were tested in a conventional cast iron boiler equipped with a flame retention head burner. The fuels included a typical ASTM No. 2 fuel oil with sulfur below 0.5 percent (1520 average ppm S), an ASTM No. 2 fuel oil with very high sulfur content (5780 ppm $\mathrm{S})$, low sulfur heating oil (322 ppm S) and an ultra low sulfur diesel fuel (11 ppm S). Three additional oil-fired heating system types were also tested with normal heating fuel, low sulfur and ultralow sulfur fuel. They included an oil-fired warm air furnace of conventional design, a high efficiency condensing warm air furnace, a condensing hydronic boiler and the conventional hydronic boiler as discussed above. The linearity in the results was observed with all of the different oil-fired equipment types (as shown in the second figure on the next page). A linear regression of the data resulted in an Rsquared value of 0.99 indicating that a very good linear relationship exits. This means that as sulfur decreases the PM 2.5 emissions are reduced in a linear manner within the sulfur content range tested. At the ultra low sulfur level (15 ppm S) the amount of PM 2.5 had been reduced dramatically to an average of $0.043 \mathrm{mg} / \mathrm{MJ}$. 
Cast Iron Boiler, Flame Retention Head Burner

With Four Distillate Fuels, Sulfur Range 11-5780 ppm

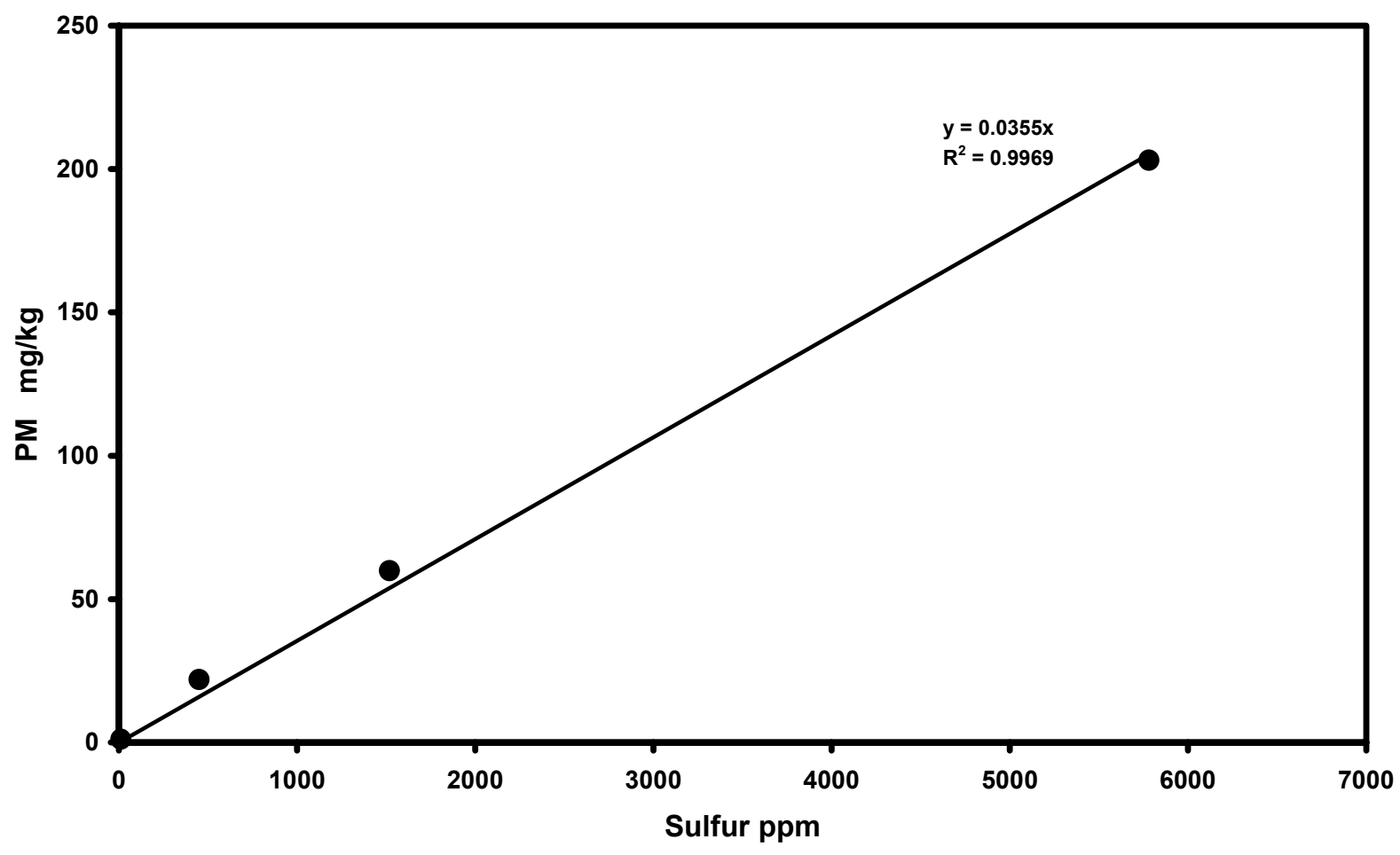

Cast iron boiler, PM 2.5 as a function of sulfur content

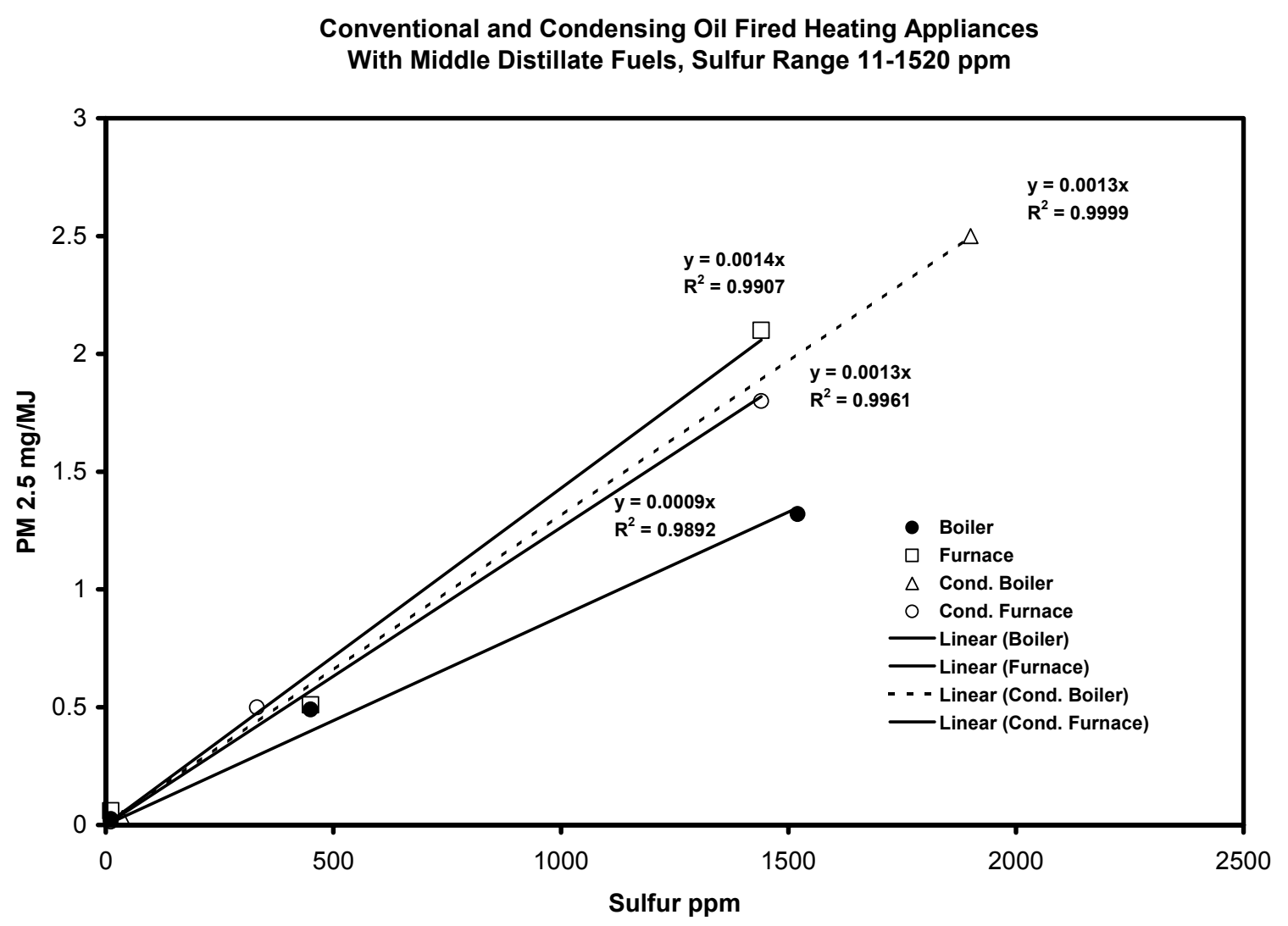

PM 2.5 for conventional and condensing, boilers and furnaces 
Three different gas-fired heating systems were tested. These included a conventional inshot induced draft warm air furnace, an atmospheric fired hydronic boiler and a high efficiency hydronic boiler. The particulate (PM 2.5) measured ranged from 0.011 to $0.036 \mathrm{mg} / \mathrm{MJ}$ (as shown in the first figure on the next page).

Three wood pellet stoves were included in this study. Wood pellet properties vary greatly depending on the raw material source used in their manufacture. All three stoves tested were fueled with premium (low ash) wood pellets obtained in a single batch to provide for uniformity in the test fuel. Unlike the oil and gas fired systems, the wood pellet stoves had measurable amounts of particulates sized above the 2.5-micron size that defines fine particulates (less than 2.5 microns). The fine particulate emissions rates ranged from 22 to $30 \mathrm{mg} / \mathrm{MJ}$ with an average value of $25 \mathrm{mg} / \mathrm{MJ}$ for the three stoves tested (as shown in the second figure on the next page).

\section{Discussion:}

Homeowners currently have many choices to heat their homes. These choices include burning natural gas, heating oil, wood. Natural gas use results in very low levels of PM 2.5 emissions but being a hydrocarbon fuel it emits substantial levels of carbon dioxide. ASTM No. 2 fuel oil fired heating appliances produce PM 2.5 levels that are about 130 times higher than natural gas and higher emission levels of carbon dioxide. Wood pelletfired heating appliances made in the Untied States produce PM 2.5 levels that are approximately 15 times higher than ASTM No. 2 fuel oil and from about 590 to 1850 times the levels possible with either utility gas or ultra low sulfur oil fueled appliances. Wood pellet heating fuel is often selected over other forms of wood fuel choices based on EPA and DOE guidance. This guidance suggests that the use of wood pellet appliances is a good choice because they are considered to be the lowest emitters of particulates when compared to other type of wood burning appliances. Wood pellet fuel is a renewable resource that absorbs carbon dioxide during the natural growth cycle. This is considered to be a benefit in helping to mitigate global climate changes by effectively reducing the carbon dioxide emissions that otherwise would be attributed to the use of wood pellet fuel. Like wood, biodiesel is also a renewable fuel and also absorbs carbon dioxide in the growth cycle of the crop plants used to produce the raw materials for biodiesel production, for example soybean or other seed crops. Biodiesel can be blended with ASTM heating No. 2 or ultra low sulfur heating oil. In either case it would effectively reduce the emissions of carbon dioxide based on its renewable nature. The extent of the carbon dioxide reduction would be proportional to the amounts of biodiesel used in the blends.

To summarize, natural gas has low PM 2.5 emissions but moderate carbon dioxide emissions. Wood pellet fuel has much higher PM 2.5 emission levels (based on current technology) but effectively lower carbon dioxide emissions due the renewable nature of trees that absorb carbon dioxide as they grow. ASTM No. 2 fuel as currently used has higher emissions of PM 2.5 than natural gas, much lower PM 2.5 emissions than wood pellet fuel and higher levels of carbon dioxide emissions than both alternatives. Transitioning the sulfur content of fuel oil to ultra low levels (less than $15 \mathrm{ppm}$ ) results in 
PM 2.5 Emission Factors for Several Natural Gas Fired Appliance

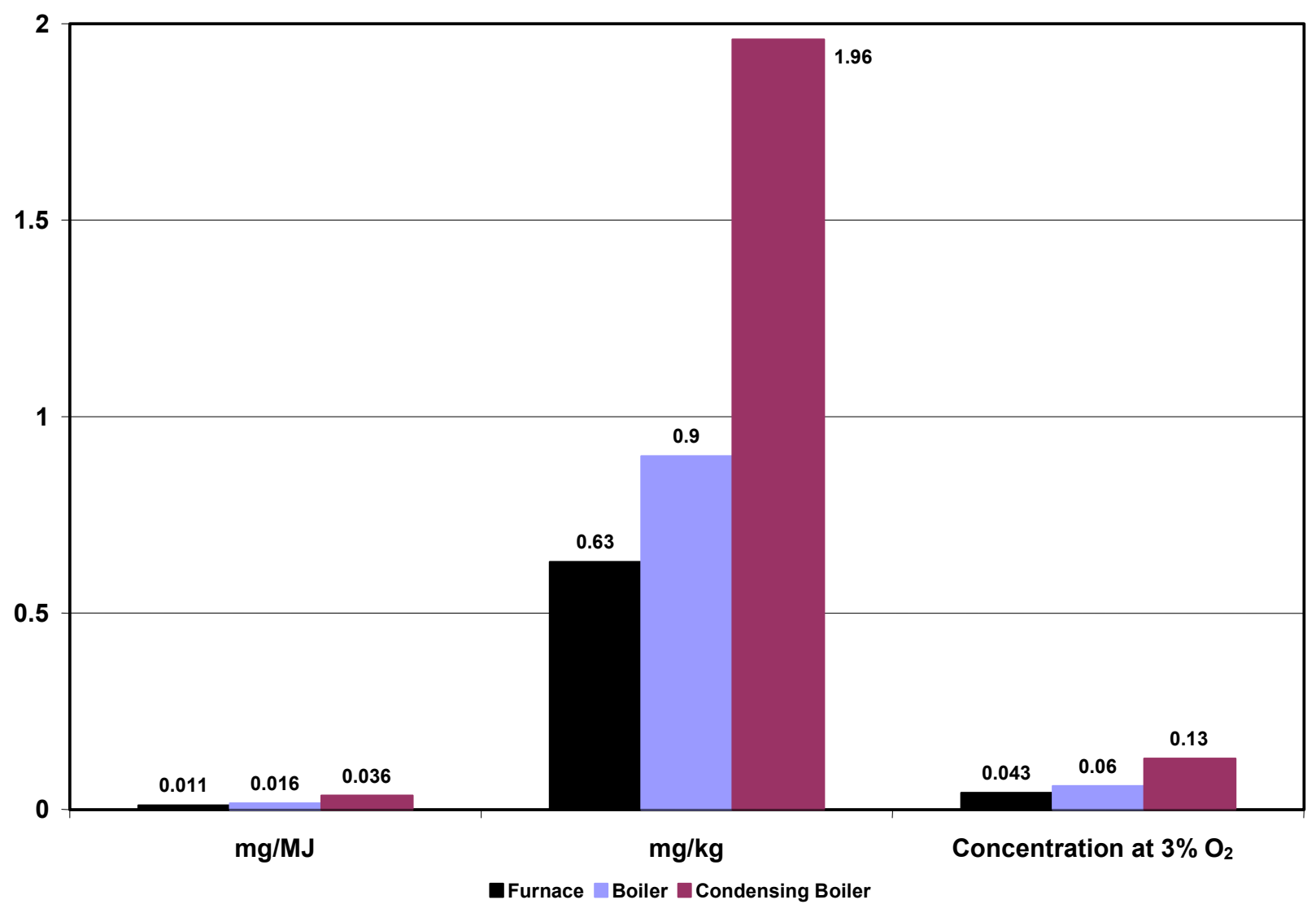

PM 2.5 emission factors for gas furnace, boiler and condensing boiler $\square$ Stove I $\square$ Stove J $\square$ Stove K

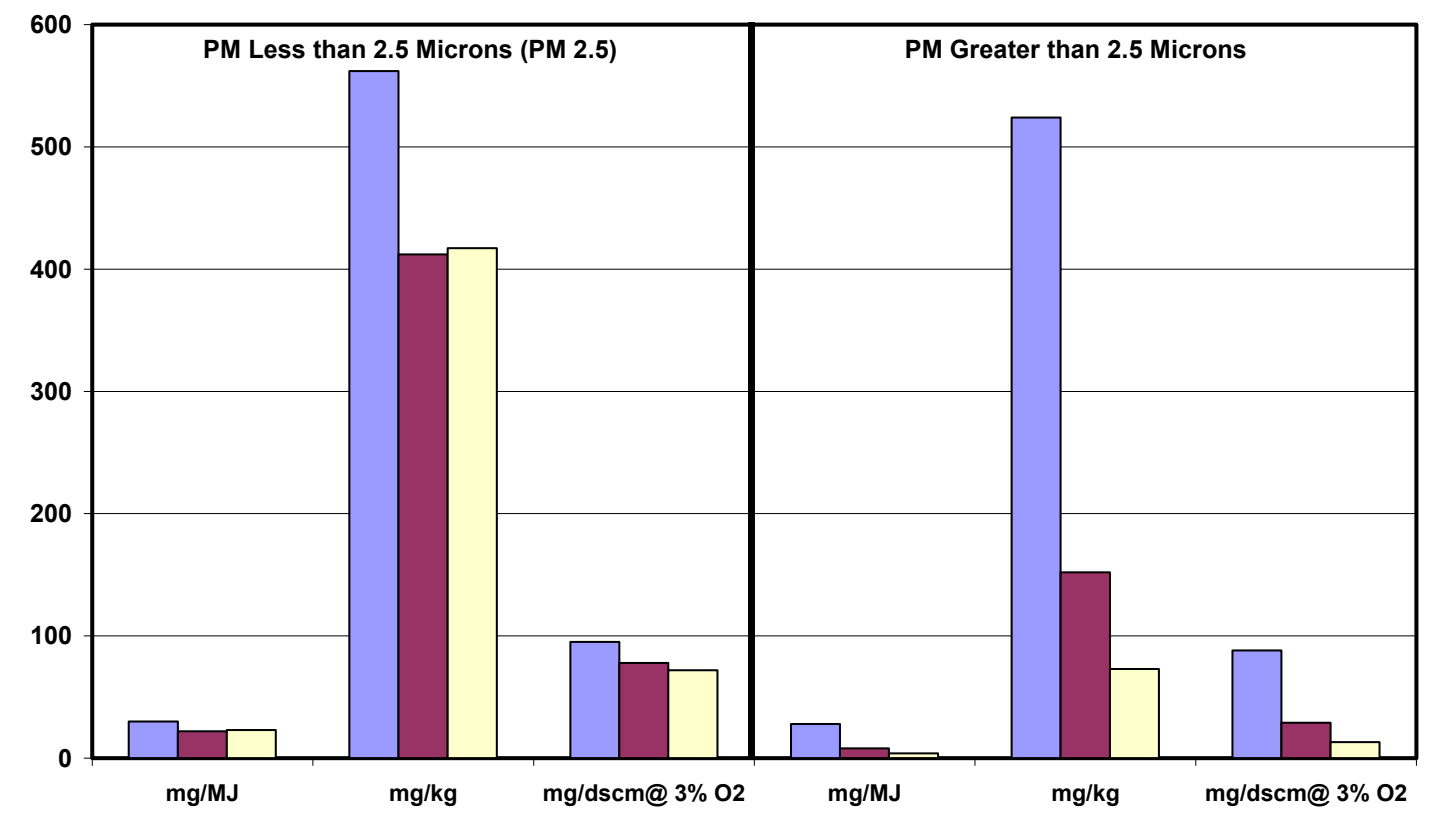

Three stoves evaluated for PM 2.5 and PM > 2.5 Microns 
PM 2.5 emissions are on the same order of magnitude as natural gas (see figure below) but still emits higher levels of carbon dioxide. Natural gas produces about 30 percent less carbon dioxide per Btu when compared to ASTM No. 2 or ultra low sulfur heating oil. Blending of ultra low sulfur with biodiesel in the future is anticipated as a alternative fuel choice and the resulting fuel blend would have very low PM 2.5 emissions as well as low net carbon dioxide emissions when the renewable nature of the fuel is taken into accounted. This report presents carbon dioxide data as it was measured but the analysis of the net carbon dioxide reduction based on the use of renewable fuels is beyond the scope of the current project

The question of how to reduce PM 2.5 emissions in areas that currently do not meet the criteria for EPA attainment is complex and is not part of the scope of this project. This project does however provide important data that should be useful to the overall decisionmaking process with regard to residential heating technology in New York State as well as the other New England and Mid-Atlantic States where a majority of home heating is based on fuel combustion technologies.

\section{Comparison of Average PM2.5 for Five Heating Fuel Types for Hydronic Boilers and Warm Air Funaces}

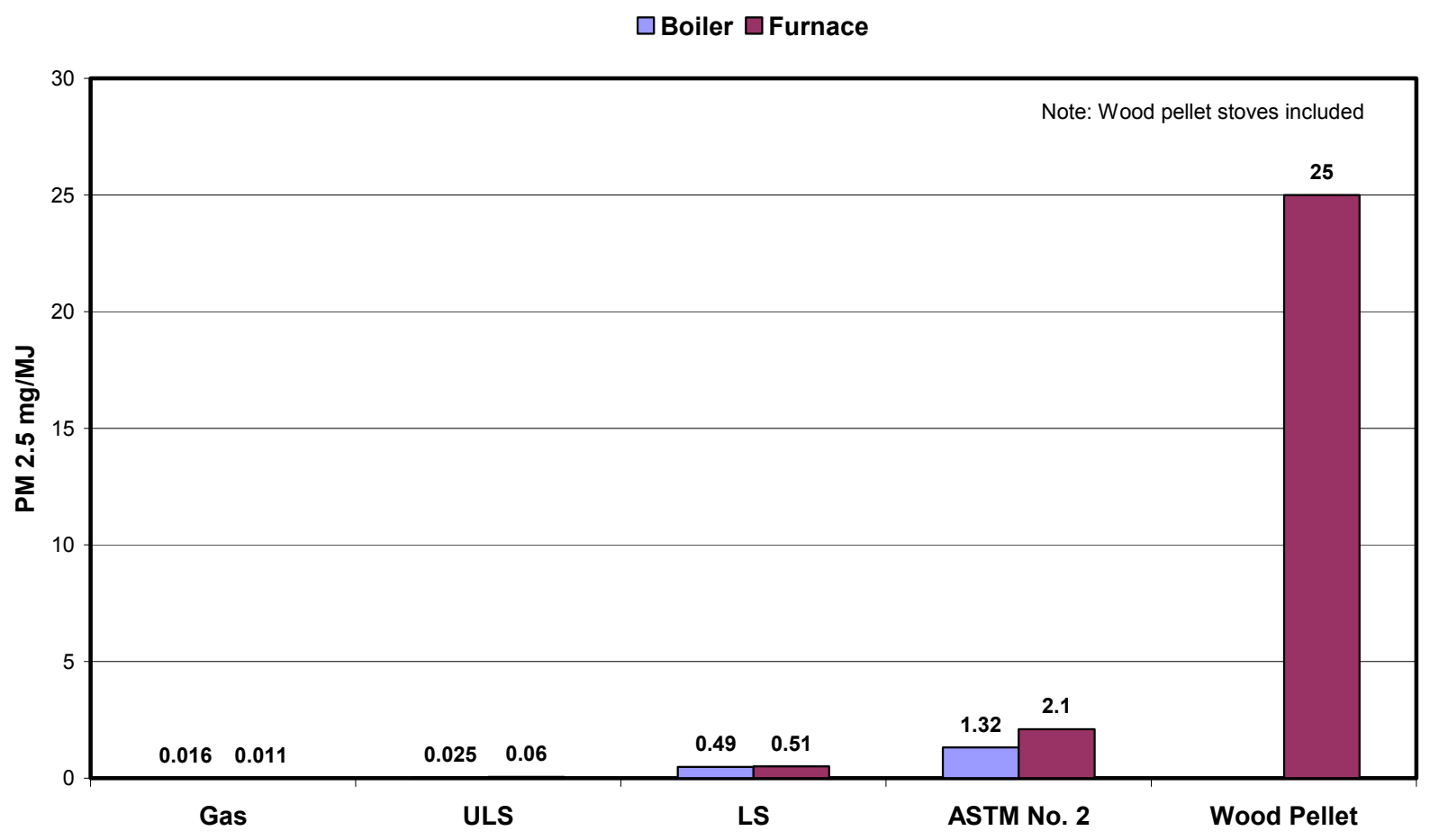

Comparison of average PM 2.5 emissions for five heating fuel options 


\section{Evaluation of Gas, Oil and Wood Pellet Fueled Residential Heating System Emissions Characteristics}

\section{Introduction}

\section{A. Overview}

This project provides an up-to-date evaluation of emissions from residential gas; oil and wood pellet fired heating equipment. This report contains an introduction to the topic and discusses recent trends that impact the subject matter. Then the project plan is reviewed and the measurement techniques are discussed. The results of all testing are presented including data on the traditional gaseous stack emissions including carbon monoxide, calculated carbon dioxide based on oxygen concentration, nitrogen oxides and oxides of sulfur. Emissions are also reported for fine particulates (PM 2.5) and those of larger size (larger than 2.5 microns) using a dilution tunnel sampling method. These particulate emissions are presented in various different ways including factors based on concentration, weight and energy content.

The project has developed emissions profiles for various equipment designs. These include units considered to be of conventional design as well as more modern designs. Modern designs can be characterized by low emission factors (for example lower nitrogen oxides) and or high thermal efficiency. High efficiency generally correlates with the inclusion of a condensing heat exchanger that captures latent heat and thereby reduces the energy discarded with the exhaust gases. This latent energy is typically lost as steam vapor contained in the stack gases. Different furnace and boiler units that incorporated condensing technology were evaluated. These units are designed specifically for use with natural gas or heating oil. Efficiency levels range up to the $90-95 \%$ level for condensing models. Units designed for heating oil fuel were tested using normal ASTM No. 2 fuel oil, low sulfur fuel with sulfur content below $500 \mathrm{ppm}$, ultra low sulfur fuel with sulfur below $15 \mathrm{ppm}$ and biodiesel fuel, also considered as an ultra low sulfur content fuel. The gas-fired units were tested using gas delivered via pipeline from the local utility on Long Island. During the course of the project the project sponsor (NYSERDA) funded an additional task to include measuring the emissions from wood pellet stoves. Three different wood pellet stoves were tested. These were all of currently marketed designs incorporating sidewall venting, variable fuel feed rates and forced room air circulation. The wood pellet units were fired with a premium wood pellet fuel, less than $1 \%$ ash content, primarily intended for residential use. While the larger portion of the particulate emissions of the three wood pellet stoves were categorized as fine particulates (PM 2.5) these units did have measurable amount of particulates sized over 2.5 microns in diameter.

The project was originally structured in two phases based on funding availability and commitment by NYSERDA. Phase one of the project sought to measure emissions from a representative sample of typical utility gas and oil-fired, residential heating systems as found in homes and small businesses in New York State. Oil-fired heating systems were tested with conventional heating oil $(0.2 \%$ or $2,000 \mathrm{ppm}$ sulfur $)$, low sulfur diesel fuel 
(500 ppm sulfur), and ultra-low sulfur diesel fuel (15 ppm sulfur). During phase one there was a great deal of emerging interest in renewable forest based fuels and before phase one was completed a modification to the project added an additional task to investigate the emissions from wood pellet stoves. These were currently marketed as a primary heat source for use in smaller open format homes and also a supplemental heat source for residential heating in general. Phase two of the project sought to measure emissions from more advanced heating technologies including low NOx burners and condensing heating appliances (boilers and furnaces). Phase two also included the testing of both conventional and advanced, oil-fired, heating technologies with liquid biofuels (biodiesel).

The largest portion of the effort was expended in generating the fine particulate data set for the various equipment types mentioned above. Originally the project was based on evaluating emissions from gas and oil fired heating systems. Given existing EPA emission factors for gas, oil and wood combustion there was the expectation that emissions would be lowest for gas, slightly higher for oil and higher yet for wood combustion. The amount of effort placed on oil heating technology was somewhat more expansive due to the nature of the fuel and the perceived possibilities for improvement based on changing fuel characteristics and equipment designs.

\section{B. Report Organization}

The main report is structured into six sections including an introduction, a discussion of background material primarily related to the topic of oil and gas fired equipment, a review of the test plan as followed, a description of the measurement techniques applied, a presentation of the project results, a summary of findings and finally recommendations based upon the study. 


\section{Background}

\section{A. Fuel Use Demographics and Current Fuel Specifications}

Utility gas and heating oil are widely used sources of energy providing safe, economical and efficient space heating comfort in approximately 100 million homes in the United States. In New York State (NYS) the majority of homes are heated with these fuels. Gas is used in 3,292,188 housing units and this represents $47 \%$ of homes in NYS. The largest concentration of oilheat use in the nation is found in NYS with 2,336,714 housing units identified as using oil as the main heating fuel (33\% of all homes in NYS). ${ }^{1}$ The United States Department of Energy's Energy Information Agency (DOE/EIA) research on housing characteristics indicates that the average gas heated home uses 112,300 cubic feet of gas and average oil heated home consumes 873 gallons of fuel each year. ${ }^{2}$ Applying these average uses to NYS produces an estimated fuel use of 369.7 billion cubic feet of utility gas and over 2.04 billion gallons of oil each year.

According to the Pellet Fuel Institute (PFI), wood pellets as a residential heating fuel are currently consumed in approximately 800,000 homes nation wide. ${ }^{3}$ A great deal of these homes use wood pellets as a supplemental heating source not their main heating fuel. The use of wood pellets to heat living spaces is a growing industry but still it represents a very small fraction of all existing homes, less than one percent of homes in the USA. Pellet stoves and pellet fuel use started in the Pacific Northwest. The popularity of the stoves was such that the second initial market was in the Northeast. Initially the fuel was transported from the west to the east coast. As the number of stoves increased in the east, local production of pellet fuel began in the east. Then the market expanded to most other parts of the country. During the last five years there has been strong growth in the Northeast and Eastern states with the highest annual sales. The East is now the number one market in the USA. The North Central and Rocky Mountains are number two, the Pacific Northwest is number three and the Southeast is number four. ${ }^{4}$

In NYS approximately 600,000 homes use wood in some form for primary or supplemental space heating. ${ }^{1}$ There is no apparent statistical information on the number of homes currently using wood pellets in NYS. The use of wood pellets is fairly popular in the Northeast and New England states. It is expected that a significant percentage of the national population of wood pellet units are likely located in NYS. With traditional heating fuel energy prices recently increasing dramatically, there has been a growth spurt in pellet-fueled unit sales. This is also coupled with a growing environmental interest in wood sourced fuels as a renewable fuel option in some homeowner's opinions.

\section{B. Fuel Characteristics}

The American Society of Testing and Materials (ASTM) maintain nationally recognized standards for specifications defining liquid fuels when used in the United States. These include those for No. 1 (kerosene) and No. 2 (heating oil) fuel oils that are used in most small residential and commercial sized fuel oil burning equipment. In addition to specifying physical properties such as density, viscosity and heating value the ASTM 
specifies the maximum sulfur content of the fuels. Sulfur content directly impacts emissions of sulfur oxides and particulates. The vast bulk of this middle distillate heating fuel is No. 2 or more commonly referred to as heating oil. The ASTM specifications regarding sulfur limits for both No. 1 and No. 2 fuels state that they must contain no more than $0.5 \%(5,000 \mathrm{ppm})$ sulfur by weight. Based upon a yearly survey of US oil refineries the typical sulfur level for No. 2 heating fuel over the last decade has been approximately $2,000 \mathrm{ppm}$. This is well below the limit established in the ASTM specification. There are also two relatively new specifications, added in June of 2002, that define new low sulfur fuel types, No. 1 Low Sulfur and No. 2 Low Sulfur, which contain no more than $0.05 \%$ or $500 \mathrm{ppm}$ sulfur by weight. In addition diesel fuel is also a middle distillate fuel and can be considered as an acceptable heating oil fuel, if not for regulations segregating it by sulfur content and color (diesel is un-dyed) for taxation purposes. Diesel also has certain specifications that fuel oil does not currently need to meet, sulfur content below $15 \mathrm{ppm}$ being one of the most relevant to the current project. Diesel meets fuel oil specification but fuel oil does not meet the diesel specification. Early on, these fuels were generally fungible and were considered the same product stored in the same tank at fuel terminals. As emissions from the transportation sector became a major concern the two were basically separated based on sulfur content. Diesel first had a limit of 500-ppm sulfur and more recently that was reduced to the current ultra low level of $15 \mathrm{ppm}$.

Utility or "Natural" gas is primarily methane and can contain minor amounts of other combustible hydrocarbon based gases. There is a very small amount of sulfur in natural gas and a large portion of this is from the sulfur containing odorants, compounds added to the gas to enable leak detection by its users. The combined sulfur content of utility gas is not openly reported in non-propriety documents and varies depending on geographic location of the source and degree to which it is removed. It is on the order of 10-ppm by weight based on the analysis of the gas delivered by the local utility on Long Island, NY.

Wood pellets are classified as premium, standard or utility grade based on the ash content of the fuel. Premium pellets used largely for residential equipment are specified as having less than $1 \%$ ash. Standard grade pellets can have up to $2 \%$ ash by weight and utility grade less than $6 \%$ ash. The exact chemical composition and physical properties of fuel pellets are based upon the raw material and vary from place to place depending on what types of tree the wood comes from. There are specifications for minimum density, physical dimensions; maximum chloride content, which limits the potential for stove corrosion and ash, content that factor into the cleaning and maintenance frequency for the user. Generally the heating value averages 8,000-9,000 Btu per pound (dry basis). ${ }^{3,4}$

\section{Prior Research in Emissions from Residential Heating Systems}

Numerous emission studies have been conducted on oil, gas and wood pellet combustion systems. Very few of these studies have attempted to measure fine particulate (PM 2.5) emissions using a dilution tunnel based methodology on small residential heating appliances. Individually these residential emission sources are not large enough to be of concern, but as a disperse source they are considered to be a significant concern. The last comprehensive emissions study on residential oil heating equipment was conducted at 
Brookhaven National Laboratory (BNL) in 1990. It answered a lot of questions and some of that data was important in documenting the advances of equipment design at that time. This reduction in emissions resulted from many years of design improvements since the first oil appliance emissions study conducted by Battelle Laboratory -Columbus, $\mathrm{OH}$ in 1970. While both studies included particulate emissions neither dealt specifically with measuring fine particulates (PM 2.5). ${ }^{5,6,6}$

Currently the most important area of concern is the emission of fine particulate (PM 2.5) due to health concerns as well as their contribution to atmospheric haze. There is also concern over how to measure it accurately and the meaning of those measurements when compared to alternative techniques. When using fuel oil, the formation of sulfur oxides, sulfates and sulfides are the area of largest concern. These are obviously linked to the sulfur content of the fuel. Likewise the particulate emissions from residential gas fired heating systems had not been a major area of concern based on the low emission factors traditionally associated with gas combustion.

The potential for PM 2.5 reduction with heating oil had also been documented to some extent by the CANMET Energy Technology Center in Canada in an experiment where the emission rate for a range of varying sulfur content fuels from 6,000 down to $500 \mathrm{ppm}$ was determined in a single boiler system of the type used in single-family residential buildings. The results indicated a basically linear relationship between sulfur content and fine particulates measured as PM 2.5. ${ }^{7}$

\section{Fine Particulate Emissions and Related Air Quality Concerns}

The U.S. EPA regulates six air pollutants $\mathrm{SO}_{2}, \mathrm{NO}_{\mathrm{X}}, \mathrm{O}_{2}, \mathrm{CO}, \mathrm{Pb}$ and particulate. EPA has established National Ambient Air Quality Standards including annual, 24-hour, 8hour and 1-hour standards. Standards are set to protect the health of the most sensitive humans. EPA set up a monitoring network to measure ambient air quality. EPA also developed an inventory of emissions. ${ }^{8}$

Initially EPA regulated total suspended particulate (TSP). Later PM 10, which are particles smaller than 10 microns and recently PM 2.5, particulates less than 2.5 microns in size were regulated. These fine particulates can be easily trapped in the lungs during normal respiration. The current standards for PM 2.5, described in micrograms per cubic meter of air $\left(\mathrm{ug} / \mathrm{m}^{3}\right)$ are $65 \mathrm{ug} / \mathrm{m}^{3}$ - 24-Hour and $15 \mathrm{ug} / \mathrm{m}^{3}$ - annual average. Areas where concentrations are below the standards are referred to as non-attainment areas. ${ }^{9}$

The results from local EPA monitoring stations are mixed with regard to the current ambient air quality concerning the Northeast. Sulfur dioxide (SO2) is in attainment; this can affect the issue of acid rain and secondary particulate formation in the upper atmosphere. With regard to particulate emissions; PM 2.5 - 24 Hour -is also in attainment, with PM 2.5 - Annual non attainment areas include DC, WV, DE PA, NJ, Bronx, NY City \& New Haven, CT. 
States with non-attainment areas are being required to prepare State Implementation Plans (SIPs) so as to regain and/or maintain attainment for all regulated emissions. In the Northeast there has been considerable effort to deal with this problem on a regional basis for several reasons. There is a great deal of concern that the different states would have different regulations. An example would be, if the sulfur content limit imposed on fuel oil varies form state to state, this would increase cost for everyone. It would unduly complicate the bulk delivery, storage and dispensing of the fuel. Like-wise the legal requirements for wood burning appliances might impose market limitations if one state does not match the next with regard to allowable appliance emission limits.

There is general agreement that ambient fine particulates (PM 2.5) do have significant potential health impacts and these are currently being addressed with regard to air quality. These fine particulates include organic and elemental carbon formed from combustion sources, acid aerosols that are produced as combustion products cool and mix with ambient air, road dust, and other sources. In the Eastern United States, sulfates are a very important part of the total ambient particulates. There has been considerable debate over the past decade about what size particulates should be regulated and what consideration should be given to composition versus simply total mass in regulations. The total mass of particulates under 2.5 microns is now the focus. Environmental regulators are currently working to put in place programs to meet the EPA ambient air standards for PM 2.5. In the Northeast and Mid-Atlantic regions the combustion of distillate oil in stationary and mobile sources is a very important part of the regional PM 2.5 picture. A national plan to limit air quality concerns with mobile sources is well in place for vehicles that use diesel fuel as discussed earlier. Ambient PM 2.5 includes sulfates and is emitted from numerous sources including in part, the combustion of home heating oil. This is of particular interest in New York State where over 2,300,000 households use oilheat as the primary heating fuel. The EPA has reported the major types of PM 2.5 as being carbon, sulfates, ammonia and nitrate in descending order based on data from regional monitoring stations. The major sources according to EPA are from all types of oil combustion, large industrial processes and the transportation sector. EPA had no PM 2.5 data for residential heating systems in its emission inventory until very recently.

The issue of combustion related PM 2.5 is complex and it results from ground level primary emissions of PM 2.5 and also secondary PM 2.5 that results from atmospheric chemical reactions of gaseous pollutants. A significant portion of the PM 2.5 is likely generated from ground sources as it forms rather rapidly once the combustion products hit the ambient air. The principal types of secondary particles are ammonium sulfate and nitrate formed in the atmosphere from gaseous emissions of sulfur dioxide $\left(\mathrm{SO}_{2}\right)$ and oxides of nitrogen (NOx), reacting with ammonia (NH3). The main sources of $\mathrm{SO}_{2}$ are the combustion of fossil fuels in boilers and the main sources of NOx are combustion of fossil fuel in boilers and mobile sources. Secondary particles comprise approximately $50 \%$ of PM 2.5 ambient concentrations throughout the East and many western urban areas. Thus, direct emissions have only about one half the impact on PM 2.5 concentrations that they would appear to have, if one were to try to interpret the inventory of directly emitted PM 2.5 without the benefit of modeling or chemically characterized air samples. Studies related to coal fired power plants have attributed 40 percent or more 
of the PM 2.5 from this type of upper atmosphere reaction causing secondary PM 2.5. Primarily this is reported as a sulfate related problem although some research papers have suggested that merely limiting sulfur in the fossil fuel may not resolve the PM 2.5 issue. This is because in the absence of $\mathrm{SO}_{2}$, additional NOx in the atmosphere would likely react with the ammonium in its place and just displace one form of PM 2.5 with another. One point to underline is that the PM 2.5 concern is not a simple problem to analyze and another important point is that solving one potential pollutant pathway may create a new pathway to open up.

\section{E. Considerations Related to Pending Changes in Diesel Fuel Specifications}

There has been past interest on the part of the NYS legislature and the Department of Environmental Conservation concerning the possible beneficial impacts of further reducing the sulfur content of heating fuel down to ultra-low levels (ULS) of less than 15 ppm. This interest was and is associated with recent changes that have occurred in the other part of the light distillate fuel market. Diesel fuels (No.1 D and No. 2D) and heating fuels (No. 1 and No. 2) are both considered middle distillates and in fact for many years were basically the same fuel with minor differences usually accommodated by the use of fuel performance additives in diesel fuel only when required. An example would be an additive to boost the cetane level to meet diesel specifications. The difference between a No. 1 and No. 2 fuel, be it with heating oil or diesel fuel, is in general defined by the viscosity limits. Earlier transportation sector programs had in several metropolitan cities already demonstrated on a small scale the clean air benefits of using ULS (No. 1) diesel in localized applications. The most recent activity in the NYS legislature has been to propose legislation that will mandate the use of ULS as heating fuel in New York State's non-attainment areas starting in $2011 .^{10}$

The reason for this national shift to the new ultra-low sulfur fuel is related to improved air quality. In a national effort to enhance ambient air quality, the US EPA mandated that diesel fuels for highway vehicles shift to 15-ppm sulfur starting in 2006, followed in 2007 by off road diesel fuel shifting from 5,000 ppm (maximum) to $500 \mathrm{ppm}$. The plans call for a phased transition through the year 2010 when all diesel fuel, on-road and offroad, must be Ultra Low Sulfur (ULS) with a maximum of 15-ppm sulfur by weight. The shift towards the ULS fuel has allowed vehicle manufacturers to utilize catalytic converter technologies for diesel engines to reduce tailpipe emissions. The use of these catalytic converters was not possible with higher fuel sulfur concentrations because the sulfur would poison the catalytic materials rendering them useless. The use of ULS diesel allows for reductions in both NOx and fine particulates, PM 2.5.

\section{F. MANE-VU}

The Mid-Atlantic/Northeast Visibility Union (MANE-VU) has been formed to develop an approach to improve air in the region. This organization is reacting to the Federal Clean Air Act and Regional Haze rule that requires that the various states with nonattainment areas within their borders create State Implementation Plans (SIP s) to address reasonable progress in correcting the current level of air quality. In the primary regions 
where oilheat is the most popular, the individual states have joined this group to formulate a joint regional plan. This plan includes Best Available Retrofit Technology (BART) for large source emitters; limiting sulfur in distillate and residual fuel oils used in the region and includes a 90\% reduction in sulfur dioxide emissions from 167 electric generating unit stacks. This plan also calls for a continued evaluation of other control measures. The goal is to reduce the particulate levels in the air that contribute to the formation of haze and reduce visibility. There is a general consensus that most pollutants that affect visibility also contribute to unhealthy concentrations of fine particulates and ozone. $^{11}$

The states of Maine, New Hampshire, Vermont, Massachusetts, Rhode Island, Connecticut, New York, New Jersey, Pennsylvania, Delaware, Maryland, the District of Columbia along with the Penobscot Indian Nation and the St. Regis Mohawk Tribe comprise the voting members of MANE-VU. It was formed to encourage a coordinated approach to meeting the requirements of EPA's regional haze rules and reducing visibility impairment in major national parks and wilderness areas in the Northeast and MidAtlantic region. MANE-VU provides technical assessments and assistance to its members, evaluates linkages to other regional air pollution issues, provides a forum for discussion, and encourages coordinated actions. MANE-VU also facilitates coordination with other regions.

BNL has presented preliminary data from this project at various venues documenting the changes in fine particulates (PM 2.5) as a function of the variation of sulfur content in different fuel oils tested. Representatives from MANE-VU have participated at these meetings. MANE-VU is currently having ongoing discussions with key stakeholders regarding limiting sulfur content in distillate fuel oil. The latest plan being proposed would call for limiting sulfur in heating oil in two stages. The first would be to transition to less than 500-ppm in New York, New Jersey, Pennsylvania and Delaware starting in 2012 (this may possibly be delayed until 2014) with the other states following by 2014. The second stage would be to limit sulfur content to less than 15-ppm in New York, New Jersey, Pennsylvania and Delaware by 2016 and in the other states by $2018 .^{12}$

\section{G. Importance of Sulfur Content in Petroleum Heating Fuels}

Sulfur is an element and in many instances an essential component of all living cells, it's also an old traditional medicine and it's also used in numerous commercial applications and industries. However, generally speaking sulfur is a problem for the petroleum industry. It has been an issue for gasoline as well as diesel. To reduce air pollutants resulting form the transportation sector it has already been virtually eliminated from transportation fuels. The most recent change is the 2006 shift to ultra-low sulfur content diesel at less than 15-ppm.

When burned, sulfur forms several oxides, sulfur dioxide $\left(\mathrm{SO}_{2}\right)$ being the predominant one, but also sulfites $\left(\mathrm{SO}_{3}\right)$ and sulfates $\left(\mathrm{SO}_{4}\right)$. None of these are good for the oilheat industry. Sulfur dioxide in the flue products contributes to secondary fine particulate formation in the upper atmosphere by means of photochemistry driven by sunlight. Sulfur 
dioxide is also one of the air emissions that alternate heating fuels suppliers like to point out when making comparisons to their own product that generally have very low levels of sulfur dioxide emissions. Sulfites and sulfates also contribute to the primary fine particulate (PM 2.5) produced by oilheating systems accounting for the largest portion of the particulates measured.

Sulfates form sulfuric acid aerosols that react with the iron in the metal walls of heat exchangers to form iron-sulfates. More than half of the fouling deposits removed from a well tuned oil-fired heating system consists of iron sulfates and these non-carbon related deposits are the most difficult to remove due to their tenacity, binding with the metal walls.

A prior NYSERDA market demonstration project involving low sulfur fuel oil has proven the numerous benefits for the consumer and the oilheat marketer with absolutely no detrimental effects over a three-year trial of the low sulfur (500-ppm) fuel in over a thousand homes located in Albany, NY. The primary benefits of using distillate fuel oil with reduced sulfur content are: an $80 \%$ reduction in sulfur oxide emissions and lower service costs for homeowners by reducing the rate of fouling deposits on heat exchange surfaces in boilers and furnaces. A small increase in system efficiency (1-2\% per year) and fuel cost savings resulting from a cleaner heat exchanger are also associated with the reduction in fouling deposits. ${ }^{13}$

The immediate benefit of using 500-ppm sulfur fuel in place of normal heating oil in New York State and the US would be a substantial decrease in sulfur oxide emissions by reducing fuel sulfur from $0.20 \%$ to $0.05 \%$. The emission rate per million Btu of fuel oil that is burned decreases from 0.20 to 0.05 pounds of $\mathrm{SO}_{2}$ based on research by $\mathrm{BNL}$ and the Energy Research Center Inc. (Easton, CT) using US EPA emissions factors. The benefit to New York can be estimated based on the US Census data from 2000 and average fuel consumption figures resulting in an estimated fuel oil use of 2.3 billion gallons a year. This is equivalent to 322 trillion Btu of oil a year at 140,000 Btu per gallon. By applying the emission rates for normal and low sulfur fuel oil, the potential reduction in sulfur oxide emissions by using low sulfur fuel oil in New York State is $67,620,000$ pounds or 33,800 tons of sulfur oxide per year. The potential reduction of sulfur oxide emissions for the US is 140,000 tons a year.

\section{H. Middle Distillate Fuel Cost and Product Supply Concerns}

Fuel costs are an issue of concern as is the question of supply sources and logistics. This is an even more sensitive area of concern for heating fuels because during the winter heating season the supply pressures during periods of very cold temperatures can cause dramatic increases in fuel prices. As with most energy types these prices are unregulated and are determined by the laws of supply and demand. They represent a freely traded commodity where the price can change from day to day or even hour to hour. When temperatures drop and demand increases many additional buyers enter the market. Many represent interruptible rate natural gas users that switch to an alternative fuel, heating oil, as required under their contracts with the gas utilities that provide lower prices for gas in 
exchange for the ability to drop gas delivery to these customers during periods of high demand. As a result more buyers enter the heating oil market and drive the prices up as the inventory drops. These extreme periods of cold weather can also cause fuel deliveries to the terminals more difficult or impossible due to harbors and rivers freezing over.

At the 15-ppm sulfur level that EPA has mandated for diesel fuel starting in 2006 the cost differential has been estimated to be as low as five cents based on EPA estimates or as high as fifteen cents based on API estimates on a per gallon basis. If this were to be applied to heating fuels, this translates to a range of $\$ 45$ to $\$ 135$ per household per year to be able to go down to the 15-ppm sulfur level. This range assumes an annual fuel usage of 900-gallons, which is very typical in NYS. As a point of reference the current untaxed cost differential between low sulfur No. 2 (500-ppm S) fuel and standard heating fuel oil (2000 ppm typical) has ranged from less than two to about four cents per gallon or less than $\$ 18$ to $\$ 36$ projected per year for the same typical NYS home. The actual reported cost differential for ULS diesel fuel during the first two years has ranged from approximately 15 to 25 cents per gallon.

\section{References, Section II}

1 Patterns and Trends, New York State Energy Profiles: 1993-2007, New York State Energy Research and Development Authority, January 2009

2 United States Department of Energy's Energy Information Agency (DOE/EIA-032(93)

3 Pellet Fuel Institute (PFI), http://www.pelletheat.org/3/residential/index.html

4 Personal communication with Dan Henry, Vice President of Advanced Technology Hearth \& Home Technologies and Member of PFI

5 Emissions Characteristics of Modern Oil Heating Equipment, R. Krajewski, Y. Celebi, R. Coughlan, T. Butcher and R.J. McDonald, Brookhaven National Laboratory, July 1990, BNL-52249

6 Investigation of Particulate Emissions from Residential Oil Fired Residential Heating Units, R. E. Barrett, D. W. Locklin and S. E. Miller (Battelle Columbus Laboratory) EPA-650/2-74-026, March 1974

7 Assessing PM 2.5 Emissions from Distillate Fuel Oil Heating, S. Win Lee (CANMET Energy Technology Center-Ottawa), Paper No. 02-13, Proceedings of the 2002 National Oilheat Research Alliance Technology Symposium, BNL-52670, August 2002

8 http://www.epa.gov/air/caa/peg/cleanup.html

9 http://www.epa.gov/air/particlepollution/

10 Assembly Bill: A6896, Title: An act to amend the environmental conservation law, in relation to requiring a reduction in sulfur for all heating oil used in non-attainment areas, http://assembly.state.ny.us/

11 http://www.manevu.org/ Mid-Atlantic, Northeast Visibility Union

12 MANE-VU Statement on Controls In MANE-VU June 20, 2007

13 NYSERDA Low Sulfur Home Heating Oil Demonstration Project, John E. Batey and Roger J. McDonald, BNL-7456-2005-IR, June 2005 


\section{Test Plan}

Phase one of the project sought to measure emissions from a representative sample of typical natural gas and oil-fired, residential heating systems as found in homes and small businesses in New York State. Oil-fired heating systems were tested with conventional heating oil (at $0.2 \%$ or 2,000-ppm sulfur), low sulfur diesel fuel (at 500-ppm sulfur), and ultra-low sulfur diesel fuel (at 15 ppm sulfur). During phase one there was a great deal of emerging interest in renewable forest based fuels and before phase one was completed a modification to the project added an additional task to investigate the emissions from wood pellet stoves that were currently being marketed as a supplemental heat source for residential heating. Phase two of the project sought to measure emissions from more advanced heating technologies including low NOx burners, gas and oil fired condensing boilers and furnaces. Phase two also included the testing of both conventional and advanced, oil-fired, heating technologies with liquid biofuels (biodiesel). One reason for this was to see if a condensing heat exchanger could help eliminate emissions due to the scrubbing of emissions into the condensate (water).

\section{A. List of Equipment Included in the Project}

1. Oil-fired cast iron boiler, equipped with flame retention head burner and various fuels

2. Oil-fired warm air furnace, with flame retention head burner and various fuels

3. Gas-fired sectional cast iron boiler, atmospheric burner and electronic spark ignition

4. Gas-fired warm air furnace, in-shot induced draft burner and electronic spark ignition

5. Gas-fired condensing aluminum boiler, premixed power burner, spark ignition

6. Oil-fired condensing steel boiler, with flame retention head burner, with various fuels

7. Oil-fired condensing warm air furnace, flame retention head burner and various fuels

8. Oil-fired cast iron boiler, equipped with blue flame retention head burner and fuel oil

9. Wood pellet stove, over feed burner, open burner grate, electric ignition

10. Wood pellet stove, over feed burner, closed self-cleaning burn grate, electric ignition

11. Wood pellet stove, side feed burner, open burner grate, manual gel ignition

\section{B. Test Plan}

Each unit was evaluated for correct operation and adjusted for proper combustion air within the limits of the equipment's design to vary the air-fuel ratio and or draft conditions. Gas supply pressures were checked to conform to the manufacturers requirements. Oil-fired systems were adjusted to operate by first finding the trace smoke point and then backing off to very slightly increased combustion air per adjustment standards used by the oil heat industry.

Measurements of combustion emissions were performed for each heating appliance tested. These included gaseous emissions of nitrogen oxides (NOx), sulfur dioxide $\left(\mathrm{SO}_{2}\right)$, carbon monoxide as well as oxygen concentration in the combustion products, which was used to determine carbon dioxide levels by instrument calculation based on the fuel chemical composition. Smoke levels were measured using ASTM Method D-2156 for distillate fuels. Early evaluation tests using oil and gas fired systems were conducted and 
indicated only small differences between operation under steady state and cyclic conditions. Some of these early tests indicated a slightly higher level of particulates would be measured under steady state conditions in comparison to cyclic tests. In other cases this trend reversed. Under either operating test condition, cyclic or steady state, the results were very close. Testing under cyclic conditions was quite possible when the emission factor was high enough to allow for tests in a timely manner. This was not the case with the units with very low emission factors and this could have required many weeks for each test (meaning a single run) to accumulate a sufficient sample size to be weighted accurately. The project schedule would not allow for this. As a result and with the concurrence of the NYSERDA project manager all subsequent tests were run under steady state conditions. 


\section{Measurement Technique}

The basic flue gas emissions data was obtained using an elecronic analyzer with electrochemical cells capable of measuring oxygen, $\mathrm{CO}, \mathrm{NO}, \mathrm{NO}_{2}$ and $\mathrm{SO}_{2}$ as well as measuring stack gas temperature and determining steady state efficiency. The acceptance of portable electrochemical-based analyzers by state and federal environmental agencies has grown significantly over the past decade. Numerous third party organizations have tested and evaluated the technology and found that not only does it satisfy the accuracy requirements of many compliance-testing programs, but also it offers a more affordable and better time managed solution. Coupled with great cross utilization capability that can identify improvements in the combustion, process and product quality, these analyzers make a valuable asset to many types of combustion research. The specific analyzer used in this project was a Testo Model 350 equipped with low range CO and NOx capabilities. This specific device was evaluated, tested and its performance verified under the US EPA's Environmental Technology Verification Program (ETV) by the Advanced Monitoring Systems (AMS) Center, one of six technology areas under ETV and operated by Battelle (Columbus, $\mathrm{OH}$ ) in cooperation with the EPA's National Exposure Laboratory.

Fine particulate measurements were conducted by a series of tests to determine the gravimetric amounts of particulates below 2.5 microns (PM 2.5). This measurement technique is based on US EPA Conditional Tests Method (CTM) 39 for Measurements of PM2.5 and PM10 Emissions by Dilution Tunnel Sampling (Constant Sampling Rate Procedures). This method was developed for larger emissions sources like oil or gasfired power generation utilities or manufacturing plants. These units have stack dimensions sized in several feet not a few inches as in our application. The method was modified to accommodate the tighter geometry found with residential heating appliance vents. The primary modification included not using the particle sizing cyclones except for the wood pellet stove evaluations. These cyclones are normally used inside the stack and are intended to function at the stack temperature. A review of the literature on emissions from gas and middle distillate oil-fired appliances resulted in several references indicating that the particle sizes were well below 2.5 micron, and actually below 1 micron in size. This allowed us to review the situation with our project manager and the decision was to forgo the use of the cyclones for No. 2 heating oil fuel and gas-fired appliances. This decision was not applicable to the investigation of wood pellet stoves. In this case a single cyclone was employed that captured particles larger than 2.5 microns. Due to the extremely small diameter flues (4-inch) used with wood pellet stoves the procedure was again modified and the cyclone was installed outside the flue and equipped with a high temperature heater tape and automatic controller to maintain the temperature at the same level as the internal stack temperature.

At the test conditions established, a series of three measurements were made. The three samples were obtained at the same operating conditions and provided data evaluation based on the standard deviation for statistical reasons. If the standard deviation was quite high due to one measurement that test was repeated to see if more consistent data was obtainable. 
Fuel oil samples were sent to reliable commercial testing laboratories for analysis of density, heating values and chemical constituents including hydrogen, carbon, sulfur, nitrogen, ash and oxygen by weight. Likewise a sample of the wood pellets was sent to a laboratory with a strong reputation for solid fuel analysis. In the case of the utility gas information regarding the analysis of the gas was supplied by the local gas utility. This information coupled with calculations for flue gas volumetric flows inclusive of excess air determinations allowed for calculations of the total volume of flue product at a given firing rate during each run. Test report examples are provided in the Appendix .

The smoke measurement was obtained using a "Bacharach" smoke tester designed to conform to ASTM D1256-94 (1999), Standard Test Method for Smoke Density in Flue Gases from Burning Distillate Fuels. The "Bacharach" smoke tester is a manually operated smoke pump used to set up the air fuel ratio.

The PM2.5 measurement system's schematic is shown in Figure 1. The stack gas is sampled through a nozzle of know dimensions located in the stack at conditions as close to isokinetic as possible. When evaluating the wood pellet stoves the sample flue gas passes through a cyclone, with a cut-off sized for 2.5 microns, which is heated to and controlled at the stack temperature. The probe and the sample flow meter venturi, which is used to measure the sample flow rate, are also kept heated. The sampled gas is cooled and diluted to near ambient conditions by mixing, at the mixing cone, with HEPA filtered ambient cool dry air at about $65-70^{\circ} \mathrm{F}$ as shown. The combined gas stream has sufficient time in the residence chamber for particulates to form and/or condense before they are trapped by the 142-mm filter. A computer is used to control temperatures, to maintain flow rates as particulate builds up on the filter and to collect the experimental data. The normal filter is desiccated and weighed to the nearest $1 / 10$ milligram using an analytical balance (Mettler Toeldo AG104) before and after sampling to determine the mass of PM 2.5 particulates collected. The stack conditions (oxygen concentration) and the sampling flow rates can be used to relate this to stack concentration and hence to the fuel burning rates. Two types of filters are used. The gravimetric samples are collected on borosilicate glass microfiber filters with woven glass cloth bonded with PTFE (Teflon). This is done in triplicate for reasonable statistics. The protocol followed (CTM-39) for setting up and operating the sampling system is more complex than suggested in this outline of the procedure. The complete method can be downloaded from the US EPA's website. ${ }^{1}$

The compact size of the dilution tunnel sampler used in this project provides for the ability to wash down with acetone and subsequent particulate residue recovery. The acetone rinse and residue is collected in pre-weighted aluminum tins. Then the acetone is evaporated in a hood and the residue is weighed using the analytical balance to determine the amount of particulate material recovered. A similar technique using an acetone wash was used to recover the sample from the sizing cyclone when used in the testing of the three wood pellet stoves. Several other research organizations have conducted dilution tunnel sampling using very large apparatus that preclude an accurate recovery of this residue. 


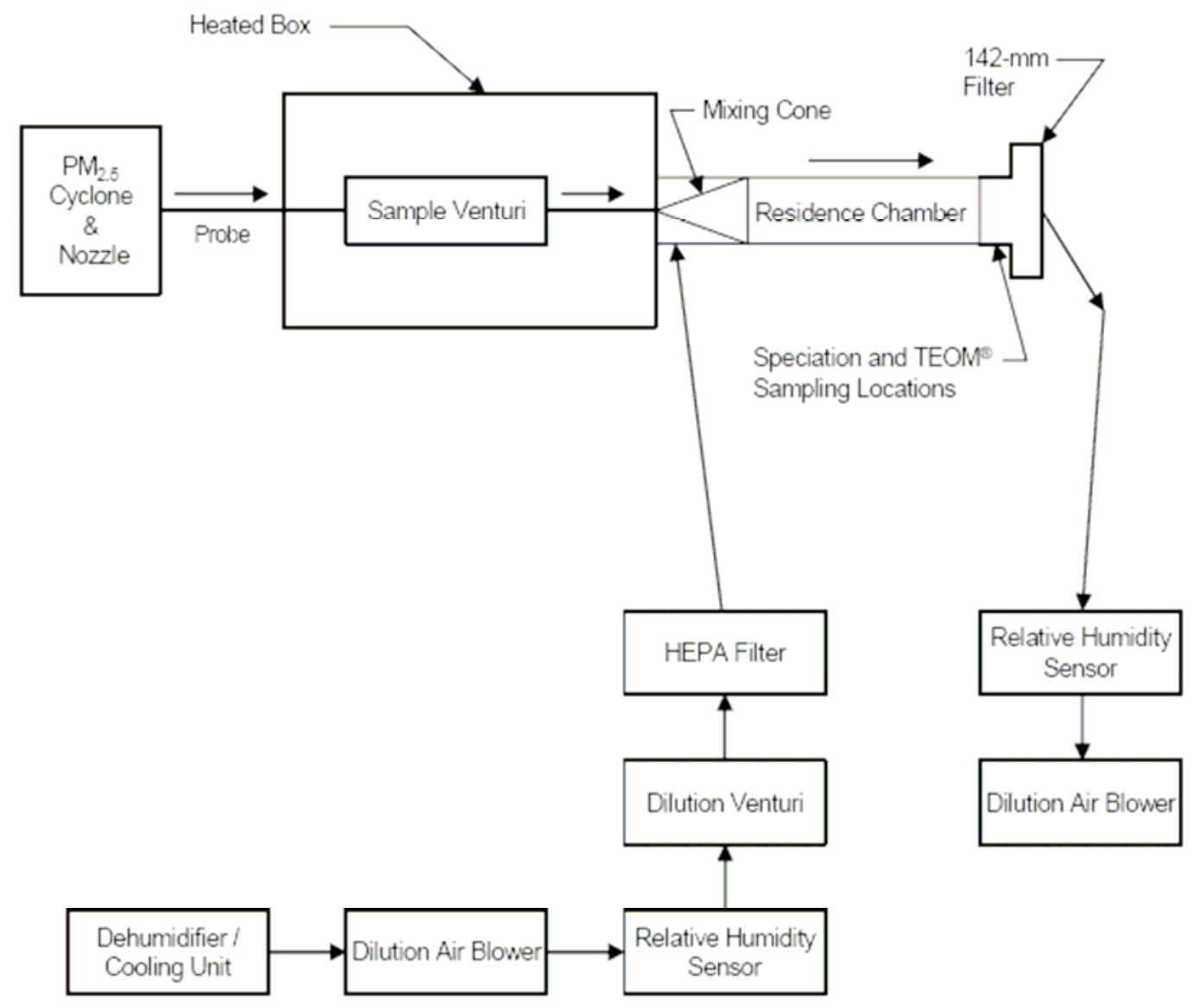

Figure 1. Schematic of the PM 2.5 Measurement

Concurrent with the beginning of this work, BNL hosted a research team from the US EPA tasked with conducting a detailed speciation profile of the fine particulates for a typical residential oil-fired boiler. This project involved testing a single unit with a single sample of fuel and was conducted over a three-day period. The EPA team utilized a very large custom-built dilution tunnel sampler. This measurement system has been deployed to conduct speciation profiles for various different types combustion systems generating fine particulate mater. This was done to determine if there are any unique emissions characteristics from these generic source types that could then be traced in their detailed air quality monitoring stations located throughout the country. This would then enable them to apportion ambient particulate concentrations to be the result of these various generic sources. The EPA dilution tunnel involved a large truckload of equipment and components. This emissions sampler was a modified dilution sampling system like that used by Hildemann et al. ${ }^{2}$

After researching different possibilities BNL had acquired a very compact dilution sampler obtained under the US DOE cost share portion of this project. It was built by a commercial vendor of emissions sampling equipment and was based on the EPA design developed for EPA CTM-039. This design was generated by another arm of the US EPA 
tasked with instrumentation development for multiple users, who are interested in conducting fine particulate measurements for compliance to EPA regulations.

The availability of both dilution tunnel samplers allowed BNL to conduct a direct simultaneous side-by-side comparison of the two measurement systems. While the EPA researchers were at BNL conducting their project BNL ran its measurement system in parallel sampling off the same stack at the same time. This provided BNL an opportunity to evaluate the performance of its compact dilution sampler against a larger version of a modified dilution sampling systems like that used by Hildemann et al. ${ }^{2}$

The boiler tested was a conventional cast iron boiler equipped with a flame retention head burner. In this case, at EPA's request the boiler was tested under cyclic on and off conditions according to the duty cycle specified in ASHRAE Standard 103-1193. The unit was fired with conventional ASTM No. 2 heating oil with a sulfur content of 1,440 ppm. The test was repeated three times over the course of three days. The gravimetric fine particulate emission factor measured by the EPA group was reported as $49+/-5$ $\mathrm{mg} / \mathrm{kg}$. The BNL measurement using the compact dilution sampler was $46 \mathrm{mg} / \mathrm{kg}$ with a standard deviation of $8 \mathrm{mg} / \mathrm{kg}$. These can be compared to the existing emission factor listed in EPA AP-42, a value of $57 \mathrm{mg} / \mathrm{kg}$. As will be discussed in this report the particulate levels measured are strongly impacted by the sulfur content of the fuel. ${ }^{3}$

\section{References, Section IV}

1 http://www.epa.gov/ttn/emc/ctm.html

2 Hildemann, L. M.; Cass, G. R.; Markowski, G. R. A dilution stack sampler for collection of organic aerosol emissions: Design, characterization and field tests. Aerosol Sci. Technol. 1989, 10, 193-204, 1989.

3 Physical and Chemical Characterization of Residential Oil Boiler Emission, Micael D. Hays, Lee Beck, et al., Environmental Science Technology, 2008, 42 (7), 2496-2502 , 27 February 


\section{Results}

List of Heating Equipment Included in the Emissions Characterization Project

1. Oil-fired cast iron boiler, equipped with flame retention head burner and various fuels

2. Oil-fired warm air furnace, with flame retention head burner and various fuels

3. Gas-fired sectional cast iron boiler, atmospheric burner and electronic spark ignition

4. Gas-fired warm air furnace, in-shot induced draft burner and electronic spark ignition

5. Gas-fired condensing aluminum boiler, premixed power burner, spark ignition

6. Oil-fired condensing steel boiler, with flame retention head burner, with various fuels

7. Oil-fired condensing warm air furnace, flame retention head burner and various fuels

8. Oil-fired cast iron boiler, equipped blue flame retention head burner fuel oil

9. Wood pellet stove, over feed burner, open burner grate, electric ignition

10. Wood pellet stove, over feed burner, closed self-cleaning burn grate, electric ignition

11. Wood pellet stove, side feed burner, open burner grate, manual gel ignition

The results are presented in tabular form for each unit tested. First the particulate data will be presented and immediately after the gaseous emissions data will follow. The sole exception is the first table where the gaseous emissions were poorly documented and are included in a note attached to the table for reference. All other data will follow the general format of first a table with particulate related data followed by a table with the gaseous emissions measured.

\section{A. Oil-fired cast iron boiler and flame retention head burner, firing various fuels}

The first unit tested was a sectional cast iron residential oil-fired boiler equipped with a flame retention head burner. This unit was a 5-section design with a nominal fuel input of $1.45 \mathrm{GPH}$ with a DOE output of $175,000 \mathrm{Btu} / \mathrm{hr}$ and an AFUE rating of $85 \%$. This unit provided the opportunity to develop and refine the measurement techniques. In particular the dilution tunnel sampler was a new research tool purchased by BNL using United States Department of Energy (DOE)) funding, see Figure 2.

The use of this measurement system required the development of a consistent methodology for its use based on the CTM-039 method. The technique requires careful preparations in clean prep/recovery laboratory (chemical lab) before the test is conducted. Then the sampling system is set up in the HVAC combustion-testing laboratory. The measurements are conducted and monitored to verify that conditions remain in approximately steady state and isokinetic conditions within reasonable ranges. Ancillary measurements like stack gas and flow measurements also need to be performed and recorded. The length of system operation and sampling run time depends on the fuel type. It can be anywhere from a day up to a week for the cleanest fuels. Then post-test sample filter conditioning and weighing is performed. The dilution tunnel is washed down for residue recovery and a sample mass determination after acetone evaporation is performed in the sample prep/recovery laboratory. The routine procedure now used was the result of several months of mistakes and improvements. 
During the testing of the first unit three different types of fuels were tested with varying sulfur content. These included nominal heating oil (ASTM No. 2) with various sulfur levels in the range of 1440 to 5870-ppm, low sulfur fuel at less than 500-ppm and ultralow-sulfur at less than $15 \mathrm{ppm}$ sulfur. Gaseous emissions measurements under the beginning of the project were limited to oxygen, stack temperature and carbon monoxide (CO) concentration while the PM 2.5 method was developed under the US DOE cost shared portion of the work. Later as the routine was developed a more sophisticated combustion analyzer was used (Testo 350) which recorded carbon dioxide $\left(\mathrm{CO}_{2}\right), \mathrm{CO}$, nitrogen oxides $(\mathrm{NOx})$, sulfur dioxide $\left(\mathrm{SO}_{2}\right)$, oxygen as well stack temperature and efficiency data. Due to early procedure development trials and errors the tests with regular (No. 2) fuel were run a second time. In this case the fuel used turned out to be much higher in sulfur content (5870-ppm). This was actually higher than the ASTM specification of less than 5000-ppm. This unit was tested under both cyclic and steady state conditions.

Table 1 presents the data for the first test series for the oil-fired cast iron boiler, equipped with a flame retention head burner using ASTM No 2 heating oil with nominal sulfur content under steady state conditions. The test laboratory's main fuel tank holds 1,000 gallon of NO. 2 heating fuel and a fuel delivery occurred in the middle of the tests. This resulted in two different fuel sulfur contents that were both in what is considered the nominal range, approximately 2,000-ppm sulfur. Due to the two different fuel samples, four test runs were conducted to see if any significant differences were observable. The average particulate level measured was $60 \mathrm{mg} / \mathrm{kg}$ of fuel with a STDEV (standard deviation) of $5 \mathrm{mg} / \mathrm{kg}$ for the four tests or in alternate units, $1.32 \mathrm{mg} / \mathrm{MJ}$ with STDEV of $0.12 \mathrm{mg} / \mathrm{MJ}$. The particulate levels are also expressed as pounds per million Btu and pounds per 1,000 gallons that are more convenient for making comparison to conventional emission databases that use these units.

In subsequent tables, the data presented will be limited to the more important factors and not include quite as much detail in terms of fuel flows, energy, and volume flows. When presenting results for natural gas fired appliances and wood pellet stoves some of the terms will be slightly different appropriate to the fuel and emission factors commonly used in the literature.

The stack samples for oil and gas emissions measurements were all conducted at 0.4 cubic feet per minute with a 12.5 dilution ratio. These were selected following a series of tests during development of the measurement methodology. Higher and lower dilution ratios up to 20:1 were tested, which shortened or lengthened the residence time. After examining the results it was determined that 12.5:1 was an adequate dilution ration. Again, these tests were conducted at approximately isokinetic conditions by selecting a nozzle to match flow rate to flue gas velocity in the stack. 
Table 1

\begin{tabular}{|c|c|c|c|c|c|c|}
\hline \multicolumn{7}{|c|}{ Oil-fired cast iron boiler, equipped with flame retention head burner in steady state operation } \\
\hline Fuel Type & ASTM No. 2 & ASTM No. 2 & ASTM No. 2 & ASTM No. 2 & \multirow{16}{*}{\multicolumn{2}{|c|}{ Steady State }} \\
\hline Fuel Sulfur ppm & 1700 & 1700 & 1440 & 1440 & & \\
\hline Fuel Flow gph & 1.50 & 1.50 & 1.50 & 1.50 & & \\
\hline Lbs /hr & 10.68 & 10.68 & 10.68 & 10.68 & & \\
\hline Btu /lb & 19696 & 19696 & 19342 & 19342 & & \\
\hline Btu /minute & 3506 & 3506 & 3442 & 3442 & & \\
\hline $\mathrm{kJ} /$ minute & 3699 & 3699 & 3632 & 3632 & & \\
\hline $\mathrm{kg}$ fuel & 399.62 & 323.25 & 116.58 & 97.52 & & \\
\hline Oxygen \% & 5.2 & 4.8 & 4.9 & 4.9 & & \\
\hline PM 2.5 sample mass $\mathrm{mg}$ & 204.7 & 189.2 & 73.2 & 59.7 & & \\
\hline Run time minutes & 4950 & 4004 & 1444 & 1208 & & \\
\hline Volume sample dcf & 1980.0 & 1601.6 & 577.6 & 483.2 & & \\
\hline Volume sample m3 & 56.07 & 45.35 & 16.36 & 13.68 & & \\
\hline Volume dcp / lb & 234.4 & 228.7 & 230.1 & 230.1 & & \\
\hline Volume dcp ft3 / hr & 2503.2 & 2442.0 & 2457.1 & 2457.1 & & \\
\hline Volume dcp $\mathrm{m} 3 / \mathrm{min}$ & 1.18 & 1.15 & 1.16 & 1.16 & & \\
\hline Total stack volume dcp m3 & 5847.92 & 4614.66 & 1674.49 & 1400.82 & Average & STDEV \\
\hline PM 2.5 mg/dscm & 3.7 & 4.2 & 4.5 & 4.4 & 4.2 & 0.4 \\
\hline PM 2.5 mg/dscm @ 3\% O & 4.2 & 4.6 & 5.0 & 4.9 & 4.7 & 0.4 \\
\hline $\mathrm{PM} 2.5 \mathrm{mg} / \mathrm{MJ}$ & 1.17 & 1.30 & 1.43 & 1.39 & 1.32 & 0.12 \\
\hline PM $2.5 \mathrm{mg} / \mathrm{kg}$ & 53.4 & 59.6 & 64.3 & 62.7 & 60.0 & 4.8 \\
\hline Lbs /MMBtu & 0.0027 & 0.0030 & 0.0033 & 0.0032 & 0.0031 & 0.0003 \\
\hline Lbs. /1000 gallons & 0.38 & 0.43 & 0.46 & 0.45 & 0.43 & 0.03 \\
\hline
\end{tabular}

Note: No detailed gaseous emission data were recorded during this of series of tests used for the development of the PM 2.5 test procedure. The oxygen level was monitored and ranged from 5.2-4.9\% with an average of $\sim 4.9 \%$, the $\mathrm{CO}_{2}$ was $\sim 12.1 \%$, and $\mathrm{CO}$ was $~$ $6 \mathrm{ppm}$ with a stack temperature of $\sim 370{ }^{\circ} \mathrm{F}$ and an efficiency of $\sim 86 \%$.

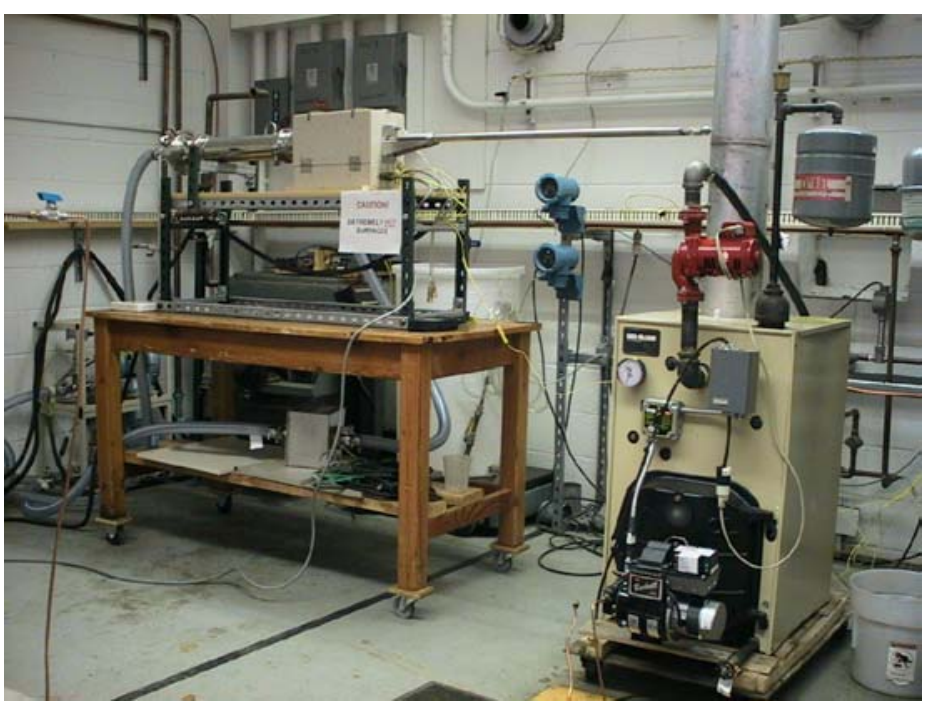

Figure 2. Cast iron boiler and PM 2.5 Dilution Tunnel Sampler 
Table 2 presents the data for a second test series for the oil-fired cast iron boiler, equipped with flame retention head burner using ASTM No 2 heating oil with nominal sulfur content under on off cyclic operating conditions. The cycling pattern was based on ASHRAE 103 Standard 103-1193. Specifically, the operating cycle followed a 9.7minute "on" time and a 33.3-minute "off" time, repeated through a 12-hour test period. Three test runs were completed in this manner. This was the series of tests mentioned earlier where BNL had the opportunity to run its test in conjunction with tests conducted by the US EPA, see Figure 3. The US EPA had sent a team of researchers to BNL to conduct a study of a residential oil-fired boiler. The gravimetric results obtained by BNL and preliminary values obtained from EPA during the test period are presented in Table 3. The boiler was operated in a cyclic pattern so there is no true ability to report concentration levels of PM 2.5 as with the case of steady state operation. The dilution tunnel technique does provide an integrated result as mass per unit mass of fuel or mass per unit value of energy. The final value EPA reported was a fine particulate emission factor of $49+/-5 \mathrm{mg} / \mathrm{kg}(1.06 \mathrm{mg} / \mathrm{MJ})$ of fuel burned. This compares very closely to the value, $46 \mathrm{mg} / \mathrm{kg}(1.02 \mathrm{mg} / \mathrm{MJ})$ with a standard deviation of $8 \mathrm{mg} / \mathrm{kg}$ determined by BNL. Both values compare favorably with the EPA AP-42 value of $57 \mathrm{mg} / \mathrm{kg}$.

Table 2

\begin{tabular}{|c|c|c|c|c|c|}
\hline \multicolumn{6}{|c|}{ Oil-fired cast iron boiler, equipped with flame retention head burner in cyclic operation } \\
\hline Fuel Type & ASTM No. 2 & ASTM No. 2 & ASTM No. 2 & \multirow{10}{*}{\multicolumn{2}{|c|}{ Cyclic }} \\
\hline Fuel Sulfur ppm & 1440 & 1440 & 1440 & & \\
\hline Fuel Flow gph & 1.50 & 1.50 & 1.50 & & \\
\hline Lbs. / hr & 10.7 & 10.6 & 10.8 & & \\
\hline Btu /lb. & 19342 & 19342 & 19342 & & \\
\hline Btu /minute & 3457 & 3431 & 3493 & & \\
\hline $\mathrm{kJ} /$ minute & 3647 & 3620 & 3685 & & \\
\hline $\mathrm{kg}$ fuel & 28.62 & 13.27 & 13.29 & & \\
\hline Oxygen \% & 3.098 & 2.819 & 3.072 & & \\
\hline PM 2.5 sample mass mg & 15.5 & 5.6 & 7.6 & & \\
\hline Run time minutes - burner & 353 & 165 & 162 & Average & STDEV \\
\hline PM $2.5 \mathrm{mg} / \mathrm{kg}$ & 48.7 & 37.1 & 51.9 & 45.9 & 7.8 \\
\hline $\mathrm{PM} 2.5 \mathrm{mg} / \mathrm{MJ}$ & 1.08 & 0.82 & 1.15 & 1.02 & 0.17 \\
\hline \multicolumn{6}{|c|}{ US EPA Residential Oil Boiler (ROB) Evaluation of Fine Particulates } \\
\hline PM $2.5 \mathrm{mg} / \mathrm{kg}$ & 54.3 & 47.7 & 44.0 & 48.1 & 5.2 \\
\hline $\mathrm{PM} 2.5 \mathrm{mg} / \mathrm{MJ}$ & 1.20 & 1.05 & 0.97 & 1.06 & 0.12 \\
\hline
\end{tabular}

Table 3

\begin{tabular}{|l|c|c|c|c|c|c|}
\hline \multicolumn{6}{|c|}{ Residential oil cast iron boiler with flame retention burner firing No. 2 fuel (EPA Series) } \\
\hline Reading Number & 1 & 2 & 2 & 4 & Average & Avg. @ $3 \% \mathrm{O}_{2}$ \\
\hline Stack Temp. ${ }^{0} \mathrm{~F}$ & 386.8 & 399.3 & 349.9 & 343 & 369.8 & $* * * *$ \\
\hline Oxygen $\%^{\mathrm{C}}$ & 3.6 & 3.5 & 3.5 & 3.5 & 3.5 & $* * * *$ \\
\hline $\mathrm{CO}_{2} \%$ & 13 & 13.1 & 13.1 & 13.1 & 13.1 & $* * * *$ \\
\hline $\mathrm{CO}$ ppm & 6 & 6 & 6 & 6 & 6 & 6.2 \\
\hline Efficiency & 86.9 & 86.7 & 87.9 & 88.1 & 87.4 & $* * * *$ \\
\hline
\end{tabular}




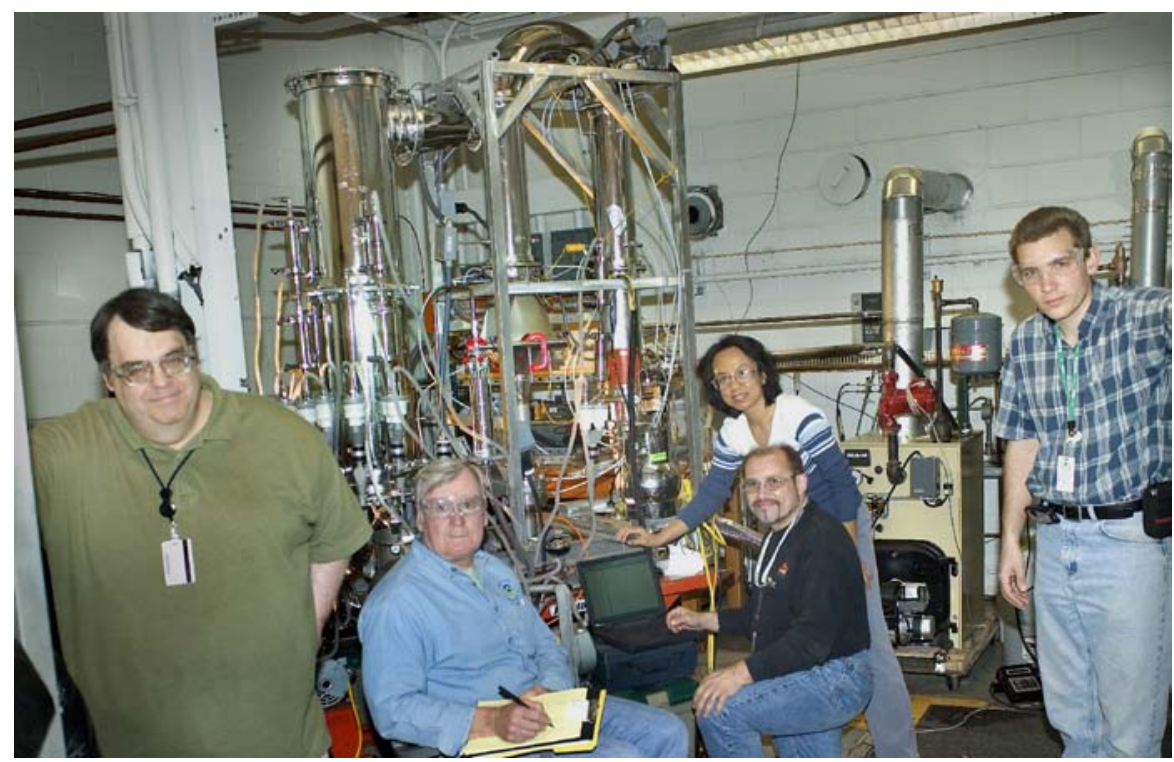

Figure 3. BNL and EPA Staff Conducting Simulations PM 2.5 Measurements

The third set of tests with this boiler was with highway use diesel fuel defined at the time as having no more than 500-ppm sulfur by weight (LS Diesel). When analyzed this fuel had a sulfur content of 322-ppm. As can be seen in Table 4, the fine particulate emission factor for this fuel was significantly lower at $22 \mathrm{mg} / \mathrm{kg}(0.49 \mathrm{mg} / \mathrm{MJ})$ when compared to that measured for conventional middle distillate heating fuel at $60 \mathrm{mg} / \mathrm{kg}$.

Table 4

\begin{tabular}{|c|c|c|c|c|}
\hline \multicolumn{5}{|c|}{ Oil-fired cast iron boiler, equipped with flame retention head burner } \\
\hline Fuel Type & LS Diesel & LS Diesel & \multirow{9}{*}{\multicolumn{2}{|c|}{ Steady State }} \\
\hline Fuel Sulfur ppm & 332 & 332 & & \\
\hline Fuel Flow gph & 1.50 & 1.50 & & \\
\hline Lbs /hr & 10.74 & 10.74 & & \\
\hline Btu /lb & 19333 & 19333 & & \\
\hline Btu /minute & 3461 & 3461 & & \\
\hline $\mathrm{kJ} / \mathrm{minute}$ & 3651 & 3651 & & \\
\hline Oxygen \% & 3.5 & 4.0 & & \\
\hline PM 2.5 sample mass $\mathrm{mg}$ & 27.4 & 31.1 & & \\
\hline Run time minutes & 1372 & 1795 & Average & STDEV \\
\hline $\mathrm{PM} 2.5 \mathrm{mg} / \mathrm{dscm}$ & 1.8 & 1.5 & 1.6 & 0.2 \\
\hline $\mathrm{PM} 2.5 \mathrm{mg} / \mathrm{dscm} @ 3 \% \mathrm{O}_{2}$ & 1.8 & 1.6 & 1.7 & 0.1 \\
\hline $\mathrm{PM} 2.5 \mathrm{mg} / \mathrm{MJ}$ & 0.52 & 0.4 & 0.49 & 0.04 \\
\hline PM $2.5 \mathrm{mg} / \mathrm{kg}$ & 23.3 & 20.8 & 22.0 & \\
\hline Lbs /MMBtu & 0.0012 & & 0.0012 & 0. \\
\hline Lbs. /1000 gallons & & 0.15 & 0.16 & \\
\hline
\end{tabular}


Table 5

\begin{tabular}{|l|c|c|c|c|}
\hline \multicolumn{6}{|c|}{ Oil-fired cast iron boiler, equipped with flame retention head burner LS fuel } \\
\hline Reading Number & 1 & 2 & Average & Average @ $3 \% \mathrm{O}_{2}$ \\
\hline Stack Temp. ${ }^{0} \mathrm{~F}$ & 343 & 366 & 354.5 & $* * * *$ \\
\hline Oxygen \% & 3.5 & 3.8 & 3.7 & $* * * *$ \\
\hline $\mathrm{CO}_{2} \%$ & 88.1 & 12.9 & 50.5 & $* * * *$ \\
\hline $\mathrm{CO}$ ppm & 5 & 6 & 6 & 5.7 \\
\hline Efficiency & 88.1 & 87.8 & 88.0 & $* * * *$ \\
\hline
\end{tabular}

The fourth set of tests (Figure 4) with this boiler utilized ultra low sulfur diesel fuel (ULS), then being developed to meet future mandated EPA requirements for a cleaner on- highway diesel fuel as introduced in the fall of 2006. BNL had obtained a limited quantity of fuel meeting ASTM No.1D specifications. The only ULS fuel type available at the time was from small pilot plants producing fuel for field trials in the transportation sector. Unlike the previous tests, the tests using ULS diesel required much longer operating times ( 3 days) to accumulate a sufficient quantity of particulate $(2-5 \mathrm{mg})$ for accurate weighing.

The measurement results are presented in Table 6 . When analyzed the sulfur content of the ULS fuel was found to be $11 \mathrm{ppm}$. The particulate measurement data shown in Table 6 indicate even further reductions in the particulate emission level, averaging $1.2 \mathrm{mg} / \mathrm{kg}$ $(0.025 \mathrm{mg} / \mathrm{MJ})$ with ULS. Gaseous flue gas constituents are found in Table 7.

Table 6

\begin{tabular}{|c|c|c|c|c|}
\hline \multicolumn{5}{|c|}{ Oil-fired cast iron boiler, equipped with flame retention head burner } \\
\hline Fuel Type & ULS Diesel & ULS Diesel & \multirow{9}{*}{\multicolumn{2}{|c|}{ Steady State }} \\
\hline Fuel Sulfur ppm & 11 & 11 & & \\
\hline Fuel Flow gph & 1.50 & 1.50 & & \\
\hline Lbs /hr & 10.29 & 10.29 & & \\
\hline Btu /lb & 19865 & 19865 & & \\
\hline Btu /minute & 3407 & 3407 & & \\
\hline $\mathrm{kJ} / \mathrm{minute}$ & 3594 & 3594 & & \\
\hline Oxygen \% & 4.1 & 4.5 & & \\
\hline PM 2.5 sample mass mg & 2.0 & 4.8 & & \\
\hline Run time minutes & 2624 & 4150 & Average & STDEV \\
\hline PM 2.5 mg/dscm & 0.0 & 0.102 & 0.085 & 0 \\
\hline PM 2.5 mg/dscm @ 3\% O & 0.0 & 0.111 & 0.092 & 0 \\
\hline $\mathrm{PM} 2.5 \mathrm{mg} / \mathrm{MJ}$ & 0. & 0 & 0 & 0.01 \\
\hline \multirow[t]{2}{*}{ PM $2.5 \mathrm{mg} / \mathrm{kg}$} & 0 & 1.43 & 1.18 & 0.36 \\
\hline & 0. & 0 & 0 & 0.00002 \\
\hline Lbs. /1000 gallons & 0.0 & 0 & 0.0080 & 0 \\
\hline
\end{tabular}


Table 7

\begin{tabular}{|l|c|c|c|c|}
\hline \multicolumn{6}{|c|}{ Oil-fired cast iron boiler, equipped with flame retention head burner ULS fuel } \\
\hline Reading Number & 1 & 2 & Average & Average @ $3 \% \mathrm{O}_{2}$ \\
\hline Stack Temp. ${ }^{0} \mathrm{~F}$ & 329 & 321.3 & 325.2 & $* * * *$ \\
\hline Oxygen \% & 4.1 & 4.3 & 4.2 & $* * * *$ \\
\hline $\mathrm{CO}_{2} \%$ & 12.6 & 12.5 & 12.6 & $* * * *$ \\
\hline $\mathrm{CO}$ ppm & 3 & 3 & 3 & 3.2 \\
\hline Efficiency & 94.7 & 88.5 & 91.6 & $* * * *$ \\
\hline
\end{tabular}

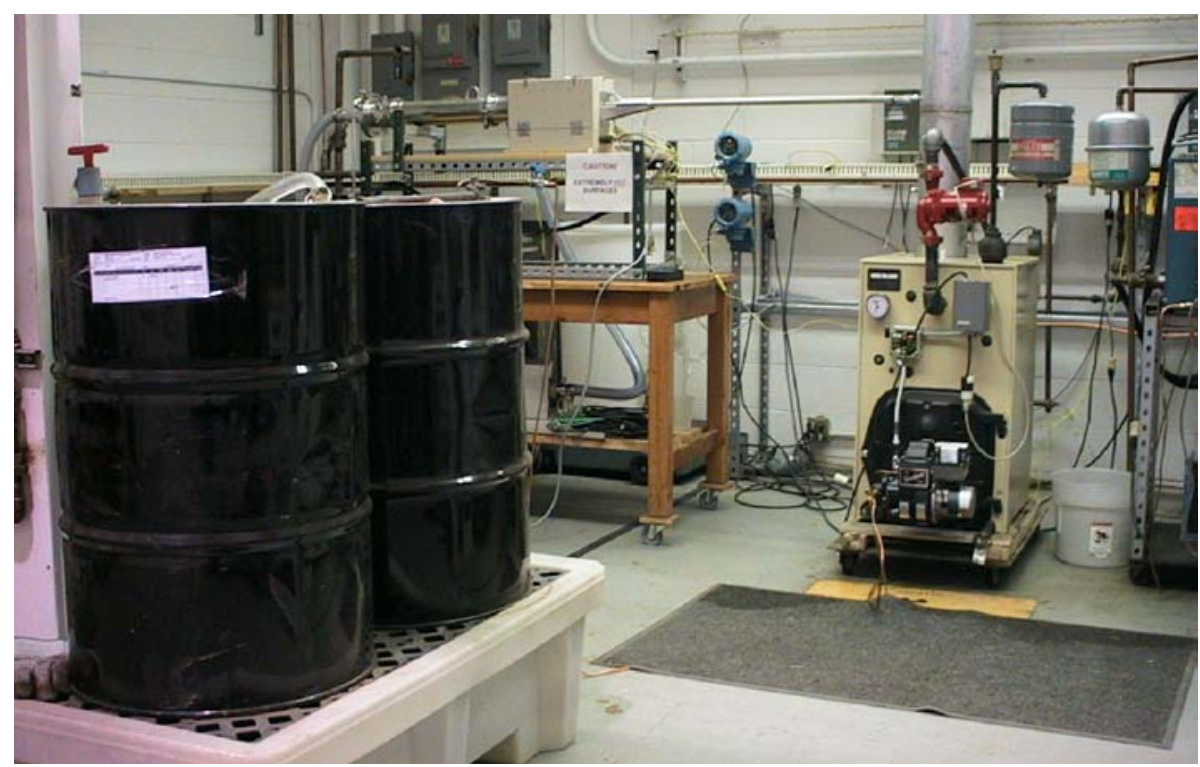

Figure 4. Cast iron boiler fueled with ULS diesel fuel

After several other units were tested, the oil-fired cast iron boiler, equipped with a flame retention head burner was re-evaluated using the refined techniques developed over several earlier tests. This was to hopefully confirm that earlier findings were repeatable. The unit was again tested with fuel delivered to the main fuel supply tank. This tank is used for all tests at BNL requiring ASTM No. 2 fuel oil. After the tests were conducted fuel results were received for a sample sent out for sulfur and heating value analysis. The fuel sulfur turned out to contain 5870-ppm sulfur. This is well above the ASTM specification for No. 2 fuel oil. The heating value was $18,999 \mathrm{Btu} / \mathrm{lb}$. This fuel was used for both a steady state test series as well as under a cyclic on and off use pattern as presented in Tables 8, 9 and 10. The cyclic pattern was again that defined in ASHRAE 103 Standard 103-1193.

As can be seen there was considerably higher amount of fine particulate, $203 \mathrm{mg} / \mathrm{kg}(4.6$ $\mathrm{mg} / \mathrm{MJ})$ for steady state and $224 \mathrm{mg} / \mathrm{kg}(5.1 \mathrm{mg} / \mathrm{MJ})$ for cyclic operation, with this high sulfur content No. 2 oil. This can be compared with the lower values as discussed and found in Table 1(steady state) and Table 2 (EPA cyclic). This was not the intended result that would have helped to confirm earlier findings. It did however once again support the assumption that the tests could be done under steady state conditions rather than 
consuming more time testing under cyclic conditions. It also provided another data point confirming a relationship between fuel sulfur content and particulate emissions.

Table 8

\begin{tabular}{|c|c|c|c|c|c|}
\hline \multicolumn{6}{|c|}{ Oil-fired cast iron boiler, equipped with flame retention head burner, steady state } \\
\hline Fuel Type & ASTM No. 2 & ASTM No. 2 & ASTM No. 2 & \multirow{7}{*}{\multicolumn{2}{|c|}{ Steady State }} \\
\hline Fuel Sulfur ppm & 5780 & 5780 & 5780 & & \\
\hline Fuel Flow gph & 1.49 & 1.49 & 1.49 & & \\
\hline Btu/Min & 3405 & 3405 & 3405 & & \\
\hline $\mathrm{kJ} / \mathrm{Min}$ & 3592 & 3592 & 3592 & & \\
\hline Oxygen \% & 5.45 & 5.53 & 5.49 & & \\
\hline PM 2.5 sample mass $\mathrm{mg}$ & 207.5 & 200.1 & 237 & & \\
\hline Run time minutes & 1375 & 1300 & 1490 & Average & STDEV \\
\hline PM $2.5 \mathrm{mg} / \mathrm{dscm}$ & 13.3 & 13.6 & 14.0 & 13.7 & 0.4 \\
\hline PM 2.5 mg/dscm @ 3\% O & 15.4 & 15.8 & 16.3 & 15.9 & 0.4 \\
\hline PM $2.5 \mathrm{mg} / \mathrm{MJ}$ & 4.47 & 4.59 & 4.73 & 4.6 & 0.1 \\
\hline PM $2.5 \mathrm{mg} / \mathrm{kg}$ & 197.67 & 202.67 & 208.89 & 203.1 & 5.6 \\
\hline Lbs /MMBtu & 0.0104 & 0.0107 & 0.0110 & 0.011 & 0.0003 \\
\hline Lbs. /1000 gallons & 1.41 & 1.45 & 1.49 & 1.4 & 0.04 \\
\hline
\end{tabular}

Table 9

\begin{tabular}{|l|c|c|c|c|c|c|c|c|}
\hline \multicolumn{8}{|c|}{ Oil-fired cast iron boiler, equipped with flame retention burner, steady state, sulfur = 5,780-ppm } \\
\hline Reading Number & 1 & 2 & 3 & 4 & 5 & 6 & Average & Avg. @ $3 \% \mathrm{O}_{2}$ \\
\hline Stack Temp. ${ }^{0} \mathrm{~F}$ & 390.2 & 394.2 & 397.4 & 395.9 & 397.3 & 398.1 & 395.5 & $* * * *$ \\
\hline Oxygen \% & 5.52 & 5.22 & 5.23 & 6.16 & 5.53 & 5.46 & 5.52 & $* * * *$ \\
\hline $\mathrm{CO}_{2} \%$ & 11.56 & 11.79 & 11.78 & 11.83 & 11.56 & 11.61 & 11.69 & $* * * *$ \\
\hline $\mathrm{CO}$ ppm & 2 & 2.3 & 1.9 & 2.4 & 2.1 & 2 & 2 & 2.5 \\
\hline $\mathrm{NOx} \mathrm{ppm}$ & 77.7 & 77.3 & 77.5 & 77.6 & 79.6 & 79.8 & 78.3 & 91.1 \\
\hline $\mathrm{SO}_{2} \mathrm{ppm}$ & 218 & 228 & 233 & 231 & 224 & 228 & 227.0 & 264.2 \\
\hline Efficiency & 86.3 & 86.4 & 86.3 & 86.4 & 86.2 & 86.2 & 86.3 & $* * * *$ \\
\hline
\end{tabular}

Table 10

\begin{tabular}{|c|c|c|c|c|c|}
\hline \multicolumn{6}{|c|}{ Oil-fired cast iron boiler, equipped with flame retention head burner, cyclic operation } \\
\hline Fuel Type & ASTM No. 2 & ASTM No. 2 & ASTM No. 2 & \multirow{7}{*}{\multicolumn{2}{|c|}{ Cyclic }} \\
\hline Fuel Sulfur ppm & 5780 & 5780 & 5780 & & \\
\hline Fuel Flow gph & 1.49 & 1.49 & 1.49 & & \\
\hline Btu/Min & 3405 & 3405 & 3405 & & \\
\hline $\mathrm{kJ} / \mathrm{Min}$ & 3592 & 3592 & 3592 & & \\
\hline Oxygen \% & 5.35 & 5.20 & 5.20 & & \\
\hline PM 2.5 sample mass mg & 110.7 & 69.1 & 99.9 & & \\
\hline Run time minutes & 627 & 399 & 637 & Average & STDEV \\
\hline PM $2.5 \mathrm{mg} / \mathrm{MJ}$ & 5.0 & 5.2 & 5.1 & 5.1 & 0.1 \\
\hline PM $2.5 \mathrm{mg} / \mathrm{kg}$ & 220.4 & 229.8 & 223.3 & 224.5 & 4.8 \\
\hline Lbs /MMBtu & 0.0116 & 0.0121 & 0.0118 & 0.012 & 0.0003 \\
\hline Lbs. /1000 gallons & 1.57 & 1.64 & 1.59 & 1.6 & 0.03 \\
\hline
\end{tabular}




\section{B. Oil-fired warm air furnace, with flame retention head burner and various fuels}

An oil-fired warm air furnace was the next appliance tested. The furnace was equipped with a flame retention head oil burner with a nominal input of $0.9 \mathrm{GPH}$, a DOE output of $101,000 \mathrm{Btu} / \mathrm{hr}$ and an AFUE rating of 81.6\%. The unit was tested with three fuels of differing sulfur content (No. 2, LS diesel and ULS diesel) and in steady state only. The results are presented in Table 11 through Table 16. The average fine particulate emission rate with normal heating oil (1440 ppm sulfur) was $95.9 \mathrm{mg} / \mathrm{kg}(2.1 \mathrm{mg} / \mathrm{MJ})$, with LS diesel $(<500$-ppm sulfur) the emission rate was $24.9 \mathrm{mg} / \mathrm{kg}(0.51 \mathrm{mg} / \mathrm{MJ})$ and with ULS $(11 \mathrm{ppm})$ it was $2.6 \mathrm{mg} / \mathrm{kg}(0.06 \mathrm{mg} / \mathrm{MJ})$.

Table 11

\begin{tabular}{|c|c|c|c|c|c|}
\hline \multicolumn{6}{|c|}{ Oil-fired warm air furnace, with flame retention head burner } \\
\hline Fuel Type & ASTM No. 2 & ASTM No. 2 & ASTM No. 2 & \multirow{7}{*}{\multicolumn{2}{|c|}{ Steady State }} \\
\hline Fuel Sulfur ppm & 1440 & 1440 & 1440 & & \\
\hline Fuel Flow gph & 0.67 & 0.67 & 0.67 & & \\
\hline Btu /minute & 1536 & 1536 & 1536 & & \\
\hline $\mathrm{kJ} /$ minute & 1621 & 1621 & 1621 & & \\
\hline Oxygen \% & 6.3 & 6.2 & 6.2 & & \\
\hline PM 2.5 sample mass $\mathrm{mg}$ & 82.7 & 71.5 & 74.0 & & \\
\hline Run time minutes & 1200 & 1020 & 1071 & Average & STDEV \\
\hline PM 2.5 mg/dscm & 6.1 & & 6.1 & 6.1 & 0.1 \\
\hline $\mathrm{PM} 2.5 \mathrm{mg} / \mathrm{dscm} @ 3 \% \mathrm{O}_{2}$ & 7.5 & 7.5 & 7.4 & 7.5 & \\
\hline PM $2.5 \mathrm{mg} / \mathrm{MJ}$ & 2.1 & 2.2 & 2.1 & 2.1 & \\
\hline PM $2.5 \mathrm{mg} / \mathrm{kg}$ & 95.7 & 96.7 & 95.3 & 95.9 & \\
\hline Lbs /MMBtu & 0.0050 & 0.0050 & 0049 & 0.005 & \\
\hline Lbs. /1000 gallons & 0.69 & 0.69 & 0.68 & 0.69 & \\
\hline
\end{tabular}

Table 12

\begin{tabular}{|l|c|c|c|c|c|c|c|c|}
\hline \multicolumn{8}{|c|}{ Oil-fired warm air furnace, with flame retention head burner with No. 2 Fuel } \\
\hline Reading Number & 1 & 2 & 3 & 4 & 5 & 6 & Average & Avg. @ $3 \% \mathrm{O}_{2}$ \\
\hline Stack Temp. ${ }^{0} \mathrm{~F}$ & 418.3 & 411 & 413.6 & 420.9 & 416.1 & 420.2 & 416.7 & $* * * *$ \\
\hline Oxygen \% & 6.2 & 6.3 & 6.2 & 6.1 & 6.4 & 6.4 & 6.27 & $* * * *$ \\
\hline $\mathrm{CO}_{2} \%$ & 11 & 11 & 11 & 11.2 & 10.9 & 10.9 & 11.00 & $* * * *$ \\
\hline $\mathrm{CO}$ ppm & 0 & 0 & 0 & 2 & 0 & 0 & 0 & 0.3 \\
\hline Efficiency & 89.7 & 89.7 & 89.7 & 89.3 & 89.3 & 89.3 & 89.5 & $* * * *$ \\
\hline
\end{tabular}


Table 13

\begin{tabular}{|c|c|c|c|c|c|}
\hline \multicolumn{6}{|c|}{ Oil-fired warm air furnace, with flame retention head burner } \\
\hline Fuel Type & LS Diesel & LS Diesel & LS Diesel & \multirow{7}{*}{\multicolumn{2}{|c|}{ Steady State }} \\
\hline Fuel Sulfur ppm * & 450 & 450 & 450 & & \\
\hline Fuel Flow gph & 0.67 & 0.67 & 0.67 & & \\
\hline Btu /minute & 1537 & 1537 & 1537 & & \\
\hline $\mathrm{kJ} /$ minute & 1622 & 1622 & 1622 & & \\
\hline Oxygen \% & 5.52 & 6.23 & 6.26 & & \\
\hline PM 2.5 sample mass $\mathrm{mg}$ & 46.8 & 44.9 & 48.4 & & \\
\hline Run time minutes & 1200 & 1020 & 1071 & Average & STDEV \\
\hline \multirow[t]{6}{*}{\begin{tabular}{|l|} 
PM $2.5 \mathrm{~m}$ \\
\end{tabular}} & 1.6 & 1.6 & 1.7 & 1.6 & 0.1 \\
\hline & 1.8 & 1.9 & 2 & 1.9 & 0.1 \\
\hline & 0.52 & 0 & 0.48 & .51 & 0.03 \\
\hline & 23.4 & 2 & 26.7 & & 1.7 \\
\hline & 0.0012 & 0. & 0.0011 & 0.0012 & 0.00007 \\
\hline & 0.17 & 0 & 0.19 & .18 & 0.01 \\
\hline \multicolumn{4}{|c|}{${ }^{*}$ Fuel sulfur taken as $450-\mathrm{ppm}(80 \%$ of maximum allowa } & \multicolumn{2}{|c|}{ likely lower. } \\
\hline
\end{tabular}

Table 14

\begin{tabular}{|l|c|c|c|c|c|c|c|c|}
\hline \multicolumn{6}{|c|}{ Oil-fired warm air furnace, with flame retention head burner - LS (<500 ppm) diesel fuel } \\
\hline Reading Number & 1 & 2 & 3 & 4 & 5 & 6 & Avg. & Avg. @ $3 \% \mathrm{O}_{2}$ \\
\hline Stack Temp. ${ }^{0} \mathrm{~F}$ & 427.9 & 422.4 & 416.2 & 404.2 & 426.8 & 437.4 & 422.5 & $* * * *$ \\
\hline Oxygen \% & 5.63 & 5.43 & 5.45 & 5.65 & 5.4 & 5.44 & 5.50 & $* * * *$ \\
\hline $\mathrm{CO}_{2} \%$ & 11.48 & 11.63 & 11.62 & 11.46 & 11.65 & 11.63 & 11.58 & $* * * *$ \\
\hline $\mathrm{CO}$ ppm & 0.6 & 0 & 0.7 & 0.1 & 0.1 & 0.1 & 0 & 0.3 \\
\hline $\mathrm{NOx} \mathrm{ppm}^{\mathrm{SO}_{2} \mathrm{ppm}}$ & 100.1 & 100.7 & 98.1 & 93.3 & 103.6 & 102.7 & 99.8 & 115.9 \\
\hline Efficiency & 9 & 9 & 9 & 9 & 9 & 9 & 9.0 & 10.5 \\
\hline
\end{tabular}


Table 15

\begin{tabular}{|c|c|c|c|c|}
\hline \multicolumn{5}{|c|}{ Oil-fired warm air furnace, with flame retention head burner } \\
\hline Fuel Type & ULS D1 & ULS D1 & \multirow{7}{*}{\multicolumn{2}{|c|}{ Steady State }} \\
\hline Fuel Sulfur ppm & 11 & 11 & & \\
\hline Fuel Flow gph & 0.62 & 0.62 & & \\
\hline Btu /minute & 1411 & 1411 & & \\
\hline $\mathrm{kJ} /$ minute & 1489 & 1489 & & \\
\hline Oxygen \% & 6.5 & 6.4 & & \\
\hline PM 2.5 sample mass mg & 9.0 & 6.2 & & \\
\hline Run time minutes & 4167 & 4077 & Average & STDEV \\
\hline PM $2.5 \mathrm{mg} / \mathrm{dscm}$ & 0.2 & 0.1 & & 0.04 \\
\hline PM 2.5 mg/dscm @ $3 \% \mathrm{O}_{2}$ & 0.2 & 0.2 & & 0.05 \\
\hline PM 2.5 mg/MJ & 0.07 & & 0.06 & 0.01 \\
\hline PM $2.5 \mathrm{mg} / \mathrm{kg}$ & 3.0 & 2.1 & 2.6 & 0.6 \\
\hline Lbs /MMBtu & 0.00015 & 0.00011 & 0.00013 & 0.00003 \\
\hline Lbs. /1000 gallons & 0.022 & 0.015 & 0.018 & 0.005 \\
\hline
\end{tabular}

Note: Two runs only, fuel availability constrained the number of tests

Table 16

\begin{tabular}{|l|c|c|c|c|c|c|c|c|}
\hline \multicolumn{7}{|c|}{ Oil-fired warm air furnace, with flame retention head burner with ULS fuel } \\
\hline Reading Number & 1 & 2 & 3 & 4 & 5 & 6 & Average & Avg, @ 3\% $\mathrm{O}_{2}$ \\
\hline Stack Temp. ${ }^{0} \mathrm{~F}$ & 402.4 & 404 & 396 & 405.4 & 400.3 & 399.9 & 401.3 & $* * *$ \\
\hline Oxygen $\%$ & 6.3 & 6.2 & 6.4 & 6.7 & 6.2 & 6.4 & 6.37 & $* * *$ \\
\hline $\mathrm{CO}_{2} \%$ & 11 & 11 & 10.9 & 10.7 & 11 & 10.9 & 10.92 & $* * *$ \\
\hline $\mathrm{CO}$ ppm & 0 & 0 & 0 & 0 & 0 & 0 & 0 & 0 \\
\hline Efficiency & 86.2 & 85.8 & 86.4 & 85.7 & 86.6 & 85.6 & 86.1 & $* * *$ \\
\hline
\end{tabular}




\section{Gas-fired cast iron boiler, atmospheric burner and electronic spark ignition}

The third heating appliance tested was a mid-efficiency natural gas-fired hydronic boiler designed for an input of $126,000 \mathrm{Btu} / \mathrm{hr}$ with a 104,000 Btu/hr output and an $81 \%$ AFUE, see Figure 5. The boiler was equipped with an atmospheric burner, intermittent pilot and vent damper. The gas boiler was tested under steady state operating conditions as well as cyclic conditions following the ASHRAE 103 cycle pattern. As was the case with the ULS diesel fired appliance tests, this boiler required long periods of run time to accumulate a sufficient quantity of particulate mass for accurate weighing. Even with these long run times ( $\sim 4$ to 7 days) sample weights measured were only in the range of roughly 3 to 6 milligrams. The results are shown in Tables 17, 18 and 19. Under steady state operation the particulate emission rate averaged $0.90 \mathrm{mg} / \mathrm{kg}(0.016 \mathrm{mg} / \mathrm{MJ})$ and under a cyclic operating pattern it averaged $2.7 \mathrm{mg} / \mathrm{kg}(0.049 \mathrm{mg} / \mathrm{MJ})$.

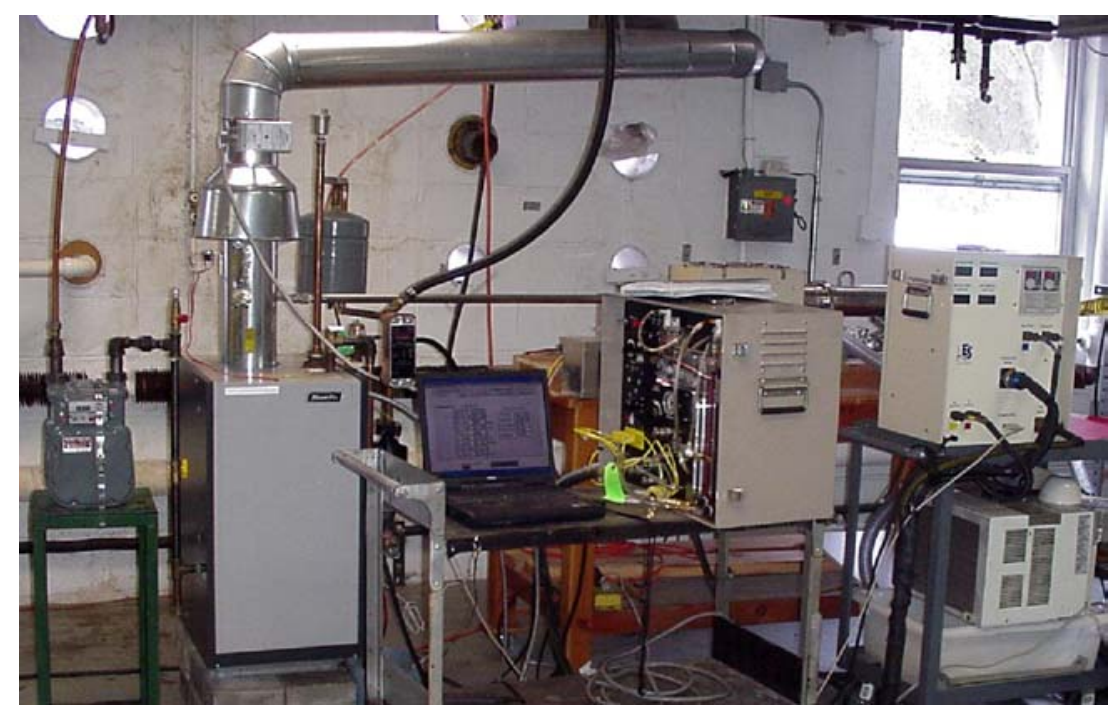

Figure 5. Atmospheric gas-fired hydronic boiler

Table 17

\begin{tabular}{|c|c|c|c|c|c|}
\hline \multicolumn{6}{|c|}{ Gas-fired sectional cast iron boiler, atmospheric burner and electronic spark ignition } \\
\hline Fuel Type & Natural Gas & Natural Gas & Natural Gas & \multirow{7}{*}{\multicolumn{2}{|c|}{ Steady State }} \\
\hline Fuel Sulfur ppm & 10.5 & 10.5 & 10.5 & & \\
\hline Fuel Flow cubic ft/minute & 1.934 & 1.934 & 1.934 & & \\
\hline Btu/Min & 1940 & 1940 & 1940 & & \\
\hline $\mathrm{kJ} / \mathrm{Min}$ & 2047 & 2047 & 2047 & & \\
\hline Oxygen \% & 8.24 & 8.20 & 8.20 & & \\
\hline PM 2.5 sample mass mg & 4.7 & 5.7 & 2.7 & & \\
\hline Run time minutes & 9825 & 9909 & 6145 & Average & STDEV \\
\hline PM $2.5 \mathrm{mg} / \mathrm{dscm}$ & 0.042 & 0.051 & 0.039 & 0.04 & 0.01 \\
\hline PM mg/dscm @ 3\% $\mathrm{O}_{2}$ & 0.060 & 0.072 & 0.055 & 0.06 & 0.01 \\
\hline PM $2.5 \mathrm{mg} / \mathrm{MJ}$ & 0.016 & 0.019 & 0.014 & 0.016 & 0.002 \\
\hline PM $2.5 \mathrm{mg} / \mathrm{kg}$ & 0.87 & 1.04 & 0.80 & 0.90 & 0.1 \\
\hline Lbs /MMBtu & 0.000037 & 0.000044 & 0.000034 & 0.000038 & 0.000005 \\
\hline Lbs. /MM cubic foot & 0.037 & 0.044 & 0.034 & 0.038 & 0.005 \\
\hline
\end{tabular}


Table 18

\begin{tabular}{|c|c|c|c|c|c|c|c|c|}
\hline \multicolumn{9}{|c|}{ Gas-fired sectional cast iron boiler, atmospheric burner and electronic spark ignition } \\
\hline Reading Number & 1 & 2 & 3 & 4 & 5 & 6 & Avg. & Avg. @ $3 \% \mathrm{O}_{2}$ \\
\hline Stack Temp. ${ }^{0} \mathrm{~F}$ & 491.9 & 506.2 & 507.8 & 505.2 & 498.6 & 499.2 & 501.5 & $* * * *$ \\
\hline Oxygen \% & 8.26 & 8.15 & 8.31 & 8.29 & 8.27 & 8.19 & 8.25 & $* * * *$ \\
\hline $\mathrm{CO}_{2} \%$ & 7.09 & 7.15 & 7.06 & 7.07 & 7.11 & 7.12 & 7.10 & $* * * *$ \\
\hline CO ppm & 0.7 & 0.7 & 0.7 & 1 & 0.4 & 0.6 & 1 & 1.0 \\
\hline NOx ppm & 92.9 & 97 & 91.9 & 92.7 & 99.9 & 100.1 & 95.8 & 135.4 \\
\hline $\mathrm{SO}_{2} \mathrm{ppm}$ & 0 & 0 & 0 & 0 & 0 & 0 & 0.0 & 0.0 \\
\hline Efficiency & 79.5 & 79.2 & 78.9 & 79 & 79.3 & 79.3 & 79.2 & $* * * *$ \\
\hline
\end{tabular}

Table 19

\begin{tabular}{|c|c|c|c|c|c|}
\hline \multicolumn{6}{|c|}{ Gas-fired sectional cast iron boiler, atmospheric burner and electronic spark ignition } \\
\hline Fuel Type & Natural Gas & Natural Gas & Natural Gas & \multirow{7}{*}{\multicolumn{2}{|c|}{ Cyclic Operation }} \\
\hline Fuel Sulfur ppm & 10.5 & 10.5 & 10.5 & & \\
\hline Fuel Flow cubic ft /minute & 2.010 & 2.010 & 2.010 & & \\
\hline Btu/Min & 2016 & 2016 & 2016 & & \\
\hline $\mathrm{kJ} / \mathrm{Min}$ & 2127 & 2127 & 2127 & & \\
\hline Oxygen \% & 7.95 & 7.95 & 7.95 & & \\
\hline PM 2.5 sample mass $\mathrm{mg}$ & 6.2 & 3.8 & 3.9 & & \\
\hline Run time minutes & 4297 & 2470 & 2489 & Average & STDEV \\
\hline PM 2.5 mg/MJ & 0 & 0 & 0 & 0.0 & 0.002 \\
\hline PM $2.5 \mathrm{mg} / \mathrm{kg}$ & 2 & 2 & 2 & 2.70 & 0.1 \\
\hline $\mathrm{L}$ & 0.0 & 0.0 & 0.0 & 0.00011 & 0.000005 \\
\hline $\mathrm{L}$ & 0. & 0 & 0 & 0.11 & 0.005 \\
\hline
\end{tabular}




\section{Gas-fired warm air furnace, in-shot induced draft burner with spark ignition}

The third heating appliance tested was a mid-efficiency natural gas-fired warm air furnace designed for an input of 125,000 Btu/hr with a 99,000 Btu/hr output and an $81 \%$ AFUE, see Figure 6. This unit included in-shot induced draft burners and electric spark ignition. The gas furnace was tested under steady state operating conditions as well as cyclic conditions following the ASHRAE 103 cycle pattern. This unit like the gas-fired boiler required long periods of run time to accumulate a sufficient quantity of particulate mass for accurate weighing. Even with these long run times ( $\sim 4$ days) sample weights measured were only in the range of roughly 2 to 4 milligrams. The results are shown in Tables 20, 21 and 22. Under steady state operation the particulate emission rate averaged $0.63 \mathrm{mg} / \mathrm{kg}(0.011 \mathrm{mg} / \mathrm{MJ})$ and under a cyclic operating pattern it averaged $3.2 \mathrm{mg} / \mathrm{kg}$ $(0.058 \mathrm{mg} / \mathrm{MJ})$.

Table 20

\begin{tabular}{|c|c|c|c|c|c|}
\hline \multicolumn{6}{|c|}{ Gas-fired warm air furnace, in-shot induced draft burner and electronic spark ignition } \\
\hline Fuel Type & Natural Gas & Natural Gas & Natural Gas & \multirow{7}{*}{\multicolumn{2}{|c|}{ Steady State }} \\
\hline Fuel Sulfur ppm & 10.5 & 10.5 & 10.5 & & \\
\hline Fuel Flow cubic ft/minute & 1.925 & 1.925 & 1.925 & & \\
\hline Btu/Min & 1931 & 1931 & 1931 & & \\
\hline $\mathrm{kJ} / \mathrm{Min}$ & 2037 & 2037 & 2037 & & \\
\hline Oxygen \% & 8.35 & 8.30 & 8.59 & & \\
\hline PM 2.5 sample mass mg & 2.0 & 1.8 & 2.2 & & \\
\hline Run time minutes & 5630 & 5928 & 5996 & Average & STDEV \\
\hline PM $2.5 \mathrm{mg} / \mathrm{dscm}$ & 0.031 & 0.027 & 0.032 & 0.030 & 0.003 \\
\hline $\mathrm{PM}$ mg/dscm @ 3\% $\mathrm{O}_{2}$ & 0.045 & 0.038 & 0.047 & 0.043 & 0.005 \\
\hline \multirow[t]{4}{*}{ PM $2.5 \mathrm{mg} / \mathrm{MJ}$} & 0.012 & 0.010 & 0.012 & 0.011 & 0.001 \\
\hline & 0.65 & 0.55 & 0.69 & 0.63 & 0.1 \\
\hline & 0. & 0. & 0.0 & 0.000027 & 0.000003 \\
\hline & 0.028 & 0 & 0 & 0.027 & 0.003 \\
\hline
\end{tabular}

Table 21

Gas-fired warm air furnace, in-shot induced draft burner and electronic spark ignition

\begin{tabular}{|l|c|c|c|c|c|c|c|c|}
\hline Reading Number & 1 & 2 & 3 & 4 & 5 & 6 & Average & Avg. @ $3 \% \mathrm{O}_{2}$ \\
\hline Stack Temp. ${ }^{0} \mathrm{~F}$ & 455.2 & 453.5 & 463.8 & 464.2 & 454.4 & 455.1 & 457. & $* * * *$ \\
\hline Oxygen \% & 8.37 & 8.34 & 8.34 & 8.29 & 8.57 & 8.61 & 8.42 & $* * * *$ \\
\hline $\mathrm{CO}_{2} \%$ & 7.03 & 7.05 & 7.04 & 7.07 & 6.91 & 6.89 & 7.00 & $* * * *$ \\
\hline $\mathrm{CO} \mathrm{ppm}$ & 5.8 & 5.8 & 6 & 5.8 & 5.8 & 5.4 & 6 & \\
\hline $\mathrm{NOx} \mathrm{ppm}^{\mathrm{SO}} \mathrm{ppm}_{2} \mathrm{ppm}$ & 57.3 & 55.8 & 56.3 & 56.1 & 54.7 & 54.7 & 55.8 & 80.1 \\
\hline Efficiency & 0 & 0 & 0 & 0 & 0 & 0 & 0.0 & 0.0 \\
\hline
\end{tabular}




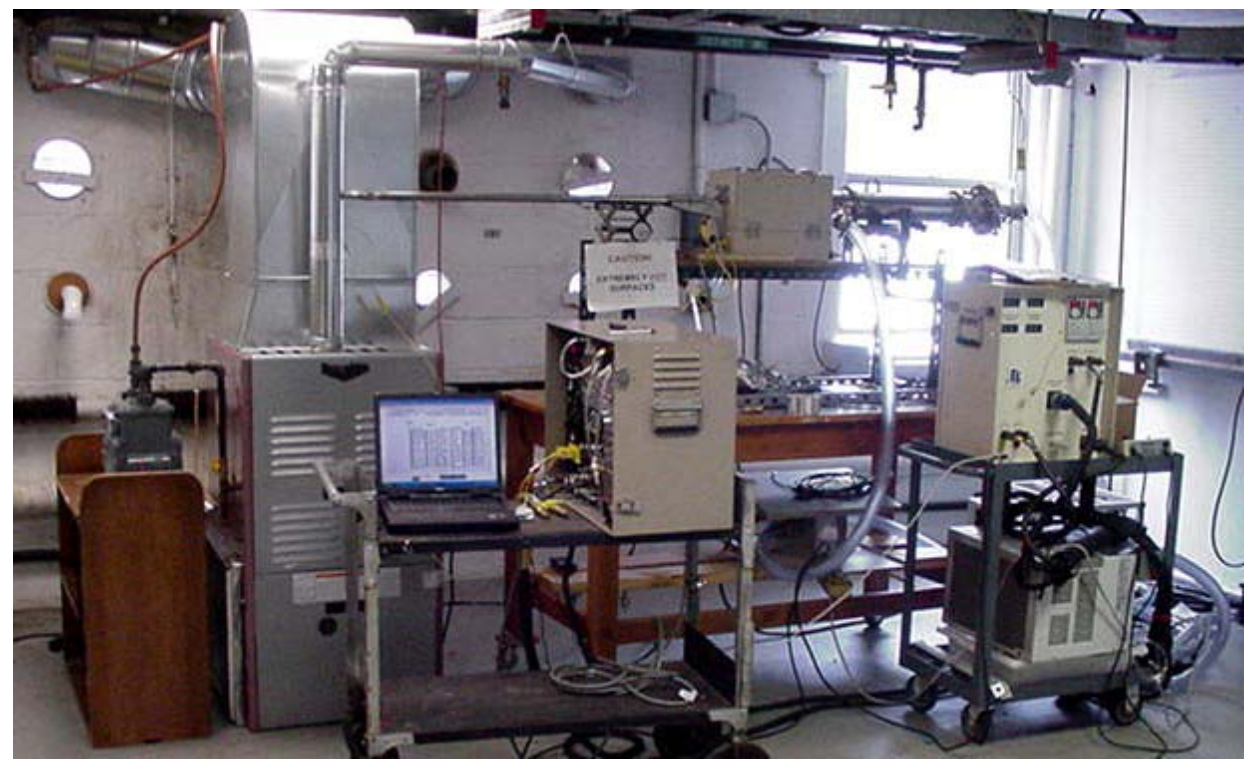

Figure 6. Gas-fired warm air furnace with in-shot induced draft burner

Table 22

\begin{tabular}{|c|c|c|c|c|c|}
\hline \multicolumn{6}{|c|}{ Gas-fired warm air furnace, in-shot induced draft burner and electronic spark ignition } \\
\hline Fuel Type & Natural Gas & Natural Gas & Natural Gas & \multirow{7}{*}{\multicolumn{2}{|c|}{ Cyclic Operation }} \\
\hline Fuel Sulfur ppm & 10.5 & 10.5 & 10.5 & & \\
\hline Fuel Flow cubic ft /minute & 1.950 & 1.950 & 1.950 & & \\
\hline Btu/Min & 1956 & 1956 & 1956 & & \\
\hline $\mathrm{kJ} / \mathrm{Min}$ & 2064 & 2064 & 2064 & & \\
\hline Oxygen $\%$ & 9.55 & 9.55 & 9.55 & & \\
\hline PM 2.5 sample mass mg & 4.0 & 2.2 & 2.4 & & \\
\hline Run time minutes & 1896 & 1641 & 1896 & Average & STDEV \\
\hline PM $2.5 \mathrm{mg} / \mathrm{MJ}$ & 0.078 & 0.049 & 0.047 & 0.058 & 0.017 \\
\hline $\mathrm{PM} 2.5 \mathrm{mg} / \mathrm{kg}$ & 4.29 & 2.72 & 2.57 & 3.19 & 0.9 \\
\hline Lbs /MMBtu & 0.00018 & 0.00012 & 0.00011 & 0.00013 & 0.000040 \\
\hline Lbs. /MM cubic foot & 0.18 & 0.12 & 0.11 & 0.14 & 0.040 \\
\hline
\end{tabular}




\section{E. Gas-fired condensing aluminum boiler, premixed power burner, spark ignition}

The condensing aluminum gas-fired boiler (see Figure 7) was designed to modulate its input rate from 80,000 up to $200,000 \mathrm{Btu} / \mathrm{hr}$ with a thermal output from 76,000 up to 190,000 with an AFUE rating of $95 \%$. Tests were conducted in steady state only due to the complexity of the automatic modulating control included to enhance the unit's efficiency. The unit was operated at an input rate of approximately $115,000 \mathrm{Btu} / \mathrm{hr}$. The particulate emission rate averaged $2.0 \mathrm{mg} / \mathrm{kg}$ of fuel $(0.36 \mathrm{mg} / \mathrm{MJ})$ as shown in Table 23 . The results of the gaseous emissions measurements can be found in Table 24.

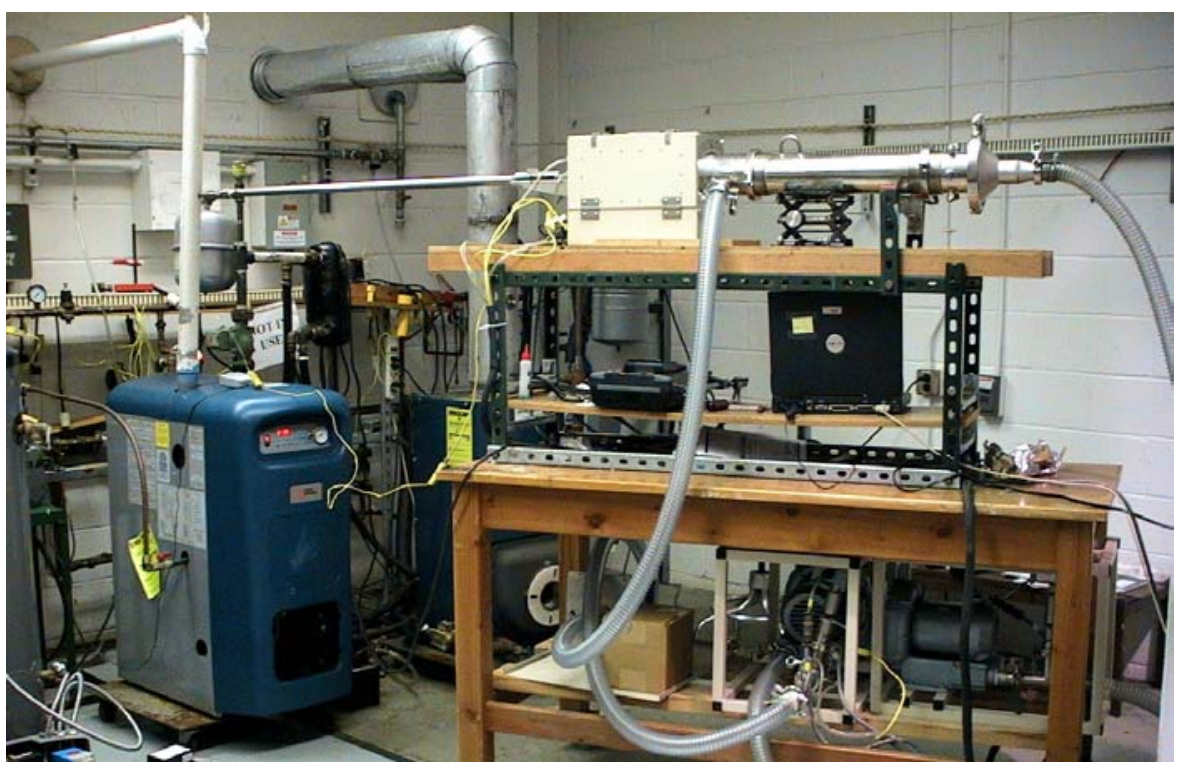

Figure 7. Gas-fired condensing boiler

Table 23

\begin{tabular}{|c|c|c|c|c|c|}
\hline \multicolumn{6}{|c|}{ Gas-fired condensing aluminum boiler, premixed power burner, spark ignition } \\
\hline Fuel Type & Natural Gas & Natural Gas & Natural Gas & \multirow{7}{*}{\multicolumn{2}{|c|}{ Steady State }} \\
\hline Fuel Sulfur ppm & 10.5 & 10.5 & 10.5 & & \\
\hline Fuel Flow cubic ft /minute & 1.925 & 1.925 & 1.925 & & \\
\hline Btu/Min & 1312 & 1288 & 1290 & & \\
\hline $\mathrm{kJ} / \mathrm{Min}$ & 1384 & 1359 & 1361 & & \\
\hline Oxygen \% & 5.86 & 5.86 & 5.92 & & \\
\hline PM 2.5 sample mass mg & 12.1 & 10.3 & 7.1 & & \\
\hline Run time minutes & 8562 & 8462 & 5963 & Ave & STD \\
\hline PM $2.5 \mathrm{mg} / \mathrm{dscm}$ & 0.12 & 0.11 & 0.11 & 0.11 & 0.01 \\
\hline $\mathrm{PM}$ mg/dscm @ 3\% $\mathrm{O}_{2}$ & 0.15 & 0 & 0 & 0 & 0 \\
\hline PM $2.5 \mathrm{mg} / \mathrm{MJ}$ & 0.039 & 0.034 & 0.033 & 0.036 & 0.003 \\
\hline PM $2.5 \mathrm{mg} / \mathrm{kg}$ & 2.17 & 1.87 & 1.83 & 1.96 & 0.2 \\
\hline Lbs /MMBtu & 0.000092 & 0.000079 & 0.000077 & 0.000083 & 0.000008 \\
\hline Lbs. /MM cubic foot & 0.092 & 0.079 & 0.078 & 0.083 & 0.008 \\
\hline
\end{tabular}


Table 24

\begin{tabular}{|l|c|c|c|c|c|c|c|c|}
\hline \multicolumn{8}{|c|}{ Gas-fired condensing aluminum boiler, premixed power burner, spark ignition } \\
\hline Reading Number & 1 & 2 & 3 & 4 & 5 & 6 & Avg. & Avg. @ $3 \% \mathrm{O}_{2}$ \\
\hline Stack Temperature ${ }^{0} \mathrm{~F}$ & 99.2 & 99.2 & 99.1 & 119.3 & 119 & 119.2 & 109.2 & $* * * *$ \\
\hline Oxygen \% & 5.9 & 5.87 & 5.86 & 6.06 & 5.93 & 5.91 & 5.92 & $* * * *$ \\
\hline $\mathrm{CO}_{2} \%$ & 8.41 & 8.42 & 8.43 & 8.32 & 8.39 & 8.4 & 8.40 & $* * * *$ \\
\hline $\mathrm{CO}$ ppm & 2.7 & 2.6 & 2.6 & 2 & 2.1 & 1.8 & 2 & 2.7 \\
\hline $\mathrm{NOx} \mathrm{ppm}^{\mathrm{SO}_{2} \text { ppm }}$ & 8.9 & 9 & 9.2 & 8.5 & 9.1 & 9 & 9.0 & 10.7 \\
\hline Efficiency $^{2}$ & 2 & 1 & 1 & 1 & 1 & 1 & 1.0 & 1.2 \\
\hline
\end{tabular}

\section{F. Oil-fired condensing steel boiler, flame retention head burner, with various fuels}

The oil-fired condensing boiler (see Figure 8) was designed with two heat exchangers. The primary heat exchanger is a unitized thick-shelled carbon steel boiler with combustion chamber and integral steel heat exchanger with a system of removable baffles. Hot gases exiting the primary heat exchanger then proceed directly to the secondary heat exchanger fabricated from corrosion resistant stainless steel with a condensate drain. The unit is fired with a high static pressure flame retention head burner with a nominal input of $81,250 \mathrm{Btu} / \mathrm{hr}$, an output rating of $76,000 \mathrm{Btu} / \mathrm{hr}$ and an AFUE rating of $95 \%$. This unit was fired with three different fuels including No. 2 heating fuel, ULS diesel and a soybean derived biodiesel meeting ASTM specifications as a blending product for use in diesel or heating fuels, see Tables 25 through 30. Particulate emissions averaged $109.8 \mathrm{mg} / \mathrm{kg}(2.5 \mathrm{mg} / \mathrm{MJ})$ for No. 2 heating oil, $1.34 \mathrm{mg} / \mathrm{kg}(0.030 \mathrm{mg} / \mathrm{MJ})$ for ULS diesel and $67.8 \mathrm{mg} / \mathrm{kg}(1.7 \mathrm{mg} / \mathrm{MJ})$ for biodiesel. The results determined when firing biodiesel was quite unexpected and unexplainable based on prior conceptions. As a result yet another boiler of cast iron construction (not a condensing unit) was tested and the data is presented in Tables 31 and 32. This unit, see Figure 9, fired with the same biodiesel fuel had an average particulate emission rate of only $12.1 \mathrm{mg} / \mathrm{kg}(0.3 \mathrm{mg} / \mathrm{MJ})$ which was still higher than typical values for ULS diesel but much closer to that expected for an ultra low sulfur content fuel. This will be discussed further in the conclusions and recommendation sections of this report.

Table 25

\begin{tabular}{|l|c|c|c|c|c|c|c|c|}
\hline \multicolumn{7}{|c|}{ Oil-fired condensing boiler with ASTM No. 2 fuel - steady state } \\
\hline Reading Number & 1 & 2 & 3 & 4 & 7 & 8 & Avg. & Avg. @ 3\% $\mathrm{O}_{2}$ \\
\hline Stack Temperature ${ }^{0} \mathrm{~F}$ & 162.4 & 161.8 & 167.8 & 169.4 & 169.8 & 170.5 & 167.9 & $* * * *$ \\
\hline Oxygen \% & 3.88 & 3.87 & 3.90 & 4.25 & 4.16 & 4.2 & 4.08 & $* * * *$ \\
\hline $\mathrm{CO}_{2} \%$ & 12.79 & 12.80 & 12.78 & 12.52 & 12.58 & 12.6 & 12.65 & $* * * *$ \\
\hline $\mathrm{CO}$ ppm & 2.7 & 2.6 & 2.9 & 1.0 & 0.7 & 1.1 & 1.7 & 2 \\
\hline $\mathrm{NOx} \mathrm{ppm}^{\mathrm{SO}_{2} \mathrm{ppm}}$ & 82.5 & 82.5 & 82.2 & 85.4 & 85.6 & 85.7 & 84.3 & 90 \\
\hline Efficiency & 53 & 53 & 51 & 69 & 69 & 69.0 & 62 & 66 \\
\hline
\end{tabular}


Table 26

\begin{tabular}{|c|c|c|c|c|c|}
\hline \multicolumn{6}{|c|}{ Oil-fired condensing steel boiler tested with flame retention head burner } \\
\hline Fuel Type & ASTM No. 2 & ASTM No. 2 & ASTM No. 2 & \multirow{7}{*}{\multicolumn{2}{|c|}{ Steady State }} \\
\hline Fuel Sulfur ppm & 1900 & 1900 & 1900 & & \\
\hline Fuel Flow gph & 0.56 & 0.57 & 0.57 & & \\
\hline Btu /minute & 1286 & 1307 & 1317 & & \\
\hline $\mathrm{kJ} /$ minute & 1357 & 1379 & 1390 & & \\
\hline Oxygen \% & 3.9 & 3.9 & 3.9 & & \\
\hline PM 2.5 sample mass $\mathrm{mg}$ & 142.5 & 143.0 & 137.5 & & \\
\hline Run time minutes & 1531 & 1490 & 1480 & Average & STDEV \\
\hline PM $2.5 \mathrm{mg} / \mathrm{dscm}$ & 8.2 & 8.5 & 8.2 & 8.3 & 0.2 \\
\hline PM 2.5 mg/dscm @ 3\% O & 8.6 & 8.9 & 8.6 & 8.7 & 0.2 \\
\hline $\mathrm{PM} 2.5 \mathrm{mg} / \mathrm{MJ}$ & 2.4 & 2.5 & 2.4 & 2.5 & 0.05 \\
\hline PM $2.5 \mathrm{mg} / \mathrm{kg}$ & 108.7 & 112.2 & 108.6 & 109.8 & 2.0 \\
\hline Lbs /MMBtu & 0.0057 & 0.0058 & 0.0056 & 0.0057 & 0.0001 \\
\hline Lbs. /1000 gallons & 0.78 & 0.81 & 0.78 & 0.79 & 0.01 \\
\hline
\end{tabular}

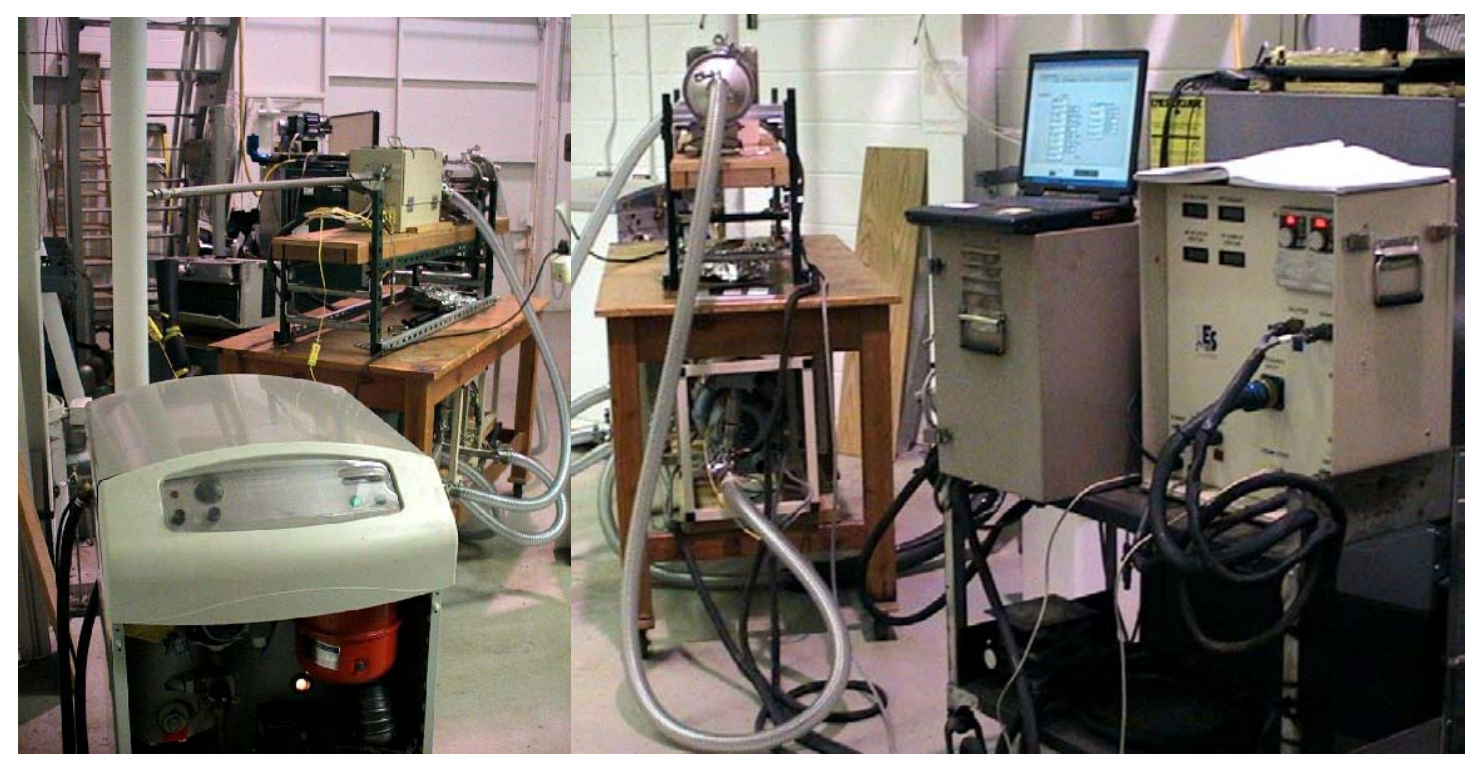

Figure 8. Oil-fired condensing steel boiler during PM 2.5 dilution tunnel testing 
Table 27

\begin{tabular}{|c|c|c|c|c|c|}
\hline \multicolumn{6}{|c|}{ Oil-fired condensing steel boiler tested with flame retention head burner } \\
\hline Fuel Type & ULS & ULS & ULS & \multirow{7}{*}{\multicolumn{2}{|c|}{ Steady State }} \\
\hline Fuel Sulfur ppm & 37 & 37 & 37 & & \\
\hline Fuel Flow gph & 0.58 & 0.57 & 0.55 & & \\
\hline Btu /minute & 1330 & 1309 & 1254 & & \\
\hline $\mathrm{kJ} /$ minute & 1404 & 1382 & 1324 & & \\
\hline Oxygen \% & 4.36 & 3.92 & 3.87 & & \\
\hline PM 2.5 sample mass mg & 7.4 & 6.2 & 5.4 & & \\
\hline \multirow[t]{3}{*}{ Run time minutes } & 5675 & 5862 & 5546 & Average & STDEV \\
\hline & 0.12 & 0.09 & 0.0 & 0.10 & 0.02 \\
\hline & 0.12 & 0.10 & 0.0 & 0.1 & 0.02 \\
\hline PM 2.5 mg/MJ & 0.036 & 0. & 0.026 & 0.030 & \\
\hline \multirow[t]{2}{*}{ PM $2.5 \mathrm{mg} / \mathrm{kg}$} & 1.6 & 1 & 1.2 & 1.34 & 0.2 \\
\hline & 0.000083 & 0.00 & 0.0000 & 0.00007 & 0.00001 \\
\hline Lbs. /1000 gallons & 0.011 & 0 & 0.00 & 0.010 & 0.002 \\
\hline
\end{tabular}

Table 28

\begin{tabular}{|l|c|c|c|c|c|c|c|c|}
\hline \multicolumn{7}{|c|}{ Oil-fired condensing boiler with ULS Fuel -steady state } \\
\hline Reading Number & 1 & 2 & 3 & 4 & 5 & 6 & Avg. & Avg. @ 3\% $\mathrm{O}_{2}$ \\
\hline Stack Temperature ${ }^{0} \mathrm{~F}$ & 161.4 & 168.4 & 188.2 & 183.1 & 173.4 & 172.1 & 174.4 & $* * * *$ \\
\hline Oxygen \% & 4.36 & 4.36 & 3.96 & 3.9 & 3.85 & 3.82 & 4.04 & $* * * *$ \\
\hline $\mathrm{CO}_{2} \%$ & 12.43 & 12.43 & 12.74 & 12.77 & 12.82 & 12.84 & 12.67 & $* * * *$ \\
\hline $\mathrm{CO}$ ppm & 2.3 & 2.6 & 2.8 & 2.8 & 3.3 & 3.1 & 2.8 & 3.0 \\
\hline $\mathrm{NOx} \mathrm{ppm}_{\mathrm{SO}_{2} \mathrm{ppm}}^{66.6}$ & 66.6 & 64.3 & 64.8 & 65.1 & 65.2 & 65.4 & 69.0 \\
\hline Efficiency \% & 1 & 1 & 1 & 1 & 1 & 1 & 1 & 1.1 \\
\hline
\end{tabular}


Table 29

\begin{tabular}{|c|c|c|c|c|c|}
\hline \multicolumn{6}{|c|}{ Oil-fired condensing steel boiler tested with flame retention head burner } \\
\hline Fuel Type & Biodiesel & Biodiesel & Biodiesel & \multirow{7}{*}{\multicolumn{2}{|c|}{ Steady State }} \\
\hline Fuel Sulfur ppm & 164 & 164 & 164 & & \\
\hline Fuel Flow gph & 0.59 & 0.59 & 0.59 & & \\
\hline Btu /minute & 1264 & 1256 & 1258 & & \\
\hline $\mathrm{kJ} / \mathrm{minute}$ & 1334 & 1325 & 1327 & & \\
\hline Oxygen \% & 4.4 & 4 & 3.8 & & \\
\hline PM 2.5 sample mass mg & 198.9 & 94.4 & 94.0 & & \\
\hline Run time minutes & 3240 & 1579 & 1399 & Average & STDEV \\
\hline PM & 5.4 & 5.3 & 5.9 & 5.5 & 0.3 \\
\hline PM 2.5 mg/dscm @ $3 \% \mathrm{O}_{2}$ & & 5.6 & 6.2 & 5.9 & 0.3 \\
\hline PM & 1.7 & 1.6 & 1.8 & 1.7 & 0.09 \\
\hline PM $2.5 \mathrm{mg} / \mathrm{kg}$ & 67.6 & 64.3 & 71.4 & 67.8 & 3.6 \\
\hline Lbs /MMBtu & 0.0039 & 0.0037 & 0.0041 & 0.0039 & 0.0002 \\
\hline Lbs. /1000 gallons & 0.49 & 0.47 & 0.52 & 0.50 & 0.03 \\
\hline
\end{tabular}

Table 30

\begin{tabular}{|l|c|c|c|c|c|c|c|c|}
\hline \multicolumn{1}{|c|}{ Oil-fired condensing steel boiler, flame retention burner with Biodiesel Fuel -steady state } \\
\hline Reading Number & 1 & 2 & 3 & 4 & 5 & 6 & Av & Avg. @ 3\% O \\
\hline Stack Temperature ${ }^{0} \mathrm{~F}$ & 165.6 & 174.2 & 201.3 & 200.8 & 112.1 & 112.5 & 16 & $* * * *$ \\
\hline Oxygen \% & 4.35 & 4.3 & 4.18 & 4.17 & 3.8 & 3.76 & 4 & $* * * *$ \\
\hline $\mathrm{CO}_{2} \%$ & 12.44 & 12.47 & 12.57 & 12.58 & 12.85 & 12.88 & 12.63 & $* * * *$ \\
\hline $\mathrm{CO}$ ppm & 1.6 & 1.4 & 0.6 & 0.3 & 2.1 & 1.8 & 1.3 & 1.4 \\
\hline $\mathrm{NOx} \mathrm{ppm}$ & 59.7 & 60.3 & 64 & 64.1 & 61.1 & 61.7 & 61.8 & 65.8 \\
\hline $\mathrm{SO}_{2}$ ppm & 4 & 4 & 7 & 7 & 8 & 9 & 6.5 & 6.9 \\
\hline Efficiency \% & 91.7 & 91.6 & 90.8 & 90.8 & 93 & 93 & 91.8 & $* * * *$ \\
\hline
\end{tabular}


Table 31

\begin{tabular}{|c|c|c|c|c|c|}
\hline \multicolumn{6}{|c|}{ Oil-fired cast iron boiler tested with flame retention head burner } \\
\hline Fuel Type & Biodiesel & Biodiesel & Biodiesel & \multirow{7}{*}{\multicolumn{2}{|c|}{ Steady State }} \\
\hline Fuel Sulfur ppm & 164 & 164 & 164 & & \\
\hline Fuel Flow gph & 0.766 & 0.766 & 0.766 & & \\
\hline Btu /minute & 1629 & 1629 & 1629 & & \\
\hline $\mathrm{kJ} /$ minute & 1719 & 1719 & 1719 & & \\
\hline Oxygen \% & 7.10 & 6.69 & 6.35 & & \\
\hline PM 2.5 sample mass $\mathrm{mg}$ & 3.3 & 3.2 & 4.8 & & \\
\hline \multirow[t]{4}{*}{ Run time minutes } & 390 & 400 & 405 & Average & STDEV \\
\hline & 0.75 & 0.71 & & 0.8 & 0.2 \\
\hline & 0.97 & 0.89 & 1.29 & 1.0 & 0.2 \\
\hline & 0.27 & 0.25 & 0.36 & 0.3 & 0.06 \\
\hline PM $2.5 \mathrm{mg} / \mathrm{kg}$ & 11.14 & 10.23 & 14.80 & & 2.4 \\
\hline \multirow[t]{2}{*}{ Lbs /MMBtu } & 0.00064 & 0.00059 & 0.00085 & 0.0007 & 0.0001 \\
\hline & 0.081 & 0.075 & 0.108 & & 0.02 \\
\hline
\end{tabular}

Table 32

\begin{tabular}{|c|c|c|c|c|c|c|c|c|}
\hline Oil-fired conventional residential cast iron boiler, flame retention with biodiesel fuel \\
\hline Reading Number & 1 & 2 & 3 & 4 & 5 & 6 & Avg. & Avg. @ $3 \% \mathrm{O}_{2}$ \\
\hline Stack Temperature ${ }^{0} \mathrm{~F}$ & 360.4 & 369.1 & 369.3 & 369.3 & 364.6 & 368.1 & 366.8 & $* * * *$ \\
\hline Oxygen \% & 7.12 & 7.13 & 6.61 & 6.77 & 6.36 & 6.34 & 6.72 & $* * * *$ \\
\hline $\mathrm{CO}_{2} \%$ & 10.37 & 10.36 & 10.75 & 10.63 & 10.93 & 10.95 & 10.67 & $* * * *$ \\
\hline $\mathrm{CO}$ ppm & 0 & 0 & 0 & 0 & 0 & 0.3 & 0 & 0 \\
\hline $\mathrm{NOx} \mathrm{ppm}$ & 117.5 & 118.4 & 117.6 & 116.6 & 110.6 & 109.5 & 115.0 & 145.2 \\
\hline $\mathrm{SO}_{2} \mathrm{ppm}$ & 10 & 10 & 10 & 10 & 11 & 12 & 10.5 & 13.3 \\
\hline Efficiency $\%$ & 86 & 85.8 & 86 & 86 & 86.4 & 86.5 & 6.1 & \\
\hline
\end{tabular}

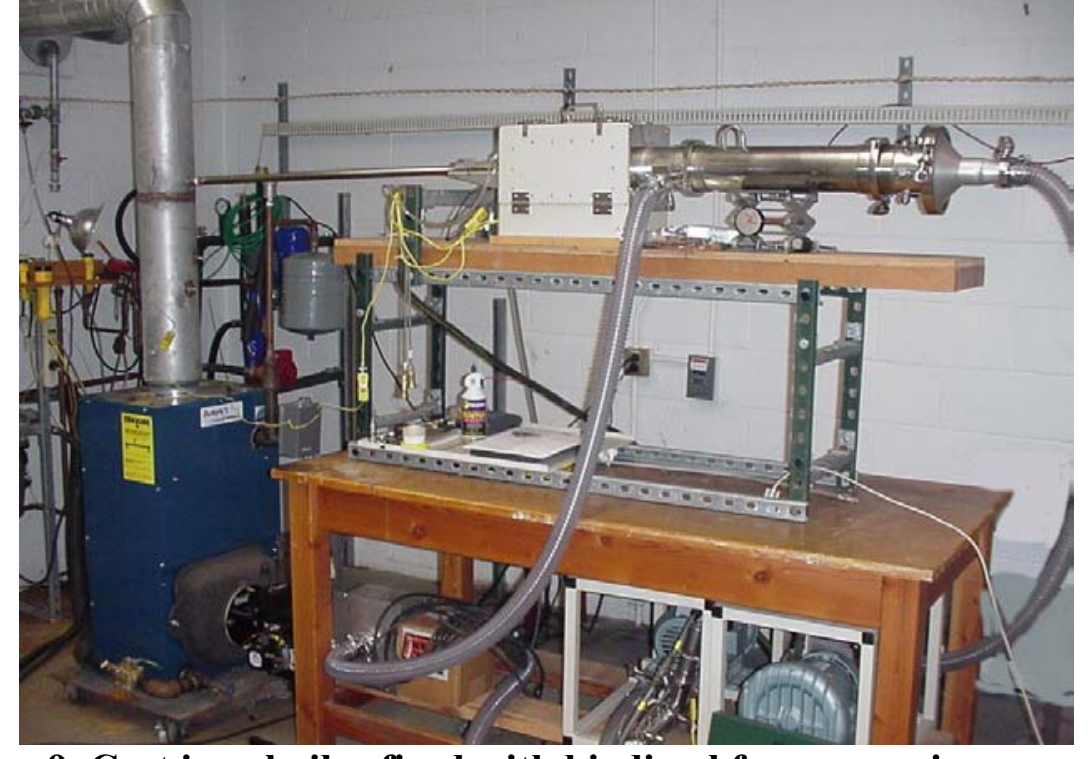

Figure 9. Cast iron boiler fired with biodiesel for comparison purposes 


\section{G. Oil-fired condensing furnace with flame retention head burner, various fuels}

The flame retention head burner equipped oil-fired condensing furnace (see Figure 10) was also designed with two heat exchangers. The first non-condensing heat exchanger (primary) was built from a common stainless steel. The condensing heat exchanger (secondary) was fabricated from a very corrosive resistant stainless steel (alloy AL294C), which is extremely resistant to the corrosion environment expected from use with No. 2 (relatively high in sulfur content). The model tested was designed to fire at 0.5 $\mathrm{GPH}$, an input of 75,000 Btu/hr with a rated output of 73,500 Btu/hr and a AFUE of $95 \%$. The unit was tested with three different fuels, No 2 oil (1,440 ppm sulfur), LS diesel (322 ppm) and ULS diesel (11 ppm sulfur). The fine particulate emission factors measured and the flue gas analysis data are presented in Tables 33 through 38 .

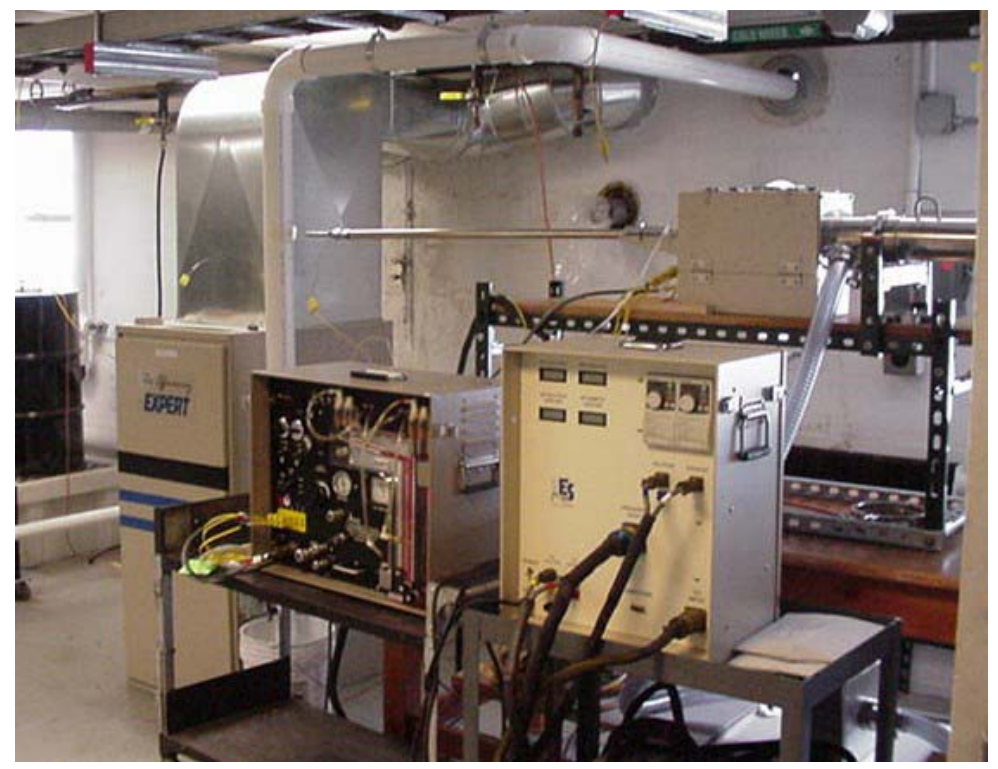

Figure 10. Oil-fired condensing warm air furnace, 95\% AFUE rating

Table 33

\begin{tabular}{|c|c|c|c|c|c|}
\hline \multicolumn{6}{|c|}{ Oil-fired condensing warm air furnace, flame retention head burner } \\
\hline Fuel Type & ASTM No. 2 & ASTM No. 2 & ASTM No. 2 & \multirow{7}{*}{\multicolumn{2}{|c|}{ Steady State }} \\
\hline Fuel Sulfur ppm & 1440 & 1440 & 1440 & & \\
\hline Fuel Flow gph & 0.48 & 0.48 & 0.48 & & \\
\hline Btu /minute & 1114 & 1114 & 1114 & & \\
\hline Kj /minute & 1175 & 1175 & 1175 & & \\
\hline Oxygen \% & 4.7 & 5.1 & 3.1 & & \\
\hline PM 2.5 sample mass $\mathrm{mg}$ & 152.1 & 106.3 & 91.3 & & \\
\hline Run time minutes & 2687 & 1578 & 1363 & Average & STDEV \\
\hline PM $2.5 \mathrm{mg} / \mathrm{dscm}$ & 5.0 & 5.9 & 5.9 & 5.6 & 0.5 \\
\hline $\mathrm{PM} 2.5 \mathrm{mg} / \mathrm{dscm} @ 3 \% \mathrm{O}_{2}$ & 5.5 & 6.7 & 5.9 & 6.1 & 0.6 \\
\hline PM $2.5 \mathrm{mg} / \mathrm{MJ}$ & 1.5 & 1.9 & 2.0 & 1.8 & 0.24 \\
\hline PM $2.5 \mathrm{mg} / \mathrm{kg}$ & 70.9 & 86.5 & 76.3 & 77.9 & 7.9 \\
\hline Lbs /MMBtu & 0.0036 & 0.0044 & 0.0047 & 0.0042 & 0.0006 \\
\hline Lbs. /1000 gallons & 0.51 & 0.62 & 0.55 & 0.56 & 0.06 \\
\hline
\end{tabular}


Table 34

\begin{tabular}{|l|c|c|c|c|c|c|c|c|}
\hline \multicolumn{7}{|c|}{ Oil condensing warm air furnace, with flame retention head burner with No. 2 fuel } \\
\hline Reading Number & 1 & 2 & 3 & 4 & 5 & 6 & Average & Avg. @ $3 \% \mathrm{O}_{2}$ \\
\hline Stack Temp. ${ }^{0} \mathrm{~F}$ & 91.2 & 91.2 & 90.5 & 90.5 & 89.7 & 87.4 & 90.1 & $* * * *$ \\
\hline Oxygen \% & 4 & 4.7 & 4.6 & 4.7 & 5.1 & 5 & 4.7 & $* * * *$ \\
\hline $\mathrm{CO}_{2} \%$ & 12.6 & 12.2 & 12.2 & 12.2 & 11.9 & 12.7 & 12.3 & $* * * *$ \\
\hline $\mathrm{CO}$ ppm & 8 & 8 & 2 & 1 & 2 & 1 & 4 & 4 \\
\hline Efficiency & 93.6 & 93.6 & 93.6 & 93.6 & 93.3 & 94.6 & 93.7 & $* * * *$ \\
\hline
\end{tabular}

Table 35

\begin{tabular}{|c|c|c|c|c|}
\hline \multicolumn{5}{|c|}{ Oil condensing warm air furnace with flame retention head burner } \\
\hline Fuel Type & LS Diesel & LS Diesel & \multirow{7}{*}{\multicolumn{2}{|c|}{ Steady State }} \\
\hline Fuel Sulfur ppm & 332 & 332 & & \\
\hline Fuel Flow gph & 0.48 & 0.48 & & \\
\hline Btu /minute & 1080 & 1080 & & \\
\hline $\mathrm{kJ} /$ minute & 1139 & 1139 & & \\
\hline Oxygen \% & 5.3 & 5.5 & & \\
\hline PM 2.5 sample mass $\mathrm{mg}$ & 26.1 & 49.5 & & \\
\hline Run time minutes & 1523 & 2889 & Average & STDEV \\
\hline $\mathrm{PM} 2.5 \mathrm{mg} / \mathrm{dscm}$ & 1.5 & 1.5 & 1.5 & 0.0002 \\
\hline $\mathrm{PM} 2.5 \mathrm{mg} / \mathrm{dscm} @ 3 \% \mathrm{O}_{2}$ & 1.7 & 1.8 & 1.7 & 0.02 \\
\hline $\mathrm{PM} 2.5 \mathrm{mg} / \mathrm{MJ}$ & 0.496 & 0.502 & 0.499 & 0.005 \\
\hline PM $2.5 \mathrm{mg} / \mathrm{kg}$ & 22.3 & 22.6 & 22.4 & 0.2 \\
\hline Lbs /MMBtu & 0.00115 & 0.00117 & 0.00116 & 0.00001 \\
\hline Lbs. /1000 gallons & 0.158 & 0.160 & 0.159 & 0.001 \\
\hline
\end{tabular}

Table 36

\begin{tabular}{|l|c|c|c|c|}
\hline \multicolumn{6}{|c|}{ Oil condensing warm air furnace, with flame retention head burner with LS fuel } \\
\hline Reading Number & 1 & 2 & Average & \\
\cline { 1 - 3 } Stack Temp. ${ }^{0} \mathrm{~F}$ & 85 & 85.4 & 85.2 & $* *$ \\
\hline Oxygen \% & 5.4 & 5.5 & 5.5 & $* * * *$ \\
\hline $\mathrm{CO}_{2} \%$ & 12.4 & 12.3 & 12.4 & $* * * *$ \\
\hline $\mathrm{CO}$ ppm & 2 & 0 & 1 & 1.2 \\
\hline Efficiency & 94.7 & 94.7 & 94.7 & $* * * *$ \\
\hline
\end{tabular}


Table 37

\begin{tabular}{|c|c|c|c|c|}
\hline \multicolumn{5}{|c|}{ Oil condensing warm air furnace with flame retention head burner } \\
\hline Fuel Type & ULS & ULS & \multirow{7}{*}{\multicolumn{2}{|c|}{ Steady State }} \\
\hline Fuel Sulfur ppm & 11 & 11 & & \\
\hline Fuel Flow gph & 0.45 & 0.45 & & \\
\hline Btu /minute & 1015 & 1015 & & \\
\hline $\mathrm{kJ} /$ minute & 1071 & 1071 & & \\
\hline Oxygen \% & 5.2 & 6.5 & & \\
\hline PM 2.5 sample mass $\mathrm{mg}$ & 4.1 & 2.2 & & \\
\hline Run time minutes & 5400 & 4330 & Average & STDEV \\
\hline PM $2.5 \mathrm{mg} / \mathrm{dscm}$ & 0.07 & 0.04 & 0.06 & 0.02 \\
\hline $\mathrm{PM} 2.5$ mg/dscm @ 3\% O & 0.08 & 0.06 & 0.07 & 0.01 \\
\hline PM $2.5 \mathrm{mg} / \mathrm{MJ}$ & 0.013 & 0.015 & 0.014 & 0.00 \\
\hline \multirow[t]{3}{*}{ PM $2.5 \mathrm{mg} / \mathrm{kg}$} & 0.98 & 0.72 & 0.85 & 0.2 \\
\hline & 0 & 0.0 & 0.00003 & 0.000003 \\
\hline & 0.01 & 0 & 0.006 & 0.001 \\
\hline
\end{tabular}

Table 38

\begin{tabular}{|l|c|c|c|c|c|c|c|c|}
\hline \multicolumn{7}{|c|}{ Oil condensing warm air furnace, with flame retention burner with ULS fuel } \\
\hline Reading Number & 1 & 2 & 3 & 4 & 5 & 6 & Average & $3 \% \mathrm{O}_{2}$ \\
\hline Stack Temp. ${ }^{0} \mathrm{~F}$ & 86.3 & 83.5 & 85 & 84.6 & 91.6 & 87.4 & 86.4 & $* * * *$ \\
\hline Oxygen $\%^{\mathrm{CO}_{2} \%}$ & 6.3 & 4.4 & 5 & 5 & 5.3 & 5.9 & 5 & $* * * *$ \\
\hline $\mathrm{CO}$ ppm & 11 & 12.4 & 11.9 & 11.9 & 11.7 & 11.3 & 11.70 & $* * * *$ \\
\hline Efficiency & 4 & 3 & 2 & 2 & 0 & 1 & 2 & 3.9 \\
\hline
\end{tabular}

\section{H. Oil-fired cast iron boiler with combustion gas recirculation burner (blue flame)}

The combustion gas recirculation (blue flame) burner (see Figure 11) was evaluated in a conventional cast iron sectional hydronic unit, the same boiler as shown in Figure 10. The tests results are presented in Tables 39 and 40. The particulate emissions were very similar to those obtained for various units equipped with flame retention head burners (yellow flame). The gaseous emissions data reflects a decrease in NOx when compared to the conventional yellow flame burner used in the United States. This unit was tested using ULS fuel only. Further testing was not warranted based on budget constraints and the extremely small installed inventory of this type of oil burner technology in the United States. Projections for future sales are also very small in the U.S. market. 
Table 39

\begin{tabular}{|c|c|c|c|c|c|}
\hline \multicolumn{6}{|c|}{ Cast iron boiler with combustion gas recirculation burner with ULS } \\
\hline Measurement & 1 & 2 & 3 & Average & Avg, @ 3\% $\mathrm{O}_{2}$ \\
\hline Stack Temperature ${ }^{\circ} \mathrm{F}$ & 337.4 & 328.8 & 317.3 & 327.8 & $* * *$ \\
\hline Oxygen \% & 4.14 & 3.89 & 3.85 & 3.96 & *** \\
\hline $\mathrm{CO}_{2} \%$ & 12.6 & 12.79 & 12.82 & 12.74 & $* * *$ \\
\hline CO ppm & 1.6 & 3.1 & 3.3 & 2.7 & 3.3 \\
\hline NOx ppm & 45.2 & 45 & 45.5 & 45.2 & 55.8 \\
\hline $\mathrm{SO}_{2} \mathrm{ppm}$ & 0 & 0 & 0 & 0 & 0 \\
\hline Efficiency \% & 88.2 & 88.5 & 88.8 & 88.5 & *** \\
\hline
\end{tabular}

Table 40

\begin{tabular}{|c|c|c|c|c|c|}
\hline \multicolumn{6}{|c|}{ Oil-fired cast iron boiler with combustion gas recirculation burner and ULS } \\
\hline Fuel Type & ULS & ULS & ULS & \multirow{7}{*}{\multicolumn{2}{|c|}{ Steady State }} \\
\hline Fuel Sulfur ppm & 37 & 37 & 37 & & \\
\hline Fuel Flow gph & 0.67 & 0.65 & 0.68 & & \\
\hline Btu /minute & 1535 & 1485 & 1563 & & \\
\hline $\mathrm{Kj} / \mathrm{minute}$ & 1619 & 1567 & 1649 & & \\
\hline Oxygen \% & 4.0 & 4.0 & 4.0 & & \\
\hline PM 2.5 sample mass mg & 7.3 & 7.6 & 7.1 & & \\
\hline Run time minutes & 4518 & 5751 & 4674 & Average & STDEV \\
\hline PM $2.5 \mathrm{mg} / \mathrm{dscm}$ & 0.14 & & 0.13 & 0.13 & \\
\hline $\mathrm{PM} 2.5 \mathrm{mg} / \mathrm{dscm} @ 3 \% \mathrm{O}_{2}$ & 0.15 & 0.1 & 0.14 & 0.14 & \\
\hline PM 2.5 mg/MJ & 0.043 & 0.035 & 0.040 & 0.039 & 0.004 \\
\hline PM 2.5 mg/kg & 1.9 & 1.6 & 1.8 & 1.8 & \\
\hline Lbs /MMBtu & 0.00010 & 0.00008 & 0.00009 & 0.00009 & 0 \\
\hline Lbs. /1000 gallons & 0.014 & 0.011 & 0.013 & 0.013 & 0.001 \\
\hline
\end{tabular}

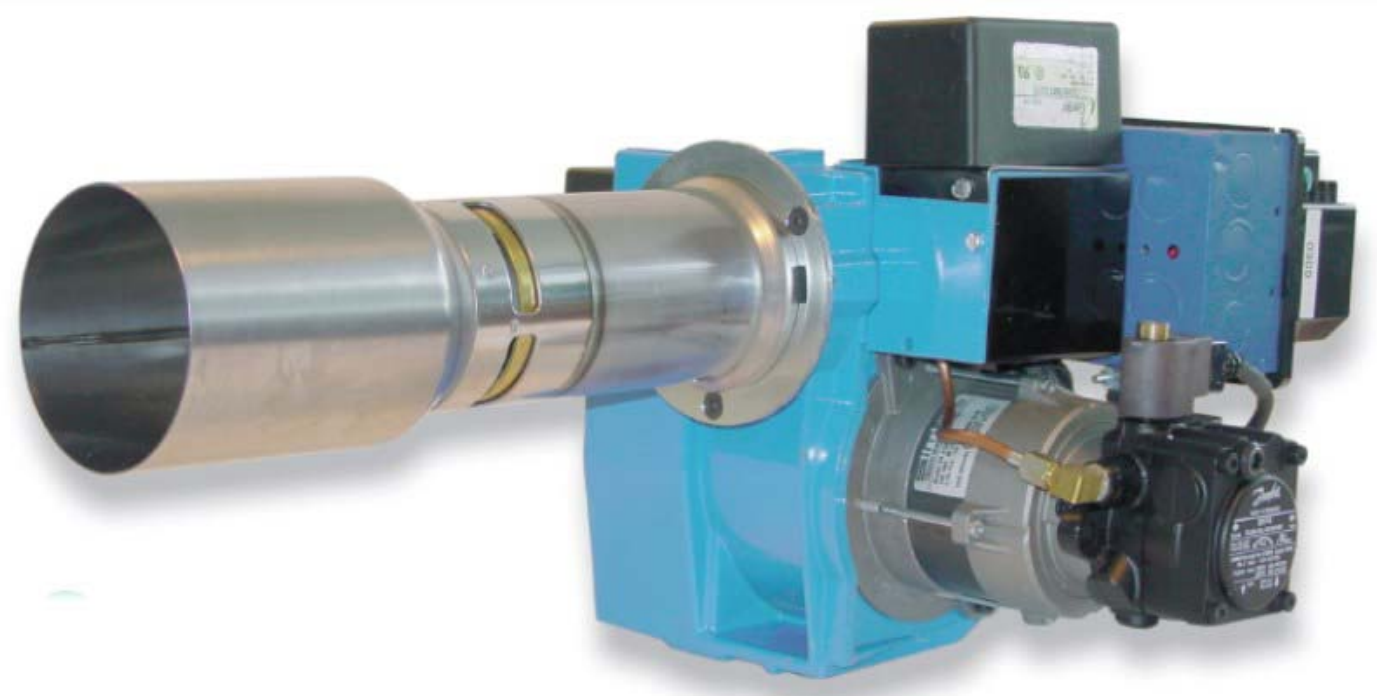

Figure 11. Combustion gas recirculation (blue flame) burner 


\section{Wood pellet stove; drop down over fed, open burner grate, and electric ignition}

The first wood pellet stove evaluated was rated for a maximum input of 4.5 pounds per hour $(\sim 38,000 \mathrm{Btu} / \mathrm{hr})$, see Figure 12 . The hot components and heat exchanger were constructed primarily out of heavy gauge steel sheet metal with an outer casing of lighter gauge metal. The design included several motors driving the fuel fed auger, air circulation blower and power draft blower. The unit was equipped with a control board that included an adjustment knob that varied the fuel input rate by changing the auger on/off cycle. Another knob on the control board was used to control the air blower speed that provides the forced convective heat transfer from the stove by circulating room air through the heat exchanger back into to the room. The unit's design incorporated a pellet feed auger that fed fuel pellets to the top of a downward chute that then dropped the pellets onto the top of the burner grate. The burn grate was open on the bottom allowing the major portion of the forced combustion air to flow upward through the burning bed of fuel. The burner grate also had eight air inlet holes across its front surface (direction facing the stove's glass door) and three larger holes on the backside with the center one being the inlet for the very hot air jet that provided for automated ignition. This air jet flowing over an electric hot surface igniter heats the air and pellets to the point of ignition. The unit was also equipped with forced combustion airflow supplied by yet another blower with an adjustable damper for draft control. It could be sidewall or vertically vented. The unit was only tested at the maximum input rating determined to be 4.3 pounds per hour based on the settings used during the tests. The stove was operated under near steady state conditions. The auger pellet feed control actually cycles on for 1 second and off for 1.15 seconds resulting in a somewhat cyclic burn pattern. This was most evident in the wide swings in $\mathrm{CO}$ measured, which is a result the changing air-fuel ratio changing over short time periods. The NOx level range on the other hand was relatively narrow most likely reflecting the fact that the largest portion of combustion NOx emissions are related to thermal NOx versus those portions related to fuel bound nitrogen and prompt NOx formation. Particulate emission rates were determined in two size categories, smaller than 2.5 microns and those larger than 2.5 microns. The results are presented in Table 41 and the gaseous emissions data recorded are presented in Table 42 .
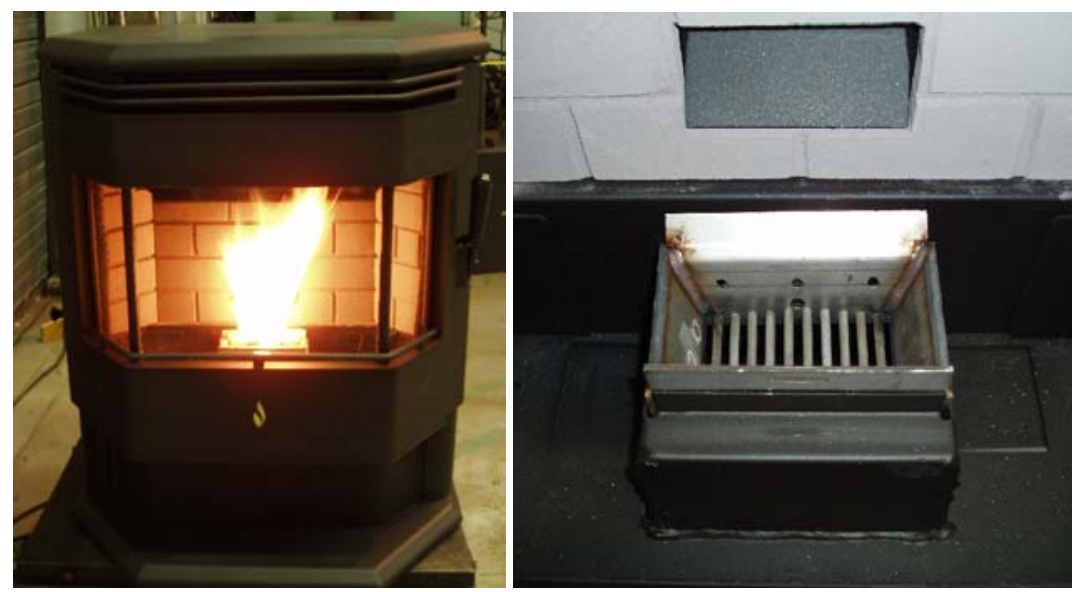

Figure 12. Pellet stove with drop down over fed, open burner grate, electric ignition 
Table 41

\begin{tabular}{|c|c|c|c|c|c|}
\hline \multicolumn{6}{|c|}{ Wood pellet stove, drop down over fed, open burner grate, electric ignition } \\
\hline \multicolumn{6}{|c|}{ Fine Particulate (PM 2.5) } \\
\hline Lbs $/ \mathrm{hr}$ & 4.3 & 4.3 & 4.3 & \multirow{5}{*}{\multicolumn{2}{|c|}{$\begin{array}{l}\text { Steady State } \\
\text { Operation } \\
\text { (8001 Btu/lb) }\end{array}$}} \\
\hline Btu /minute & 569 & 569 & 569 & & \\
\hline $\mathrm{Kj} /$ minute & 601 & 601 & 601 & & \\
\hline Oxygen \% & 13.25 & 13.25 & 13.25 & & \\
\hline PM 2.5 sample mass $\mathrm{mg}$ & 11.1 & 15.8 & 14.8 & & \\
\hline Run time minutes & 75 & 60 & 90 & Average & STDEV \\
\hline PM $2.5 \mathrm{mg} / \mathrm{dscm}$ & 16 & 22 & 15 & 18 & 4 \\
\hline $\mathrm{PM}$ mg/dscm @ 3\% $\mathrm{O}_{2}$ & 84 & 123 & 77 & 95 & 25 \\
\hline PM $2.5 \mathrm{mg} / \mathrm{MJ}$ & 28 & 39 & 24 & 30 & 8 \\
\hline PM $2.5 \mathrm{mg} / \mathrm{kg}$ & 519 & 718 & 447 & 562 & 140 \\
\hline Lbs /MMBtu & 0.065 & 0.090 & 0.056 & 0.070 & 0.018 \\
\hline Lb /Ton & 1.04 & 1.44 & 0.89 & 1.12 & 0.28 \\
\hline Gram particulate $/ \mathrm{hr}$ & 1.00 & 1.03 & 0.93 & 0.99 & 0.05 \\
\hline Larg & te $(>P 1$ & 2.5) Cy & lone $\mathrm{C}$ & & \\
\hline $\mathrm{PM}>2.5$ sample mass $\mathrm{mg}$ & 6.1 & 7.5 & 5.1 & Average & STDEV \\
\hline $\mathrm{PM}>2.5 \mathrm{mg} / \mathrm{dscm}$ & 14 & 21 & 16 & 17 & 4 \\
\hline $\mathrm{PM}>\mathrm{mg} / \mathrm{dscm} @ 3 \% \mathrm{O}_{2}$ & 71 & 112 & 81 & 88 & 21 \\
\hline $\mathrm{PM}>2.5 \mathrm{mg} / \mathrm{MJ}$ & 24 & 35 & 26 & 28 & 6 \\
\hline $\mathrm{PM}>2.5 \mathrm{mg} / \mathrm{kg}$ & 444 & 655 & 475 & 524 & 114 \\
\hline Lbs /MMBtu & 0.056 & 0.082 & 0.059 & 0.066 & 0.014 \\
\hline $\mathrm{Lb} /$ Ton & 0.89 & 1.31 & 0.95 & 1.05 & 0.23 \\
\hline Gram particulate $/ \mathrm{hr}$ & 0.86 & 1.27 & 0.92 & 1.02 & 0.22 \\
\hline
\end{tabular}

Table 42

\begin{tabular}{|l|c|c|c|}
\hline \multicolumn{4}{|c|}{ Wood pellet stove, over feed, open grate, electric ignition } \\
\hline Measurement & Range & Average & Avg. @ 3\% Oxygen \\
\hline Temperature ${ }^{\circ} \mathrm{F}$ & $387.1-420.5$ & 403.1 & ${ }^{* * * *}$ \\
\hline Oxygen $\%$ & $16.70-18.10$ & 17.5 & ${ }^{* * * *}$ \\
\hline $\mathrm{CO}_{2} \%$ & $2.72-4.06$ & 3.29 & 116.4 \\
\hline $\mathrm{NOx} \mathrm{ppm}$ & $18.3-27.6$ & 22.1 & 619.7 \\
\hline $\mathrm{CO}$ ppm & $60.7-187.4$ & 117.7 & 5.3 \\
\hline $\mathrm{SO}_{2} \mathrm{ppm}$ & $0-2$ & 1 & ${ }^{* * * *}$ \\
\hline Efficiency \% & $48.7-64.4$ & 58.5 & \\
\hline
\end{tabular}




\section{J. Pellet stove, over fed burner, enclosed self-clean burn grate, electric ignition}

The second wood pellet stove was similar in form and function to the first including automatic ignition based a on very hot air jet using a hot surface igniter. It was fabricated from cast iron as well as heavy gauge steel sheet. It incorporated a self-cleaning feature that required yet another electric motor. The second unit had an input range of 14,600 to $60,200 \mathrm{Btu} /$ hour or about $1.8-7.5$ pounds of fuel per hour. This unit was operated at about the same fuel input as the other wood pellet stoves to make a more direct comparison of performance. The actual test runs were conducted in the range of $34,400-$ $38,400 \mathrm{Btu} / \mathrm{hr}$. The major design differences being the self-cleaning ductile iron firepot (fire grate) and a microprocessor control that allowed for customizing the stoves operation to the fuel type. In addition to premium wood pellets $(<1 \%$ ash content $)$ this unit was designed to burn standard grade and high ash content wood pellets, shelled field corn (kernels), and other biomass fuels with higher ash contents like wheat and black oil sunflower seeds. Like the previous unit, the pellets are again transferred from the fuel storage hopper in the back of the unit to the top of an internal fuel delivery chute. The fuel drops by gravity down the chute that ends behind and slightly above the burn pot. Once the pellets drop from the chute they fall onto the top of the burning fuel bed. Combustion air is forced through the fire bed from below, fed through a series of inlet holes in the bottom plate of the burn pot. The bottom plate of the burn pot is hinged. Periodically the control stops the burn process and once the fire is no longer detected the bottom plate of the burn pot drops away on its hinge and a motor driven scarper bar cleans any clinkers by moving across the bottom of the open burn pot. This is all controlled by the microprocessor and occurs on a predetermined schedule based on the type of fuel and the firing rate selected. Once the cleaning cycle is completed the unit feeds more fuel and automatically re-starts the burning process.

Particulate emission rates were again determined in two size categories, smaller than 2.5 microns and those larger than 2.5 microns. The results are presented in Table 43 and the gaseous emissions data recorded are presented in Table 44.

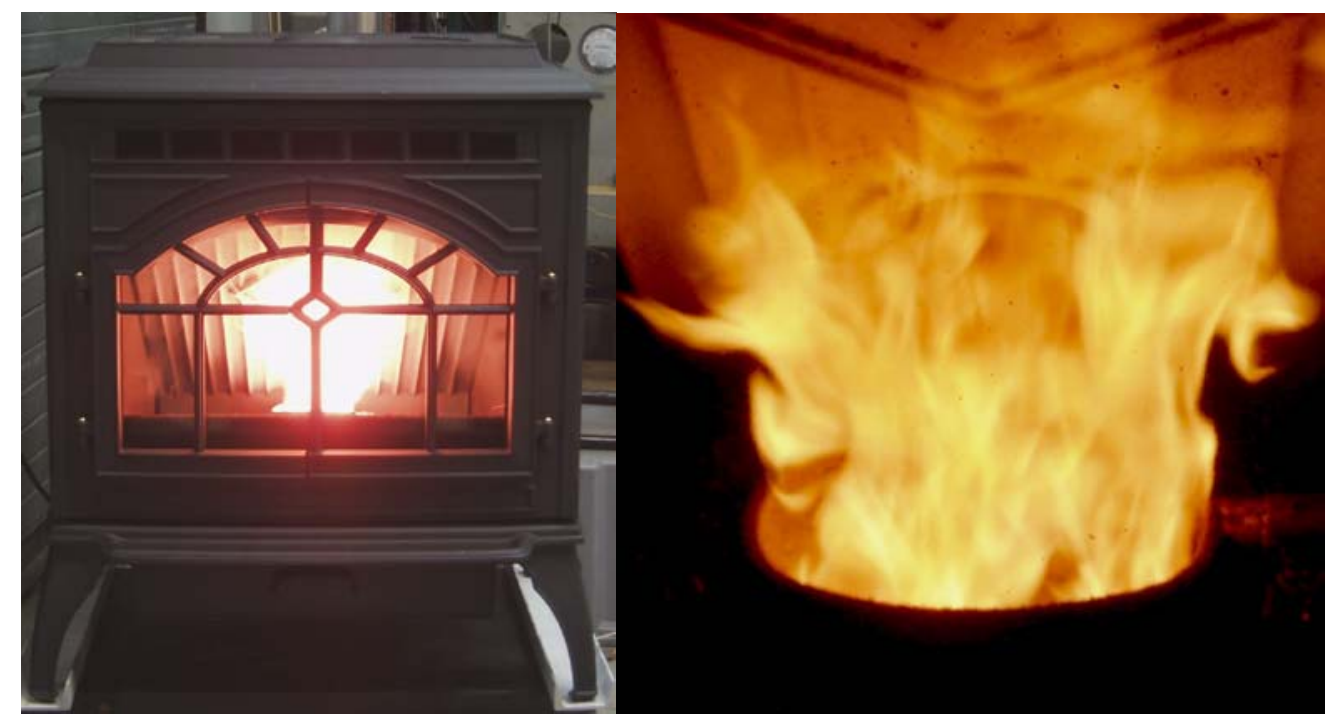

Figure 13. Stove, overfed burner, enclosed self-clean burn pot/grate, electric ignition 
Table 43

\begin{tabular}{|c|c|c|c|c|c|}
\hline \multicolumn{6}{|c|}{ Pellet stove, over fed burner, closed self-clean burn grate, electric ignition } \\
\hline \multicolumn{6}{|c|}{ Fine Particulate (PM 2.5) } \\
\hline Lbs /hr & 4.3 & 4.6 & 4.8 & \multirow{5}{*}{\multicolumn{2}{|c|}{$\begin{array}{l}\text { Steady State } \\
\text { Operation } \\
\text { (8001 Btu/lb) }\end{array}$}} \\
\hline Btu /minute & 567 & 620 & 633 & & \\
\hline Kj /minute & 598 & 653 & 668 & & \\
\hline Oxygen \% & 13.25 & 13.25 & 13.25 & & \\
\hline PM 2.5 sample mass mg & 23.9 & 19.6 & 17.2 & & \\
\hline Run time minutes & 90 & 62 & 60 & Average & STDEV \\
\hline PM 2.5 mg/dscm & 24 & 28 & 26 & 26 & 2 \\
\hline PM mg/dscm @ 3\% O & 71 & 85 & 77 & 78 & 7 \\
\hline PM $2.5 \mathrm{mg} / \mathrm{MJ}$ & 20 & 24 & 22 & 22 & 2 \\
\hline PM $2.5 \mathrm{mg} / \mathrm{kg}$ & 377 & 450 & 409 & 412 & 37 \\
\hline Lbs /MMBtu & 0.047 & 0.056 & 0.051 & 0.051 & 0.005 \\
\hline Lb /Ton & 0.75 & 0.90 & 0.82 & 0.82 & 0.07 \\
\hline Gram particulate /hr & 0.73 & 0.95 & 0.88 & 0.85 & 0.11 \\
\hline \multicolumn{6}{|c|}{ Larger Particulate (>PM 2.5) Cyclone Catch } \\
\hline PM > 2.5 sample mass $\mathrm{mg}$ & 10.1 & 8.1 & 4.7 & Average & STDEV \\
\hline $\mathrm{PM}>2.5 \mathrm{mg} / \mathrm{dscm}$ & 10 & 12 & 7 & 10 & 2 \\
\hline$P M>$ mg/dscm @ 3\% $\mathrm{O}_{2}$ & 30 & 35 & 21 & 29 & 7 \\
\hline $\mathrm{PM}>2.5 \mathrm{mg} / \mathrm{MJ}$ & 9 & 10 & 6 & 8 & 2 \\
\hline $\mathrm{PM}>2.5 \mathrm{mg} / \mathrm{kg}$ & 159 & 186 & 112 & 152 & 38 \\
\hline Lbs /MMBtu & 0.020 & 0.023 & 0.014 & 0.019 & 0.005 \\
\hline Lb /Ton & 0.32 & 0.37 & 0.22 & 0.30 & 0.08 \\
\hline Gram particulate $/ \mathrm{hr}$ & 0.31 & 0.39 & 0.24 & 0.31 & 0.08 \\
\hline
\end{tabular}

Table 44

\begin{tabular}{|l|c|c|c|}
\hline \multicolumn{3}{|c|}{ Pellet stove, over fed burner, closed self-clean burn grate, electric ignition } \\
\hline Measurement & Range & Average & Avg. @ 3\% Oxygen \\
\hline Temperature ${ }^{\circ} \mathrm{F}$ & $377.6-395.4$ & 386.4 & ${ }^{* * *}$ \\
\hline Oxygen \% & $13.77-16.40$ & 14.76 & ${ }^{* * *}$ \\
\hline $\mathrm{CO}_{2} \%$ & $4.35-7.02$ & 5.91 & 131.4 \\
\hline $\mathrm{NOx} \mathrm{ppm}$ & $28.3-45.7$ & 38.6 & 196.4 \\
\hline $\mathrm{CO}_{\mathrm{ppm}}$ & $34.9-91.1$ & 57.7 & 0 \\
\hline $\mathrm{SO}_{2} \mathrm{ppm}$ & 0 & 0 & $* * *$ \\
\hline Efficiency \% & $68.1-76.6$ & 73.5 & \\
\hline
\end{tabular}




\section{K. Wood pellet stove, horizontal under feed, open grate, with manual gel ignition}

The third pellet stove (see Figure 14) was fabricated from heavy steel plate and included a few cast iron components as well. It was designed for a fuel input range of 0.75 to 5.5 pounds per hour $(6,000-44,000 \mathrm{Btu} / \mathrm{hr})$. During the test run it was fired from a low of 4.9 to a high of 5.2 pounds of fuel per hour. The burner pot (grate) on this unit can best be described as a rear under-fed design with front side combustion air inlets (approximating an under fed burner type). Pellets from the integrated storage bin dropped down into the feeder body weldment where an auger transferred the pellets forward into the base of the burner pot (grate). The unit was not equipped with an automatic start feature and required the use of a fire starting gel. The gel was spread out on top of the fuel bed in the burn pot and ignited with a match to start the unit. The front face of the burn pot had a series of holes for combustion air. First, the pellets are fed by the fuel auger into the bottom of the burner grate. Then by the design of the grate they are forced upward towards the open burner face where the pellets are burned. As the burning process proceeds the ash produced then falls off the outer edge of the burner grate. As with all three stoves this unit had a fuel feed rate adjustment and an air circulation blower adjustment on the control board. It also was equipped with an induced draft blower as were the other stoves.

Particulate emission rates were again determined in two size categories, smaller than 2.5 microns and those larger than 2.5 microns. The results are presented in Table 45 and the gaseous emissions data recorded are presented in Table 46.

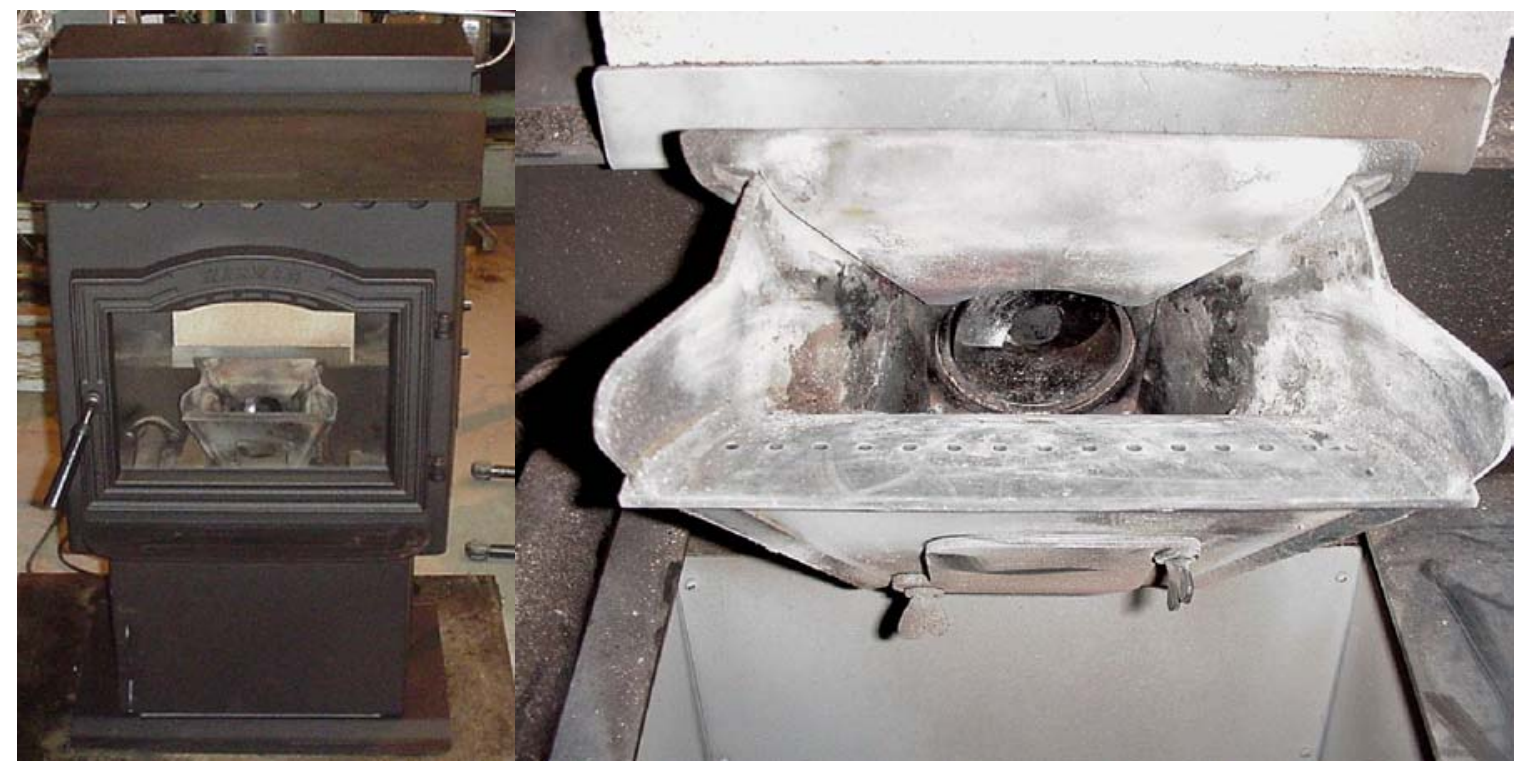

Figure 14. Pellet stove, side feed burner, open burner grate, and manual gel ignition 
Table 45

\begin{tabular}{|c|c|c|c|c|c|}
\hline \multicolumn{6}{|c|}{ Wood pellet stove, horizontal under feed burner, open grate, manual gel ignition } \\
\hline \multicolumn{6}{|c|}{ Fine Particulate (PM 2.5) } \\
\hline Lbs $/ \mathrm{hr}$ & 4.9 & 5.5 & 5.2 & \multirow{3}{*}{\multicolumn{2}{|c|}{$\begin{array}{l}\text { Steady State } \\
\text { Operation }\end{array}$}} \\
\hline Btu /minute & 653 & 728 & 696 & & \\
\hline $\mathrm{Kj} /$ minute & 689 & 768 & 734 & & \\
\hline Oxygen \% & 13.25 & 13.25 & 13.25 & \multirow{2}{*}{\multicolumn{2}{|c|}{ (8001 Btu/lb) }} \\
\hline PM 2.5 sample mass $\mathrm{mg}$ & 33.7 & 38.4 & 35.7 & & \\
\hline Run time minutes & 91 & 112 & 110 & Average & STDEV \\
\hline$P$ & 33 & 30 & 29 & 31 & 2 \\
\hline $\mathrm{P}$ & 77 & 71 & 67 & 72 & 5 \\
\hline $\mathrm{P}$ & 24 & 22 & 21 & 23 & 2 \\
\hline$P$ & 451 & 417 & 393 & 421 & 29 \\
\hline Lbs /MMBtu & 0.056 & 0.052 & 0.049 & 0.053 & 0.004 \\
\hline Lb /Ton & 0.90 & 0.83 & 0.79 & 0.84 & 0.06 \\
\hline G & 1.00 & 1.03 & 0.93 & 0.99 & 0.05 \\
\hline \multicolumn{6}{|c|}{ Larger Particulate (>PM 2.5) Cyclone Catch } \\
\hline $\mathrm{PM}>2.5$ sample mass $\mathrm{mg}$ & 6.1 & 7.5 & 5.1 & Average & STDEV \\
\hline$P M>2.5 \mathrm{mg} / \mathrm{dscm}$ & 6 & 6 & 4 & 5 & 1 \\
\hline$P M>m g / d s c m @ 3 \% \mathrm{O}_{2}$ & 14 & 14 & 10 & 13 & 3 \\
\hline $\mathrm{PM}>2.5 \mathrm{mg} / \mathrm{MJ}$ & 4 & 4 & 3 & 4 & 1 \\
\hline $\mathrm{PM}>2.5 \mathrm{mg} / \mathrm{kg}$ & 82 & 81 & 56 & 73 & 15 \\
\hline Lbs /MMBtu & 0.010 & 0.010 & 0.007 & 0.009 & 0.002 \\
\hline Lb /Ton & 0.16 & 0.16 & 0.11 & 0.15 & 0.03 \\
\hline Gram particulate $/ \mathrm{hr}$ & 0.18 & 0.20 & 0.13 & 0.17 & 0.04 \\
\hline
\end{tabular}


Table 46

\begin{tabular}{|l|c|c|c|}
\hline \multicolumn{4}{|c|}{ Wood pellet stove, horizontal under feed burner, open grate, manual gel ignition } \\
\hline Measurement & Range & Average & Avg. @ 3\% Oxygen \\
\hline Temperature ${ }^{\mathrm{O}} \mathrm{F}$ & $410.9-424.1$ & 419.7 & ${ }^{* * *}$ \\
\hline Oxygen \% & $11.69-14.43$ & 13.23 & ${ }^{* * *}$ \\
\hline $\mathrm{CO}_{2} \%$ & $6.22-8.84$ & 7.36 & 105.7 \\
\hline $\mathrm{NOx} \mathrm{ppm}$ & $34.8-44.5$ & 38.8 & 569.5 \\
\hline $\mathrm{CO}$ ppm & $53.5-500+$ & 2 & 10.9 \\
\hline $\mathrm{SO}_{2}$ ppm & $0-15$ & 4 & ${ }^{* * * *}$ \\
\hline Efficiency \% & $71.4-78.2$ & 7 & . \\
\hline
\end{tabular}

+ Three readings were off scale $(>500 \mathrm{ppm} \mathrm{CO})$, taken as $500 \mathrm{ppm}$ in average. 


\section{Conclusions}

This project has provided a compilation of emission data for residential heating equipment used in New York State. The results update gaseous emissions as well as provide a detailed gravimetric determination of fine particulate emissions for a broad comparison of oil, gas and wood pellet emissions including liquid fuels of various sulfur contents. The oil-fired systems results will be reviewed first, followed by those for gasfired heating appliances and then wood-fired pellet stoves. Then a comparison of results between the different fuel options will be presented. All of the equipment tested was manufactured and available for installation in the United States. The determination of fine particulates was based on a dilution tunnel measurement following a conditional test protocol developed by the US-EPA, Conditional Test Method 39 (CTM-039).

\section{A. Results for Oil-fired Heating Appliances}

The gaseous measurements of $\mathrm{O}_{2}, \mathrm{CO}_{2}, \mathrm{CO}, \mathrm{NOx}$ and $\mathrm{SO}_{2}$ are presented in the previous chapter of this report for each test series. The results are basically as expected and as reported in prior studies on emissions. Based on excess air levels and ultimate analysis of the fuel's chemical composition the emission results are as expected and fall within the range of emission factors contained in the US-EPA AP 42, Emission Factors Volume I, Fifth Edition. One area of the work that does expand on prior knowledge is the documentation of gaseous emissions for heating systems fired with biodiesel. Since were no unexpected findings the bulk of this report discussion will be centered on the emissions of fine particulates, or PM 2.5.

The results for fine particulate (PM 2.5) indicate a very strong linear relationship between the masses of fine particulate for the different fuel oils as a function of the sulfur content of the fuel in question. This is illustrated by the plot contained in Figure 15 which clearly illustrates the linear relationship between the measured mass of fine particulate per unit of energy expressed as $\mathrm{mg} / \mathrm{MJ}$ versus the different sulfur contents of four different heating fuels when used in the conventional cast iron boiler equipped with a flame retention head burner. The fuels included a typical No. 2 fuel oil with sulfur below 0.5 percent (1520 average ppm S), a No. 2 fuel oil with very high sulfur content (5780-ppm $\mathrm{S})$, low sulfur heating oil (322-ppm S) and an ultra low sulfur diesel fuel (11-ppm S). The bar chart in Figure 16 is a summary of results for three fuels (No. 2, LS and ULS) again when fired in the conventional cast iron boiler with a flame retention head burner. Three different emission rate units with each bar labeled with the value given to two significant figures. Three additional heating system types were also tested with normal heating fuel, low sulfur and ultralow sulfur fuel. These included an oil-fired warm air furnace of conventional design, a high efficiency condensing warm air furnace, a condensing hydronic boiler and the conventional hydronic boiler as discussed above. The linearity in the results was observed with all of the different oil-fired equipment types as shown in Figure 17. In this plot only the three fuels were included which explains the difference in the formula for the trend line and $\mathrm{R}^{2}$ factor (the coefficient of determination which is an indicator of goodness of the fit) of the linear regression analysis. In all four cases the $\mathrm{r}$ squared for the linear regression was 0.99 or better. 


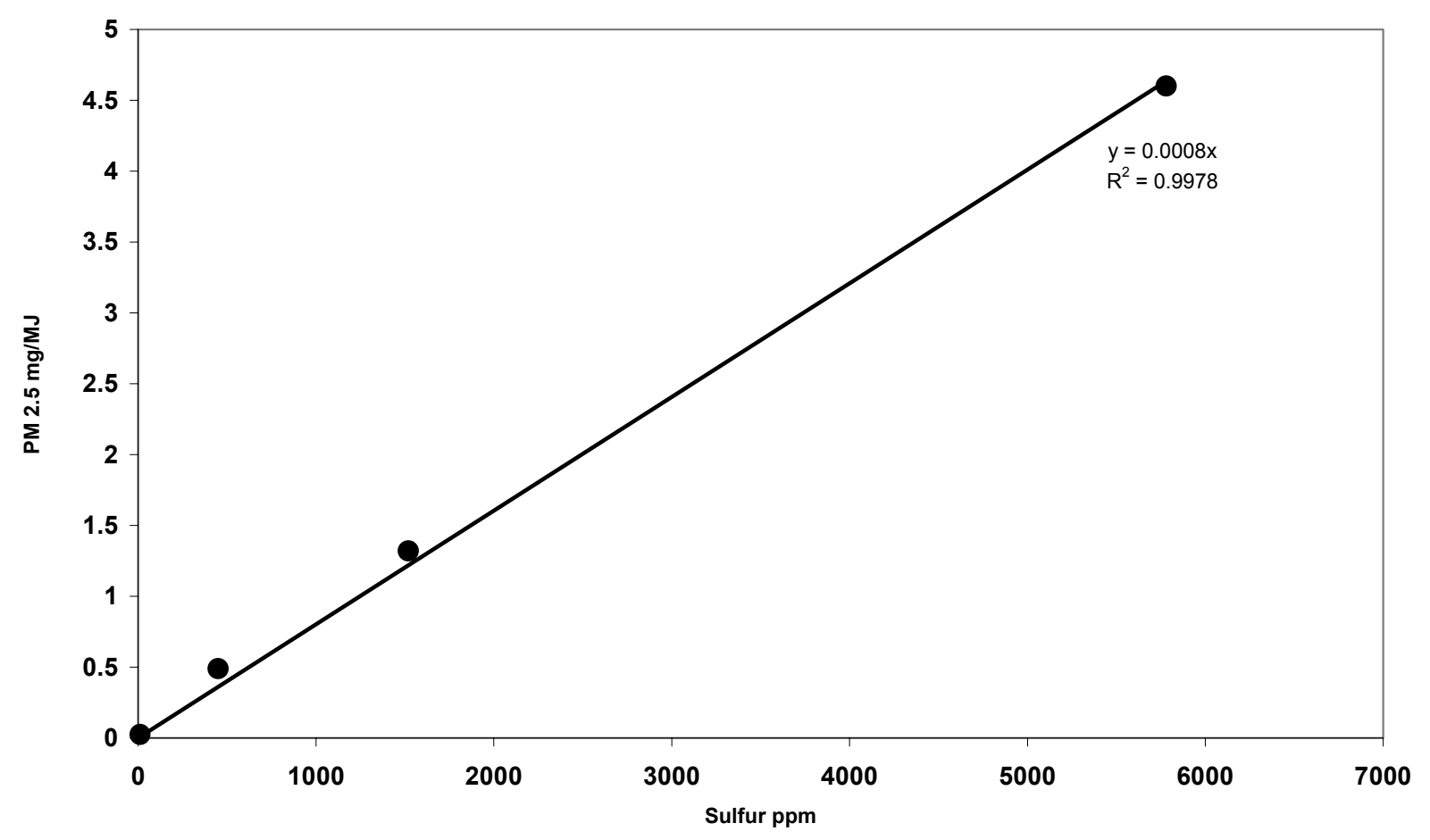

Figure 15. Cast iron boiler, PM 2.5 as a function of sulfur content

Cast Iron Boiler, Flame Retention Head Burner With Three Distillate Fuels, Sulfur Range 11-1520 ppm

DUS 11-ppm S LS 450-ppm S No. 2 1520-ppm S

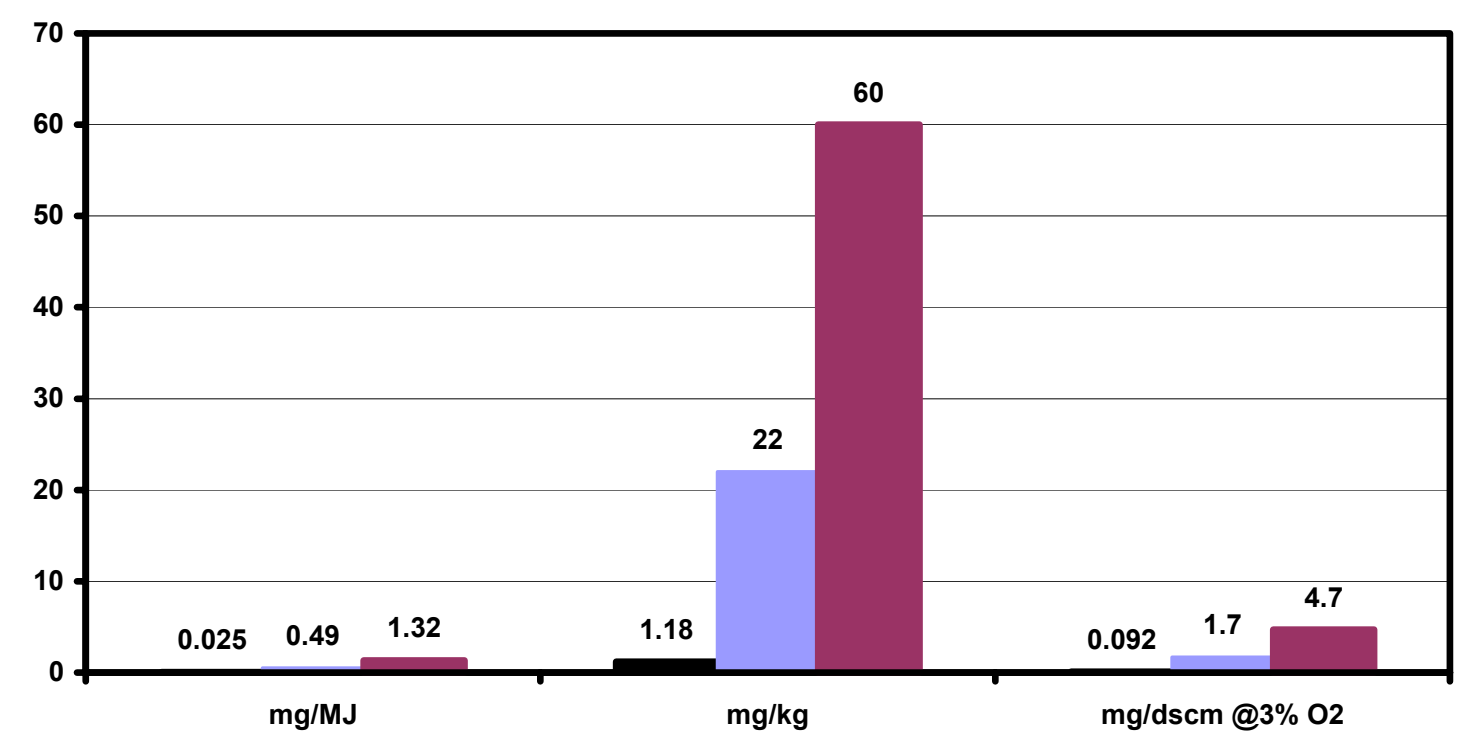

Figure 16. Cast iron boiler PM $2.5 \mathrm{mg} / \mathrm{MJ}, \mathrm{mg} / \mathrm{kg}, \mathrm{mg} / \mathrm{dscm}$ for three fuels 


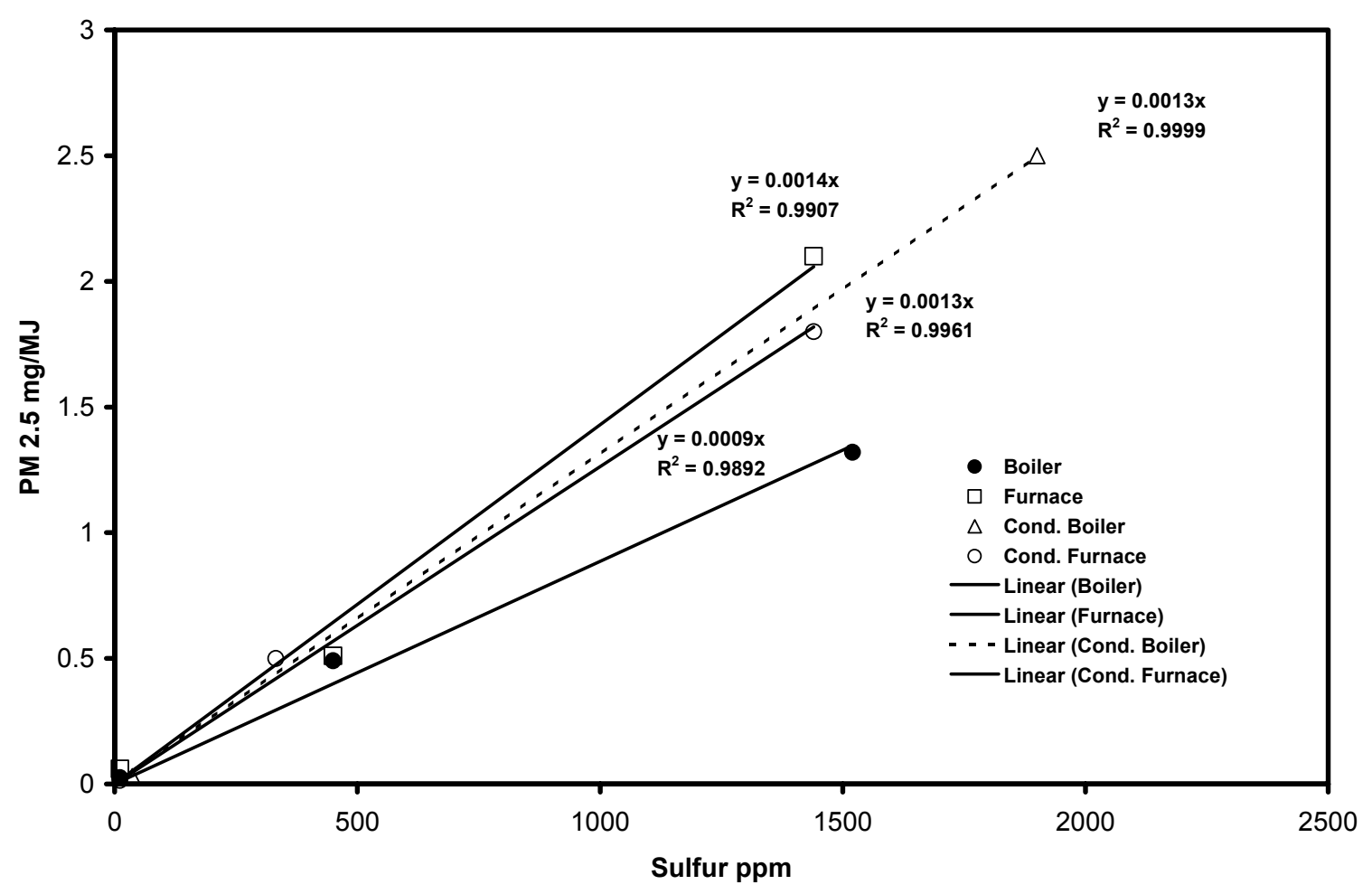

Figure 17. PM 2.5 for conventional and condensing, boilers and furnaces

\section{B. Discussion of Biodiesel Blends}

As discussed in Section VI, F, the results obtained while testing with a soy biodiesel were quite unexpected. The first test was with biodiesel fired into a condensing oil-fired hydronic boiler. The result was a fine particulate emission of $1.7 \mathrm{mg} / \mathrm{MJ}$ that was only slight lower then the level found in the same boiler, which was $2.5 \mathrm{mg} / \mathrm{MJ}$ when fired with No. 2 fuel with a typical sulfur content of 1900-ppm sulfur. The uniqueness of the condensing oil-fired boiler which had been used in a prior field demonstration caused concern that either the condensing mode might be exhibiting an unknown phenomenon or that the nature of the biofuel was so radically different as to cause a major difference in the particulate emissions even though it was very low in sulfur content. In an attempt to resolve this, a conventional oil-fired boiler was tested with the same fuel. The result was an emission rate of $0.3 \mathrm{mg} / \mathrm{MJ}$, still higher than one would expect based on a fuel that is supposed to be nearly sulfur free. This level is about 60 percent of the average value found when using LS (500-ppm S) fuel as determined during this project equivalent to a fuel with approximately 300-ppm sulfur. Based on the measurable levels of sulfur dioxide and prior fuel analysis that found sulfur content in soy based biodiesel at a level of 340-ppm the result from the conventional boiler seems reasonable. However the level in the condensing boiler is still about five times greater. It would appear that there is something unusual occurring with the condensing boiler. Whether this was an artifact from prior use in the field and possible particulates from the boiler being washed up in the flue gas stream or some other particulate generation phenomenon is unknown. 
Unfortunately this was the last oil-fired boiler tested during the project. Limited funds remained for completing the reporting and information dissemination tasks and the budget would not allow for any additional tests to further investigate this question.

\section{Results for Gas-fired Heating Appliances}

Again, the gaseous measurements of $\mathrm{O}_{2}, \mathrm{CO}_{2}, \mathrm{CO}, \mathrm{NOx}$ and $\mathrm{SO}_{2}$ are presented in the previous chapter of this report and the results are basically as expected and reported in prior studies on emissions. Based on excess air levels and ultimate analysis of the fuel's composition, the emission results are as expected and fall within the range provided for emission factors contained in the US-EPA AP 42, Emission Factors Volume I, Fifth Edition. Since there were no unexpected findings, the bulk of this discussion will be centered on the emissions of fine particulates, or PM 2.5.

PM 2.5 Emission Factors for Several Natural Gas Fired Appliance

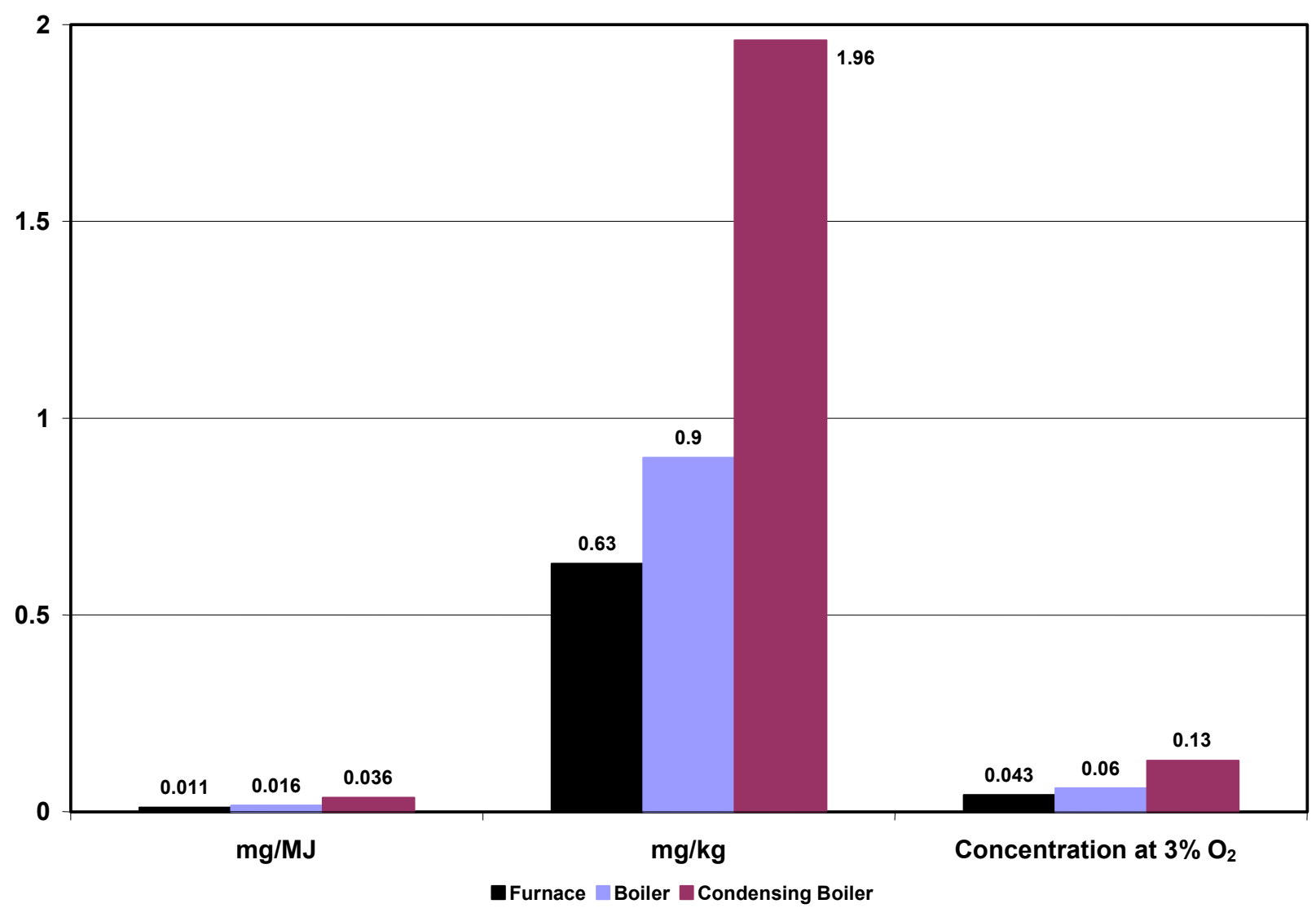

Figure 18. PM 2.5 emission factors for gas furnace, boiler and condensing boiler

Three different gas-fired heating systems were tested. These included a conventional inshot induced draft warm air furnace, an atmospheric fired hydronic boiler and a high efficiency hydronic boiler. The particulate (PM 2.5) measured ranged from 0.011 to $0.036 \mathrm{mg} / \mathrm{MJ}$ as shown in Figure 18. Tests included both steady state and cyclic operation. These were very low emission rates and to obtain these values sampling 
occurred over long periods of operation. The actual sample size collected ranged form $2-$ $12 \mathrm{mg}$. Although there appears to be a difference in the level of emissions based on the heating system type the actual difference is well with in the range expected for gas-fired equipment based on prior studies. In a 1993 study done by the California Institute of Technology using one of the first original dilution tunnel designs, the value determined was $0.046 \mathrm{mg}$ per $\mathrm{MJ}+/-0.017$ for the residential heating units evaluated in the field which closely matches the values obtained in the current study.

\section{Results for Wood Pellet Stoves Manufactured in the United States}

Three pellet stoves were included in this study. Wood pellet properties vary greatly depending on the raw material source used in their manufacture. All three stoves were fueled with wood pellets obtained in a single batch to provide for uniformity in the test fuel. Unlike the oil and gas fired systems the wood pellet stoves had measurable amounts of particulates sized above the 2.5-micron size that defines fine particulates (less than 2.5 microns). The fine particulate emissions rates ranged from 22 to $30 \mathrm{mg} / \mathrm{MJ}$ as indicated in Figure 19, also included in the graph are emissions expressed in milligrams per kilogram $\mathrm{mg} / \mathrm{kg}$ and emission concentration as $\mathrm{mg}$ per dry standard cubic meter (mg/dscm). Although "Stove I" had larger emissions than the other two they are still within the same order of magnitude relative to each other. In addition to the particulate emissions being so high it is important to note that these stoves had significant levels of carbon monoxide in their flue products and so special attention should be followed to venting requirements to avoid human exposure as with any combustion system in a home. Carbon monoxide levels in the exhaust flue averaged between 200 and 600-ppm.

Three Pellet Stoves Evaluated for PM 2.5 and PM > 2.5 Microns

$\square$ Stove I $\square$ Stove J $\square$ Stove K

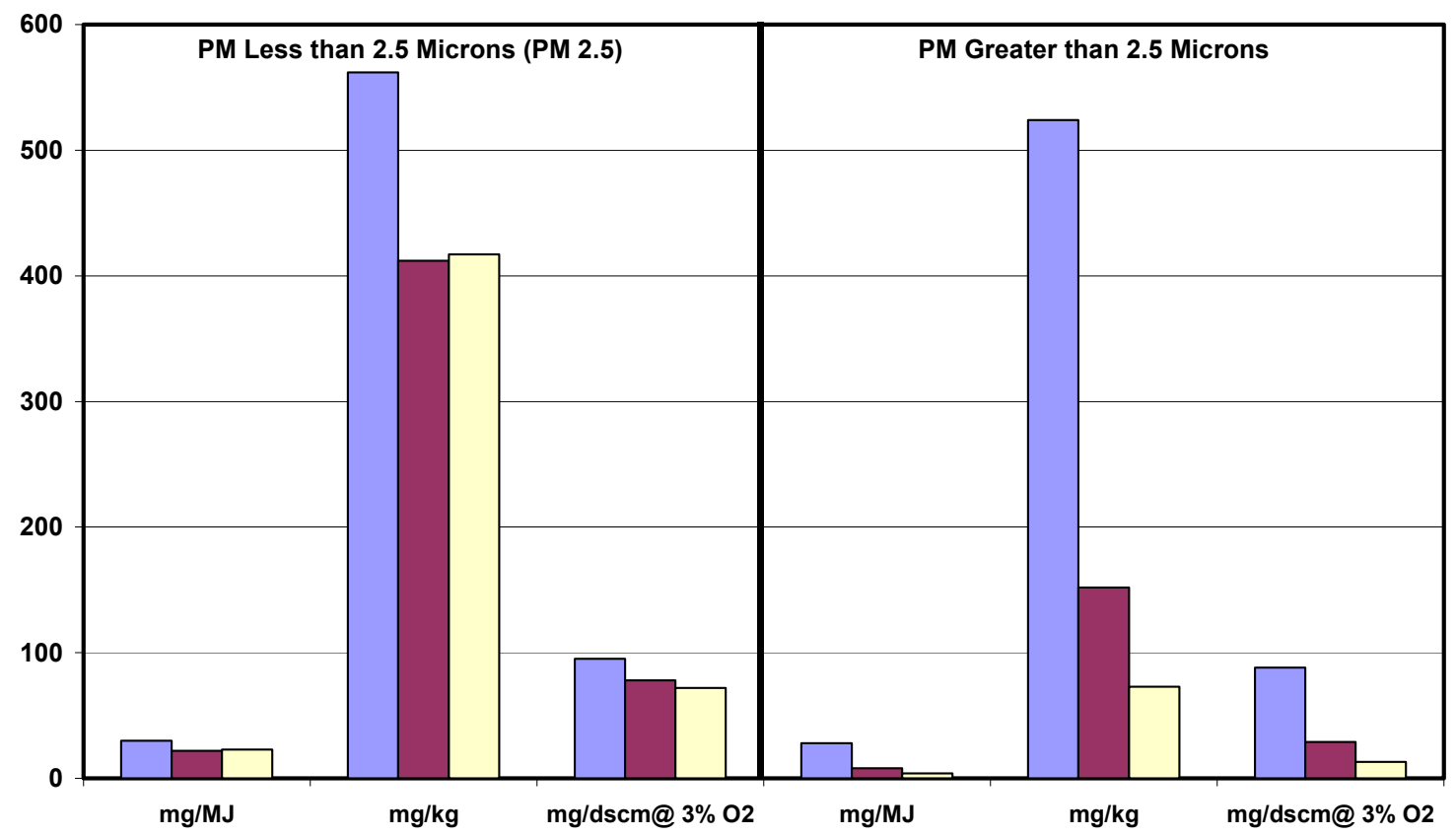

Figure 19. Three stoves evaluated for $P M 2.5$ and $P M>2.5$ Microns 


\section{E. Comparison of Results for all Residential Heating Appliances}

A summary comparison of results averaged by fuel types is shown in Figure 20 for the equipment included in this study. This summarizes the basic conclusions of the study with regard to fine particulate emissions.

- Gas-fired equipment has the lowest current particulate emissions averaging 0.014 milligram per mega-Joule (mg/MJ).

- Oil-fired units currently have emissions averaging $1.7 \mathrm{mg} / \mathrm{MJ}$ with typical sulfur levels and this is approximately 120 times greater when compared to those for gas-fired units; reductions of $71 \%$ can be accomplished by using low sulfur fuel oil (500 ppm limit).

- In the near future when fuel oil will be required to meet Ultra Low Sulfur limits of 15-ppm sulfur, the particulate emissions will be of the same order of magnitude as those found for gas fired units. In parts of New York this may happen by 2011.

- Wood pellet stoves have emissions averaging $25 \mathrm{mg} / \mathrm{MJ}$ and this is approximately 15 times greater than those of oil-fired units or approximately 1800 times greater than gas fired units.

- Wood pellet stoves are considered to have the lowest level of all wood fueled heating systems in the United States.

\section{Comparison of Average PM2.5 for Five Heating Fuel Types for Hydronic Boilers and Warm Air Funaces}

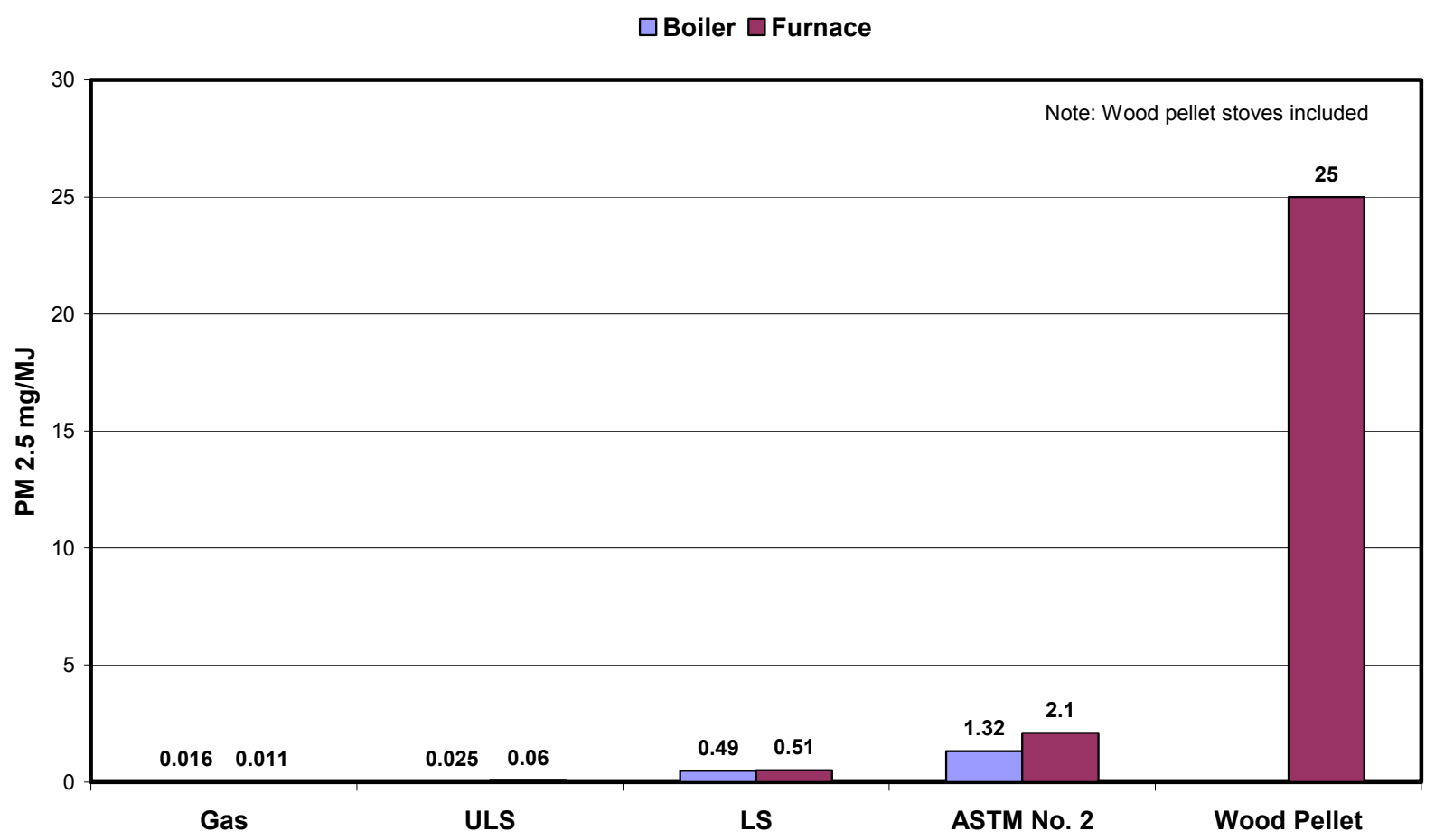

Figure 20. Comparison of average PM 2.5 emissions for five heating fuel options 


\section{Recommendations}

This report has identified the emissions to be expected from a wide range of heating equipment based on liquid fuel options, utility supplied gas and wood pellet resources. The greater part of effort was placed on generating a database for the mass emission rate of fine particulates (PM 2.5) for the various fuel types studied when fired in residential appliances.

\section{Discussion:}

Homeowners currently have many choices to heat their homes. These choices include burning natural gas, heating oil, wood. Natural gas use results in very low levels of PM 2.5 emissions but being a hydrocarbon fuel it emits substantial levels of carbon dioxide. ASTM No. 2 fuel oil fired heating appliances produce PM 2.5 levels that are about 130 times higher than natural gas and higher emission levels of carbon dioxide. Wood pelletfired heating appliances made in the Untied States produce PM 2.5 levels that are approximately 15 times higher than ASTM fuel oil and from about 590 to 1850 times the levels possible with either utility gas or ultra low sulfur oil fueled appliances. Wood pellet heating fuel is often selected over other forms of wood fuel choices based on EPA and DOE guidance. This guidance suggests that the use of wood pellet appliances is a good choice because they are considered to be the lowest emitters of particulates when compared to other type of wood burning appliances. Wood pellet fuel is a renewable resource that absorbs carbon dioxide during the natural growth cycle. This is considered to be a benefit in helping to mitigate global climate changes by effectively reducing the carbon dioxide emissions that otherwise would be attributed to the use of wood pellet fuel. Like wood, biodiesel is also a renewable fuel and also absorbs carbon dioxide in the growth cycle of the crop plants used to produce the raw materials for biodiesel production, for example soybean or other seed crops. Biodiesel can be blended with ASTM heating No. 2 or ultra low sulfur heating oil. In either case it would effectively reduce the emissions of carbon dioxide based on its renewable nature. The extent of the carbon dioxide reduction would be proportional to the amounts of biodiesel used in the blends.

To summarize, natural gas has low PM 2.5 emissions but moderate carbon dioxide emissions. Wood pellet fuel has much higher PM 2.5 emission levels (based on current technology) but effectively lower carbon dioxide emissions due the renewable nature of trees that absorb carbon dioxide as they grow. ASTM No. 2 fuel as currently used has higher emissions of PM 2.5 than natural gas, much lower PM 2.5 emissions than wood pellet fuel and higher levels of carbon dioxide emissions than both alternatives. Transitioning the sulfur content of fuel oil to ultra low levels (less than $15 \mathrm{ppm}$ ) results in PM 2.5 emissions are on the same order of magnitude as natural gas but still emits higher levels of carbon dioxide. Natural gas produces about 30 percent less carbon dioxide per Btu when compared to ASTM No. 2 or ultra low sulfur heating oil. Blending of ultra low sulfur with biodiesel in the future is anticipated as a alternative fuel choice and the resulting fuel blend would have very low PM 2.5 emissions as well as low net carbon dioxide emissions when the renewable nature of the fuel is taken into accounted. This report presents carbon dioxide data as it was measured but the analysis of the net carbon 
dioxide reduction based on the use of renewable fuels is beyond the scope of the current project

The question of how to reduce PM 2.5 emissions in areas that currently do not meet the criteria for EPA attainment is complex and is not part of the scope of this project. This project does however provide important data that should be useful to the overall decisionmaking process with regard to residential heating technology in New York State as well as the other New England and Mid-Atlantic States where a majority of home heating is based on fuel combustion technologies. 


\section{Appendix A: Examples of Fuel Analysis Results}

Liquid Fuels Performed by Outside Testing Laboratories

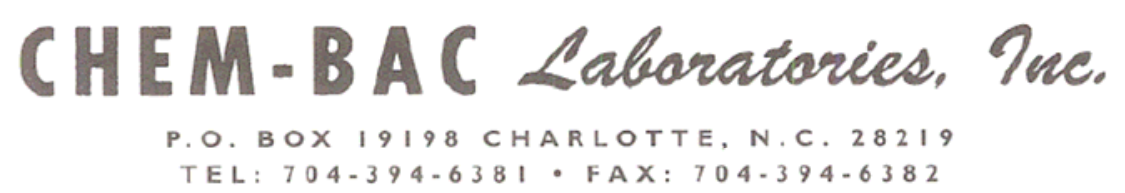

\section{Certificate of Analysis}

\begin{tabular}{llll}
\hline Client: & Brookhaven National Lab & Client Number: & 9999 \\
& P.O. Box 5000 Building 526 & Work Order: & $2508-08$ \\
Upton, NY 11973 & Sample Date: & $11-04-08$ \\
Attn: Roger McDonald & Report Date: & $12-09-08$
\end{tabular}

Analyses of Oil Samples

Brookhaven National Lab PO \# BNL-0000141212

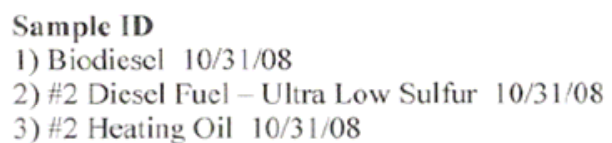

Parameter

Gross Heat of Combustion

Density@15 $15^{\circ} \mathrm{C}$

Nitrogen

Carbon

Hydrogen

Sulfur (Biodiesel \& USL Diesel)

Sulfur (\#2 Heating Oil)
Test Method

ASTM D 240

ASTM D 4052

ASTM 3228

ASTM D 5291

ASTM D 5291

EPA $3051 /$ ICP-OES

ASTM D 4294/XRF
Sample \#1
$40.614 \mathrm{MJ} / \mathrm{kg}$
$876.2 \mathrm{~kg} / \mathrm{m}^{3}$
$<.03 \%$
$78.31 \%$
$12.33 \%$

$164 \mathrm{ppm}(.016 \%)$
Sample \#3 $44.694 \mathrm{MJ} / \mathrm{kg}$ $865.0 \mathrm{~kg} / \mathrm{m}^{3}$ $.04 \%$ $85.02 \%$ $12.70 \%$

2385 ppm (.238\%)

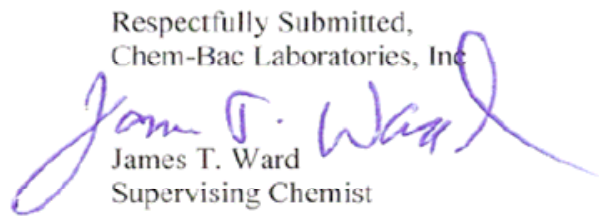




\title{
Utility Supplied Natural Gas Analysis
}

$\begin{array}{ll}\text { 287 Maspeth Avenue, Brooklyn, NY 11211 } & \text { Lab Report \#: BL0605044 } \\ \text { KeySpan Laboratory Services } & \text { ELAP Number: } 11173 \\ \text { Certificate of Results } & \end{array}$

\section{Customer Information}

\author{
Company Name: Laboratory Operations-Brooklyn \\ Customer Contact: Amy T. Drogalis \\ Address: 287 Maspeth Avenue \\ Brooklyn, NY 11211
}

\author{
Phone Number: $\quad 718-963-5421$ \\ Fax Number: \\ Customer PO: $\quad 244$ CS0505 0731 \\ Project ID: $\quad$ Gas LI
}

\section{Laboratory Information}

Receive Date: 05/03/2006 3:38:52 PM Approved By $2832 \quad$ Report Date: 05/12/2006

\section{SAMPLE CONDITION RECORD}

\begin{tabular}{llll}
\hline Are samples submitted with a chain of custody? & Yes & Are the number of samples the same as stated on the chain of custody? \\
Are bottle caps tight and securely in place? & Yes & Were samples within the holding time for the requested test(s)? \\
Were all containers intact when received? & Yes & Is the volume of sample submitted sufficient for the requested test(s)? \\
Were samples submitted in an ice chest? & N/A & Are all samples for volatile organic analyses free of headspace? \\
Were samples received cold? & N/A & & N/A
\end{tabular}

Were samples received cold? N/A

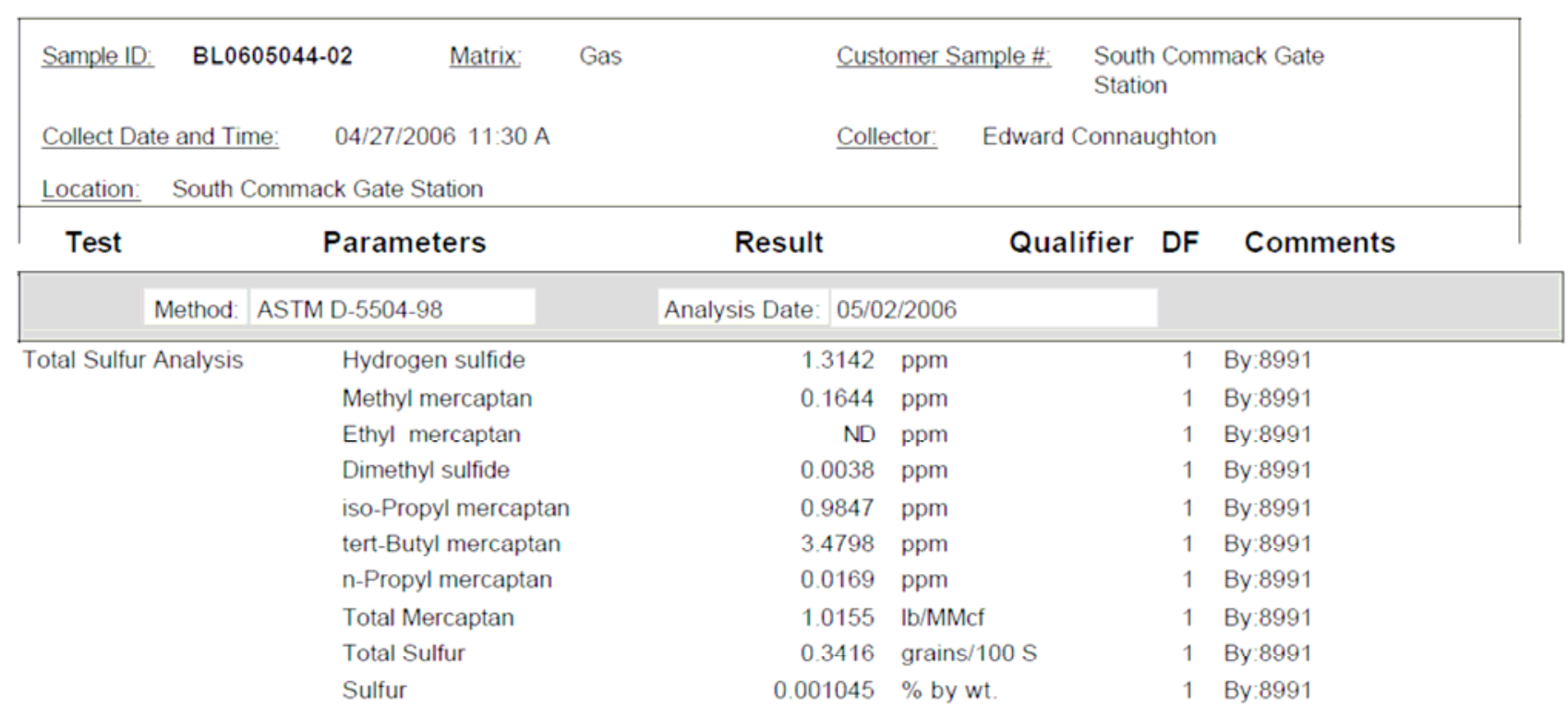




\section{Utility Supplied Natural Gas Analysis}

287 Maspeth Avenue, Brooklyn, NY 11211
$\begin{aligned} & \text { KeySpan Laboratory Services } \\ & \text { Certificate of Results }\end{aligned}$

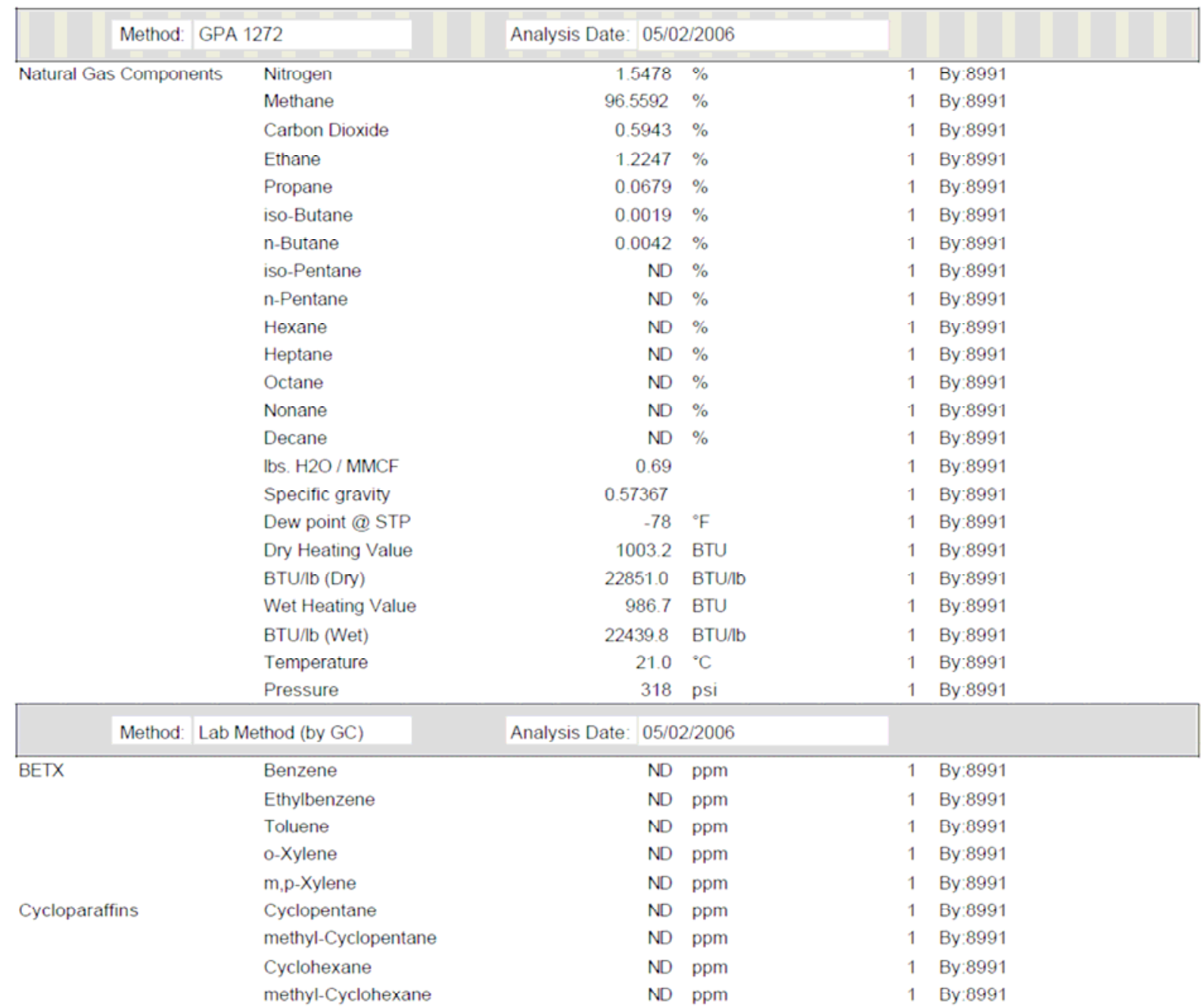


Wood Pellet Analysis Performed by Outside Testing Laboratory

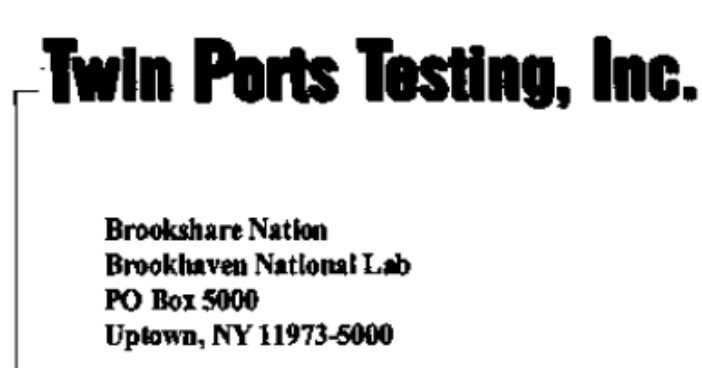

Attm: Roger McDonald

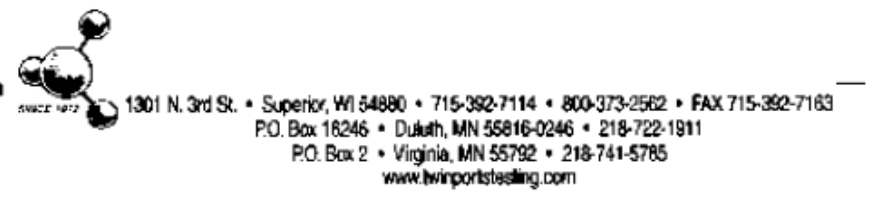

Date Received: $\quad$ Mar 19, 2007

Date Tested: $\quad$ Mar 28, 2007

PO Number: $\quad$ BNL-118938

Sample Log No: 07 C0445

Sample Designation: Pellet 03/14/07

PROXIMATE / SHORT PROXIMATE ANALYSIS REPORT MOISTURE \& MOISTURE

ASH FREE

FREE

AS

Moisture Total \%

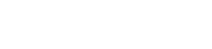

6. 27

Ash \%

0.40

0.37

Volatile Matter \%

84.09

78.82

Fixed Carbon By Difference \%

15.51

14.54

Sulfar $\%$

0.01

0.01

Heating Value BTU/LB

8569

8535

8001

Chlorine ug/g

Floorine ugig

Mercury $\quad$ ag/g

Carbon ugeg

Sodium Oxide in Ash:

Hardgrove Grindability Index:

Remarks:

Carbon
Hydrogen
Nitrogen
Oxygen

Dry
$50.02 \%$
$6.17 \%$
$<0.20 \%$
$>43.19 \%$
As Received $46.89 \%$ $5.78 \%$ $<0.19 \%$
$>40.48 \%$

Methods: Moisture: ASTM D3173; Ash: ASTM D3174; Btunb: ASTM D5865; Sulfur: ASTM D4239; Volatiles: ASTM 03175

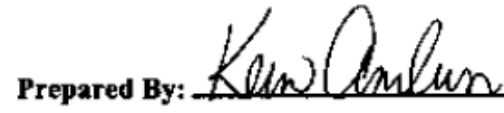
Date: $3 / 2061$ 


\section{Appendix B: List of Abbreviations and Symbols}

\begin{tabular}{|c|c|}
\hline$<$ & less than \\
\hline$>$ & greater than \\
\hline$\sim$ & approximately \\
\hline $\mathrm{C}$ & carbon \\
\hline $\mathrm{CO}$ & carbon monoxide \\
\hline $\mathrm{CO}_{2}$ & carbon dioxide \\
\hline$\Omega$ & oxygen \\
\hline $\mathrm{O}_{2}$ & molecular oxygen \\
\hline $\mathrm{H}$ & hydrogen \\
\hline $\mathrm{S}$ & sulfur \\
\hline $\mathrm{SO}_{2}$ & sulfur dioxide \\
\hline $\mathrm{SO}_{3}$ & sulphur trioxide \\
\hline $\mathrm{SO}_{4}$ & sulfate \\
\hline $\mathrm{N}$ & nitrogen \\
\hline $\mathrm{NH}_{3}$ & ammonia \\
\hline NO & nitric oxide or nitrogen monoxide \\
\hline $\mathrm{NO}_{2}$ & nitrogen dioxide \\
\hline NOx & $\mathrm{NO}+\mathrm{NO}_{2}$ \\
\hline $\mathrm{Pb}$ & lead \\
\hline Avg & average \\
\hline AFUE & Annual Fuel Utilization Efficiency (US DOE rating) \\
\hline ASHRAE & $\begin{array}{l}\text { American Society of Heating and Refrigeration and Air- } \\
\text { conditioning Engineers }\end{array}$ \\
\hline ASME & American Society of Mechanical Engineers \\
\hline ASTM & American Society for Testing and Materials \\
\hline ASTM International & Current official designation of ASTM \\
\hline ASTM No. 2 & petroleum middle distillate fuel oil used as a heating fuel \\
\hline ASTM No. D1 & $\begin{array}{l}\text { petroleum middle distillate diesel fuel (kerosene) used as a } \\
\text { transportation fuel with less than 15-ppm sulfur content }\end{array}$ \\
\hline ASTM No. D2 & $\begin{array}{l}\text { petroleum middle distillate diesel fuel used as a transportation fuel } \\
\text { with less than } 15-\mathrm{ppm} \text { sulfur content }\end{array}$ \\
\hline BART & best available retrofit technology \\
\hline Btu & British thermal unit \\
\hline CANMET & $\begin{array}{l}\text { Canada Centre for Mineral and Energy Technology, CANMET } \\
\text { Energy Technology Centre }\end{array}$ \\
\hline CTM & contingency test method (as in EPA CTM-039) \\
\hline dep & dry combustion products \\
\hline def & dry cubic foot (combustion products) \\
\hline DOE & United States Department of Energy \\
\hline $\begin{array}{l}\text { DOE-EIA } \\
\text { dscm }\end{array}$ & $\begin{array}{l}\text { United States Department of Energy - Energy Information Agency } \\
\text { dry standard cubic meter }\end{array}$ \\
\hline EPA, US EPA & United States Environmental Protection Agency \\
\hline ETV & US EPA Environmental Technology Verification Program \\
\hline
\end{tabular}




$\begin{array}{ll}\mathrm{ft}^{3} & \text { cubic foot } \\ \mathrm{gph} & \text { gallons per hour } \\ \mathrm{g} & \text { gram } \\ \mu \mathrm{g} & \text { microgram } \\ \mathrm{mg} & \text { milligram } \\ \mathrm{kg} & \text { kilogram } \\ \mathrm{hr} & \text { hour } \\ \mu \mathrm{m} & \text { micrometers (microns) } \\ \mathrm{m} & \text { meter } \\ \mathrm{m}^{3} & \text { cubic meter } \\ \mathrm{NY} & \text { New York } \\ \mathrm{NYS} & \text { New York State } \\ \mathrm{NYSERDA} & \text { New York State Energy Research and Development Authority } \\ \mathrm{dscm} & \text { dry standard cubic meters (combustion products) } \\ \mathrm{J} & \text { Joule } \\ \text { Lb } & \text { pound } \\ \text { LS } & \text { low sulfur content fuel oil, less than 500-ppm sulfur } \\ \mathrm{kJ} & \text { kilo-Joule } \\ \mathrm{MJ} & \text { mega-Joule } \\ \mathrm{MMBtu} & \text { million British thermal unit } \\ \text { PFI } & \text { Pellet Fuel Institute } \\ \text { ppm } & \text { parts per million } \\ \text { PM 2.5 } & \text { particulates less than 2.5 microns } \\ \text { PM 10 } & \text { particulates less than 10 microns } \\ \mathrm{SIP} & \text { state implimentation plan } \\ \mathrm{TSP} & \text { total suspended particulates } \\ & \end{array}$

